\title{
Integrando banco de dados relacional e orientado a grafos para otimizar consultas com alto grau de indireção
}

\author{
Marino Hilário Catarino
}

\author{
DISSERTAÇÃO APRESENTADA \\ $\mathrm{AO}$ \\ INSTITUTO DE MATEMÁTICA E ESTATÍSTICA \\ DA \\ UNIVERSIDADE DE SÃO PAULO \\ PARA \\ OBTENÇÃO DO TÍTULO \\ $\mathrm{DE}$ \\ MESTRE EM CIÊNCIAS
}

Programa de Mestrado em Ciência da Computação

Orientador: Prof. Dr. João Eduardo Ferreira 


\section{Integrando banco de dados relacional e orientado a grafos para otimizar consultas com alto grau de indireção}

Esta versão da dissertação contém as correções e alterações sugeridas pela Comissão Julgadora durante a defesa da versão original do trabalho, realizada em 10/11/2017. Uma cópia da versão original está disponível no Instituto de Matemática e Estatística da Universidade de São Paulo.

Comissão Julgadora:

- Prof. Dr. João Eduardo Ferreira - IME-USP

- Prof. Dr. Flávio Soares Corrêa da Silva - IME-USP

- Prof. Dr. Marcio Katsumi Oikawa - UFABC 


\section{Agradecimentos}

Agradeço ao meu orientador, Prof. Dr. João Eduardo Ferreira, não somente pela oportunidade oferecida, mas pela confiança e amizade ao longo destes anos. Os ensinamentos, tanto no meio acadêmico quanto fora dele me acompanharão para sempre.

Aos meus pais, Antônio e Maria Hilário, por tudo que fizeram e tem feito por mim, sempre me apoiando e ajudando.

Agradeço a minha esposa Clara e ao meu irmão Andrei, por sempre estarem ao meu lado, me escutando e incentivando nesta nova etapa.

Agradeço aos amigos de jornada, Bruno, Rafael, Rodrigo, Pedro, Mauro e a todos que contribuíram ao longo destes anos, pois o trabalho entregue não só é possível graças as opiniões, mas pelos conselhos e contribuições de todos. 


\section{Resumo}

CATARINO, M. H. Integrando banco de dados relacional e orientado a grafos para otimizar consultas com alto grau de indireção. 2017. Dissertação de Mestrado - Instituto de Matemática e Estatística, Universidade de São Paulo, São Paulo, 2017.

Um indicador importante na área acadêmica está relacionado ao grau de impacto de uma publicação, o que pode auxiliar na avaliação da qualidade e do grau de internacionalização de uma instituição. Para melhor delimitar esse indicador torna-se necessária a realização de uma análise das redes de colaboração dos autores envolvidos. Considerando que o modelo de dados relacional é o modelo predominante dos bancos de dados atuais, observa-se que a análise das redes de colaboração é prejudicada pelo fato desse modelo não atender, com o mesmo desempenho, a todos os tipos de consultas realizadas. Uma alternativa para executar as consultas que perdem desempenho no modelo de banco de dados relacional é a utilização do modelo de banco de dados orientado a grafos. Porém, não é claro quais parâmetros podem ser utilizados para definir quando utilizar cada um dos modelos de bancos de dados. Assim, este trabalho tem como objetivo fazer uma análise de consultas que, a partir da sintaxe da consulta e do ambiente de execução, possa apontar o modelo de dados mais adequado para execução da referida consulta. Com essa análise, é possível delimitar em que cenários uma integração entre o modelo relacional e o orientado a grafos é mais adequada.

Palavras-chave: banco de dados orientado a grafos, integração, NoSQL, internacionalização, redes de colaboração. 


\section{Abstract}

CATARINO, M. H. Integrating relational and graph-oriented database to optimize queries with high degree of indirection. 2017. Master's Dissertation - Instituto de Matemática e Estatística, Universidade de São Paulo, São Paulo, 2017.

An important indicator in the academic area is related to the degree of impact of a publication that can help in evaluating the quality and degree of internationalization in academic institutions. One approach to better understand the aforementioned indicator is analyzing the collaboration network formed by each researcher. In order to analyze this network, several alternatives use the well known relational data model which is predominant in most databases used today. Even though this model is widely used, it has a performance drawback when some types of queries are performed. For overcoming this drawback, certain alternatives are using a graph-oriented database model which is similar to a collaboration network model. However, it is unclear what parameters can be used to define when to use a relational or graph-oriented model. In this work, we propose an analysis of queries that, from the syntax of a query and the execution environment, can point to the most suitable data model for the execution given a specific query. With this query analysis, it is possible to delimit in which scenarios an integration between the relational and the graph-oriented models is more appropriate.

Keywords: graph database, integration, NoSQL, internationalization, collaboration networks. 


\section{Sumário}

Lista de Abreviaturas .........................................................................................

Lista de Figuras................................................................................................. xvii

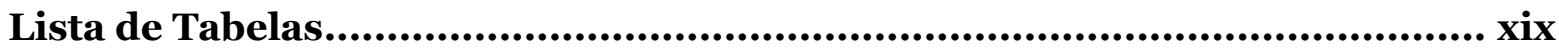

1. Introduçãa.......................................................................................................1

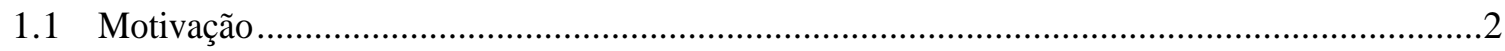

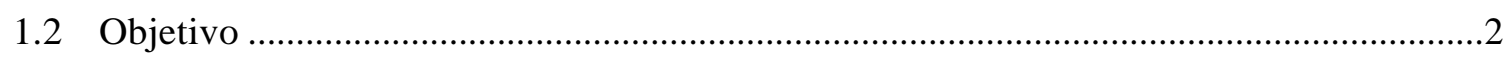

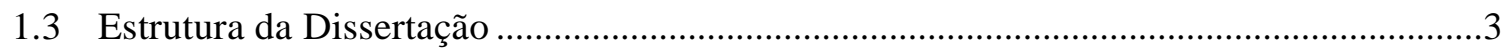

2. Trabalhos relacionados …............................................................................... 5

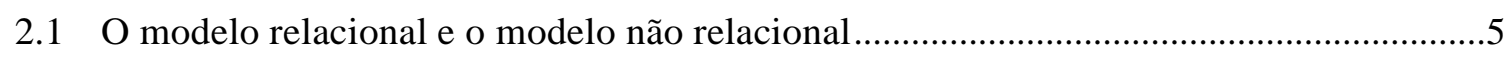

2.2 Integração entre o modelo relacional e o modelo não relacional ........................................6

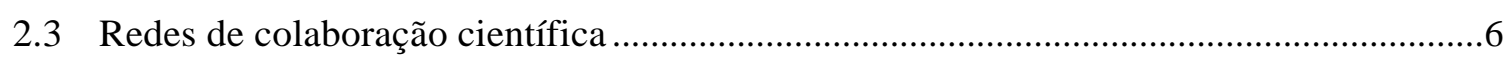

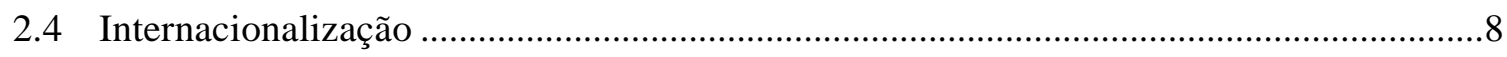

3. Conceitos fundamentais ......................................................... 11

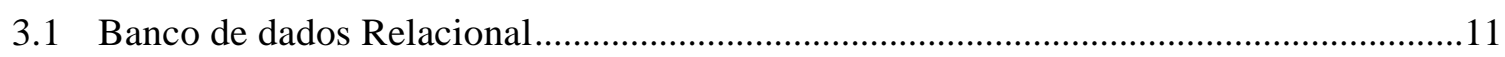

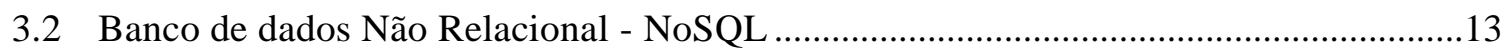

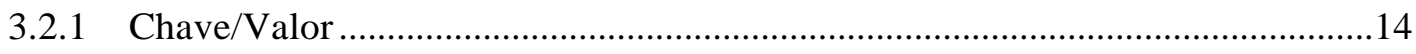

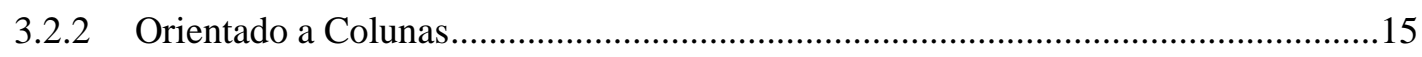

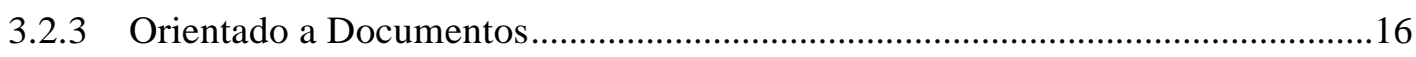

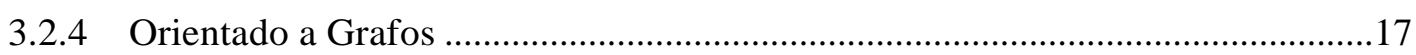

3.3 Grafos 17

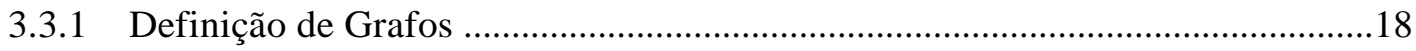

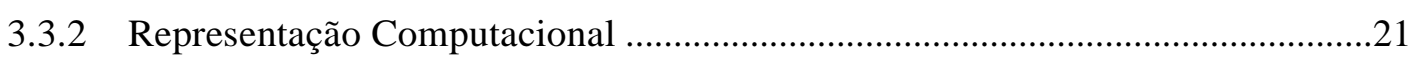

3.4 Diferenças entre Banco de dados Relacional e NoSQL ...................................................21

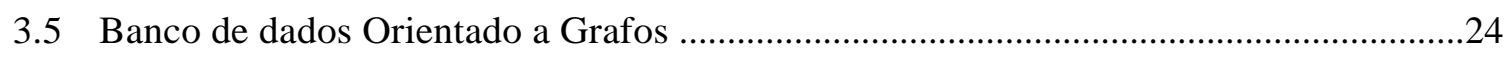

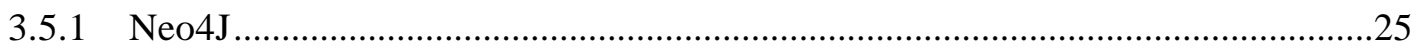

3.5.2 Usabilidade de bancos de dados orientados a grafos .......................................28

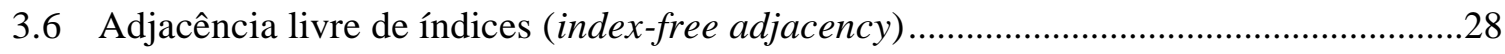

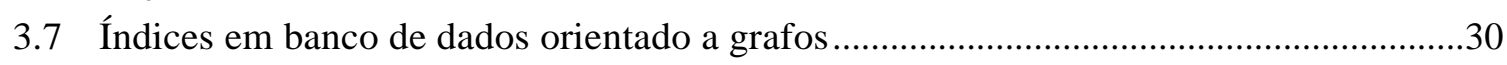

4. Metodologia ...........................................................................................31

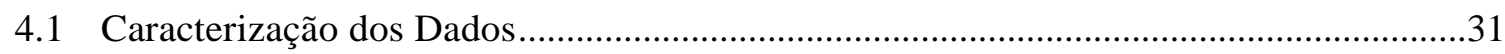




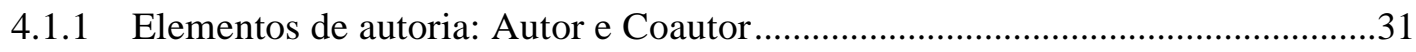

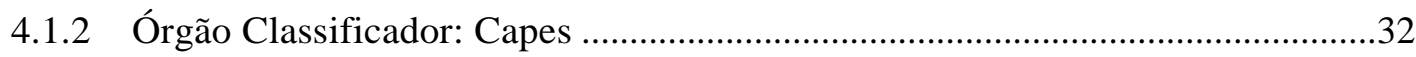

4.1.3 Elementos para Classificação: ISSN e Qualis .......................................................32

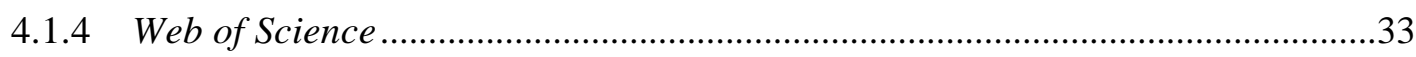

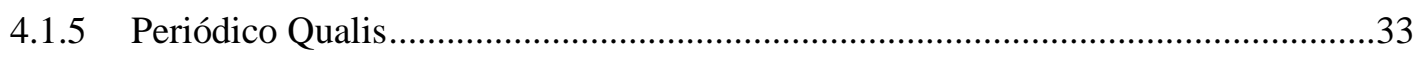

4.1.6 Banco de dados Corporativo da Universidade de São Paulo ................................35

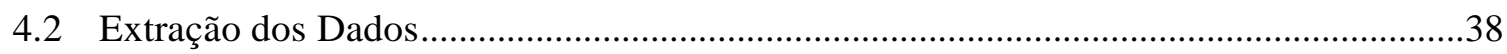

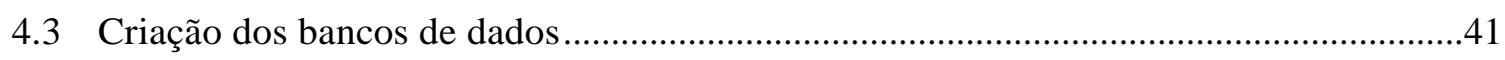

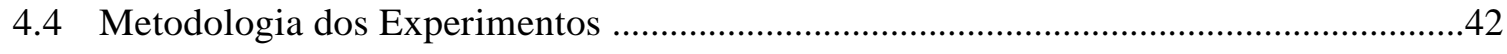

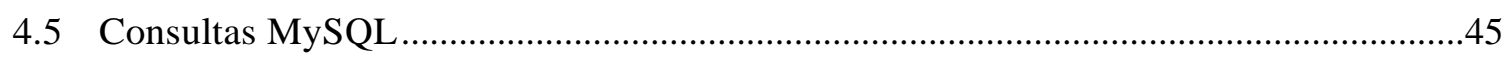

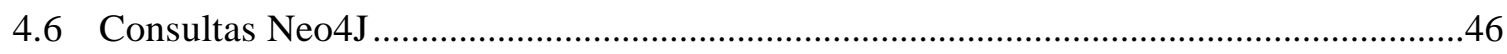

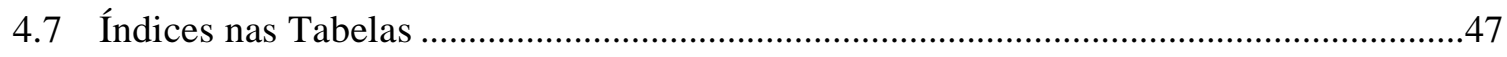

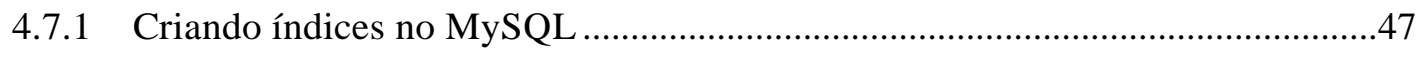

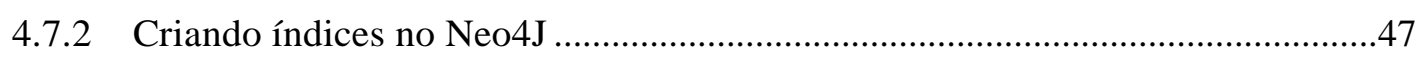

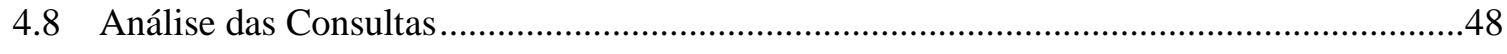

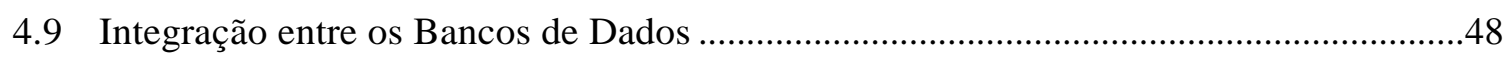

5. Modelagem e armazenamento dos dados ........................................ 49

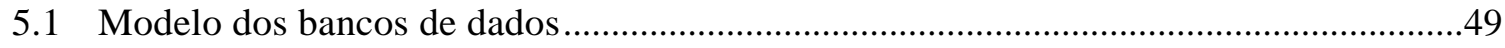

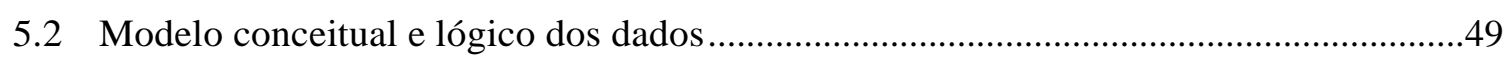

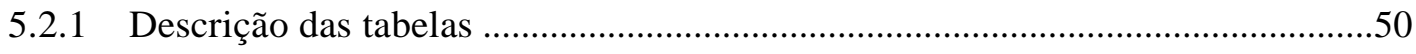

5.2.2 Criação da base de dados e das tabelas .............................................................52

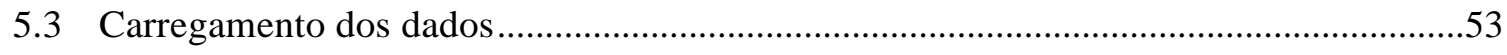

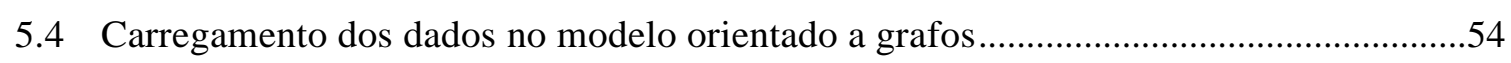

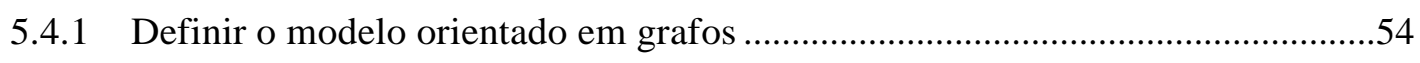

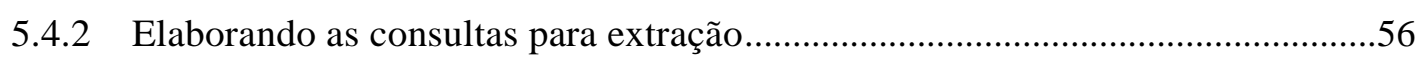

5.4.3 Exportar informações para arquivo csv ........................................................5

5.4.4 Preparar arquivos para serem importados ...........................................................58

5.4.5 Importar e criar o banco de dados orientados a grafos ......................................59

6. Experimentos e Resultados obtidos ................................................661

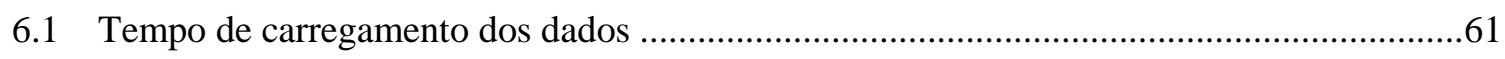

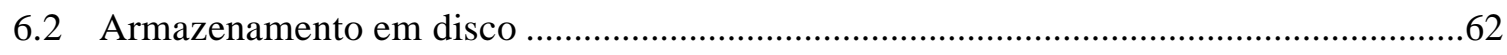

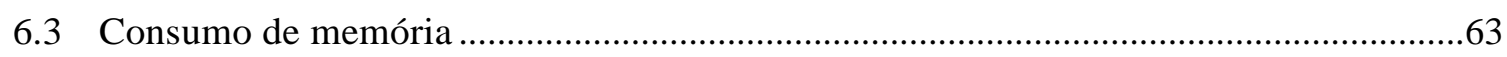

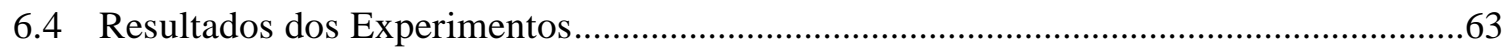

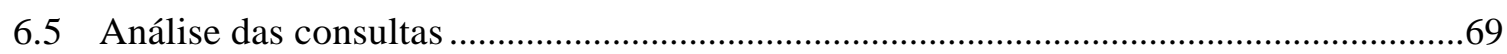

6.5. Tempo de execução na modelagem orientada a grafos ....................................................72

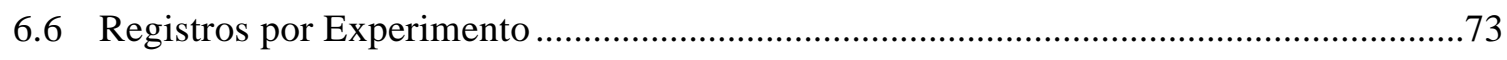

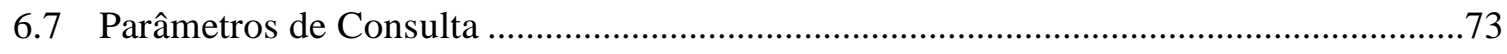

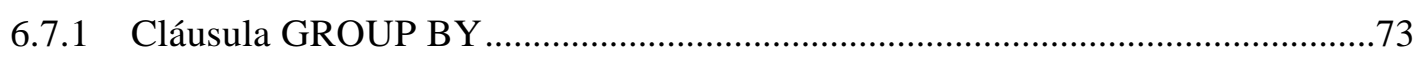

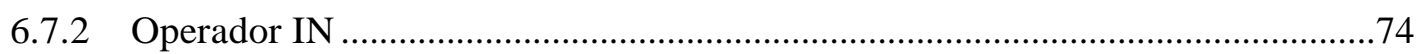

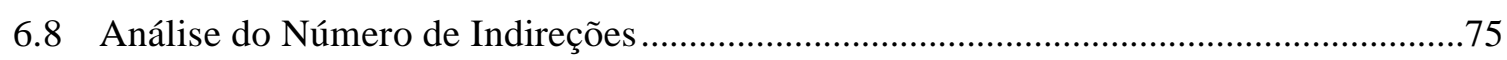

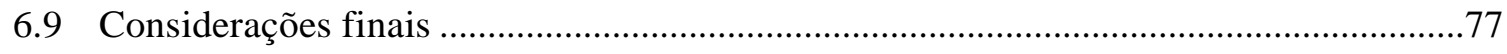


7 Conclusões ................................................................................ 79

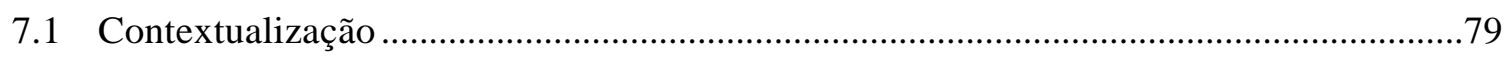

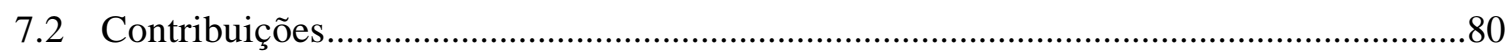

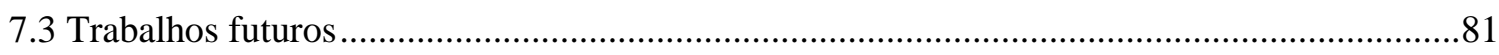

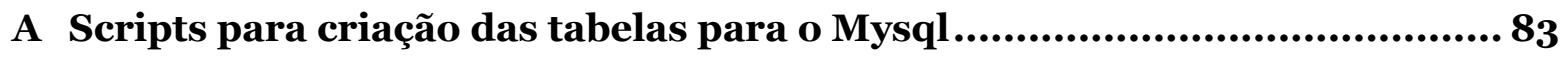

B Consultas em SQL para o Mysql ....................................................... 85

C Consultas na linguagem Cypher do Neo4J ........................................... 89

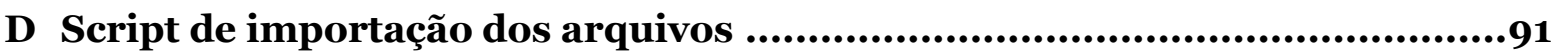

Referências Bibliográficas ................................................................. 93 


\section{Lista de Abreviaturas}

ACID Atomicidade, Consistência, Isolamento e Durabilidade.

API Interface de Programação de Aplicação.

BASE Basically Available, Soft state, Eventual consistency.

CAPES Coordenação de Aperfeiçoamento de Pessoal de Nível Superior.

DAO Data Access Object.

ISSN International Standard Serial Number.

JDK Java Development Kit.

JSON JavaScript Object Notation.

MEC Ministério da Educação.

NoSQL Not Only SQL.

OBDA Ontology Based Data Access.

POM modelo de objeto de projeto.

SGBD Sistema de Gerenciamento de Banco de Dados.

SQL Structured Query Language.

XML eXtensible Markup Language. 


\section{Lista de Figuras}

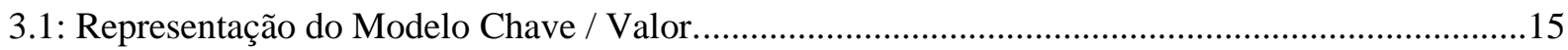

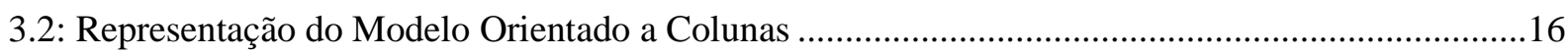

3.3: Representação da estrutura do modelo Orientado a Documentos ...................................................17

3.4: Mapa de Königsberg de 1890 com as pontes demarcadas ...........................................................18

3.5: Representação das sete pontes de Könisberg ………...................................................................18

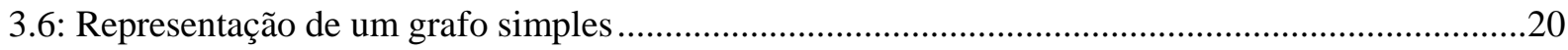

3.7: Classificação por categoria do DB-Engines, abril de 2016 ...........................................................22

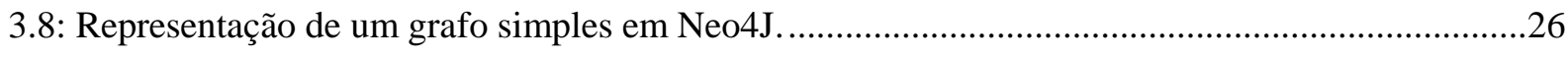

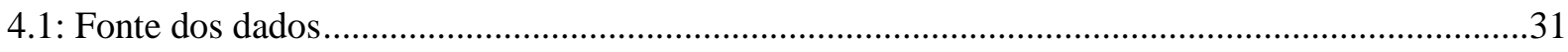

4.2: Trecho do arquivo com os periódicos Qualis obtido pela Plataforma Sucupira. .............................34

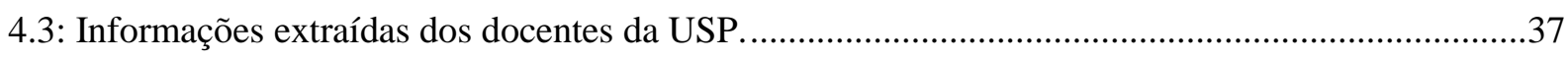

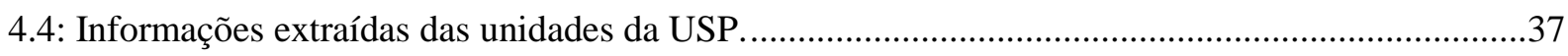

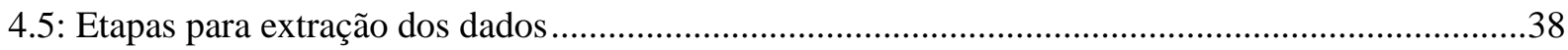

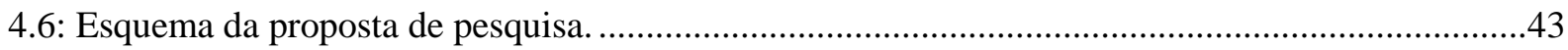

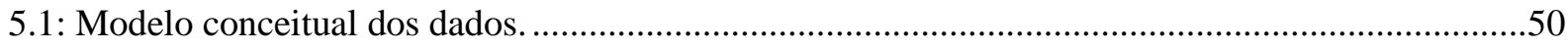

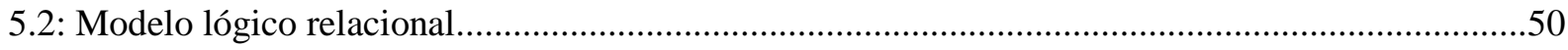

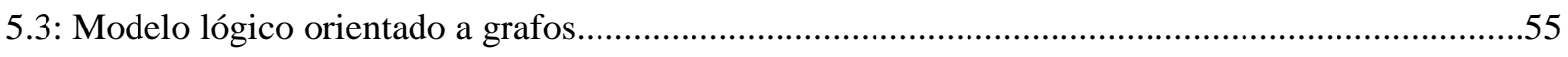

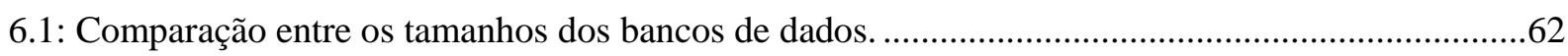

6.2: Memória utilizada na inicialização dos bancos de dados..............................................................63

6.3: Resultados do tempo de execução do experimento 1 ......................................................................64

6.4: Resultados do tempo de execução do experimento 2 ......................................................................64

6.5: Resultados do tempo de execução do experimento 3 ......................................................................65

6.6: Resultados do tempo de execução do experimento 4 ..................................................................65

6.7: Resultados do tempo de execução do experimento 5.....................................................................66

6.8: Resultados do tempo de execução do experimento 6.....................................................................66

6.9: Resultados do tempo de execução do experimento 7 .....................................................................67

6.10: Resultados do tempo de execução do experimento 8 ..................................................................67

6.11: Resultados do tempo de execução do experimento 9.................................................................68

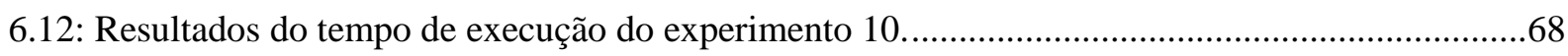

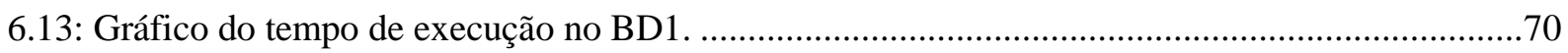


6.14: Gráfico do tempo de execução no BD2. .70

6.15: Gráfico do tempo de execução no BD3. .71

6.16: Gráfico do tempo de execução no BD4. .71

6.17: Gráfico do tempo de execução no BD5. .72

6.18: Desempenho entre os experimentos 1 e 6 . .76 


\section{Lista de Tabelas}

3.1: Análise Comparativa Modelo Relacional x NoSQL [Brito 2010] ….............................................22

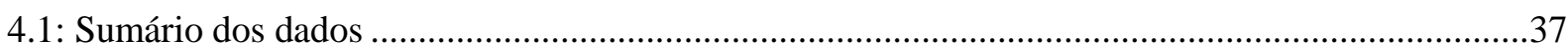

4.2: Informações disponíveis pelo web service da Thomson Reuters....................................................39

4.3: Discriminação dos bancos de dados relacionais. ............................................................................

4.4: Discriminação dos bancos de dados orientados a grafos. ..............................................................

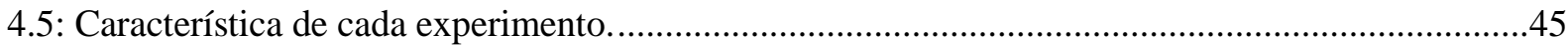

4.6: Relações existentes em cada experimento. .................................................................................

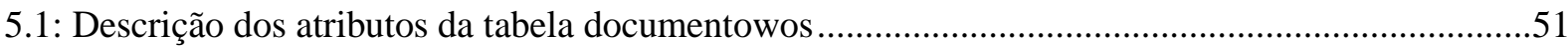

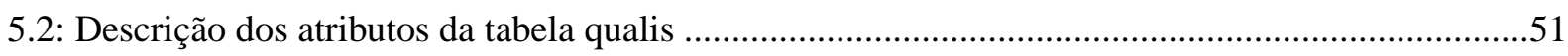

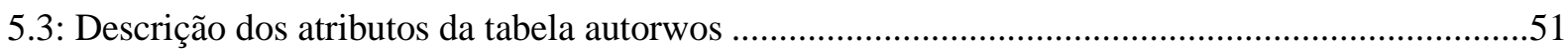

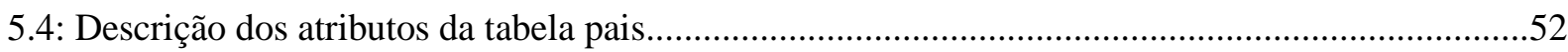

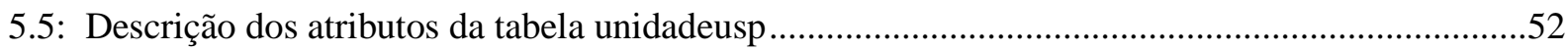

5.6: Descrição dos atributos da tabela tipounidade ………..................................................................52

6.1: Tempo de importação para o banco de dados orientado a grafos. ...................................................61

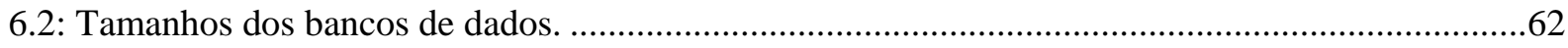

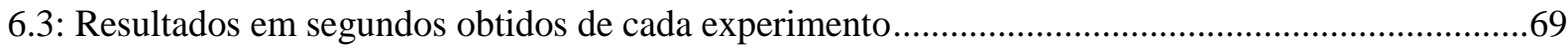

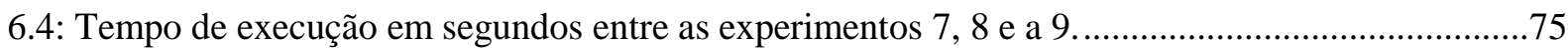

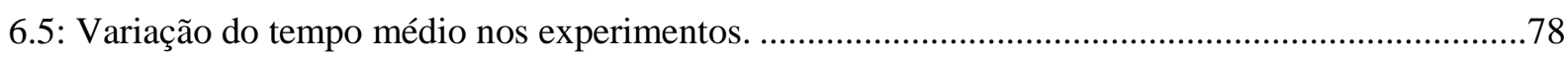




\section{Capítulo 1}

\section{Introdução}

O grau de impacto de uma publicação pode indicar a qualidade e o nível de internacionalização de uma instituição de ensino superior e pesquisa na área acadêmica. Devido à disseminação da internet que vem ocorrendo nos últimos anos, o volume de dados disponibilizados das publicações cresceu exponencialmente. Um dos crescimentos é referente aos dados sobre redes sociais, entre elas, a rede de colaboração acadêmica originária das publicações de trabalhos e de seus autores.

Com esse crescimento, surgiram novas necessidades de aplicações para gerenciar grandes quantidades de dados não estruturados, e constatou-se que o modelo de Sistema de Gerenciamento de Banco de Dados (SGBD) relacional não atende bem a essa necessidade [Sattar 2013].

Atualmente o modelo relacional é o modelo predominante dos bancos de dados atuais [King 2015; DB-Engines 2016] e normalmente utilizado para o armazenamento de dados estruturados. Porém, a análise das redes de colaboração deve ser feita numa nova estrutura, pois o modelo de dados relacional não é adequado para todas as consultas requeridas nesse ambiente de colaboração [Meijer 2011].

Conforme pesquisa de [Meijer 2011; Nance 2013] sobre adotar ou o modelo Not Only SQL (NoSQL), ou o modelo relacional, eles concluíram que não existe um modelo que atenda bem a todos os desafios. Desse modo ambos os modelos não estão em conflito, sendo até possível adotar qualquer um dos dois modelos para uma mesma necessidade, sem perda de desempenho dependendo das solicitações da consulta e do volume de dados.

Uma das características mais relevantes a serem alcançadas pelos grandes sistemas de análise de dados é a flexibilização dos modelos NoSQL. Para obter essa propriedade, é preciso combinar os benefícios do modelo de banco de dados relacional com o modelo não relacional [Cattell 2010].

Dentre os modelos de bancos não relacionais, o modelo orientado a grafos consegue 
representar facilmente uma rede de colaboração, pois proporciona uma estrutura de armazenamento de dados para representação de relações com alto nível de indireção e dispõe de algoritmos para estudos dessas relações [Gubichev 2010].

A integração entre o modelo de banco de dados relacional com o modelo de banco de dados orientado a grafos é uma alternativa para as consultas que perdem desempenho. Para que seja definido qual o melhor modelo para executar as consultas, deve-se analisar os parâmetros do ambiente de execução.

Dessa forma, este trabalho propõe um analisador de consultas que, conforme a sintaxe e o ambiente de execução indiquem qual é o modelo mais apropriado para execução; se o modelo de banco de dados relacional ou o modelo de banco de dados orientado a grafos.

A seguir, é vista a motivação e o objetivo desta dissertação. Sendo finalizada pela apresentação da estrutura do trabalho.

\subsection{Motivação}

Muitos trabalhos já foram apresentados sobre o modelo de dados NoSQL. Apesar de muitos bancos de dados se utilizarem do modelo de banco de dados relacional [King 2015; DB-Engines 2016], estudos comparativos entre os dois modelos apresentam as vantagens existentes em realizar consultas em bancos de dados não relacionais [Vicknair 2010; Batra 2012]. Os dois modelos apresentam características que os tornam mais efetivos para determinados tipos de situações. Não existe um modelo de banco de dados que atenda bem a todas as solicitações. Assim, a integração desses modelos surge como uma hipótese de solução para o atendimento de uma demanda híbrida. [Cattell 2010]. Esta dissertação tem como motivação principal investigar ambos os modelos, pesquisando a definição de padrões na consulta que indique qual dos modelos é o mais indicado, propondo uma integração entre eles de modo a obter um desempenho melhor para consultas com grande número de indireções.

\subsection{Objetivo}

O objetivo desta proposta é apresentar uma solução de integração entre o modelo relacional e o modelo orientado a grafos, apresentando uma estratégia que possa determinar qual dos modelos é a melhor opção de execução. Um dos motivos dessa integração dos bancos é que conforme a estrutura que cada consulta apresenta, os 
modelos retornam o resultado com um desempenho diferente.

Outro objetivo deste trabalho é a contribuição por meio da viabilização de consultas dinâmicas em um modelo relacional ou em um ambiente de publicação intelectual representa no modelo em grafos. Desse modo estudando a possibilidade de mudança do nível de granularidade, indo de uma visão inicial sumariada até uma menor granularidade. Esse procedimento é denominado Drill Down [van der Aalst 2013].

Para isto, ao invés de criarmos um banco de dados controlado, utilizaremos os dados reais extraídos de diversas fontes de dados, deste modo verificando a viabilidade da proposta em uma situação real na qual este procedimento pode vir a ser utilizado.

Tendo ainda que, a extração e o carregamento do banco de dados utilizado para este estudo permitirão investigar a relação entre autores e a internacionalização de seus coautores com a quantidade e qualidade de publicações quanto ao número de citações incluindo o estrato Qualis da Capes [Qualis 2016].

Para isso foram analisados e comparados várias características de consultas, seus desempenhos obtidos durante a execução nos banco de dados relacional e orientado a grafos e uma análise dos resultados.

\subsection{Estrutura da Dissertação}

Esta dissertação segue a seguinte organização: o Capítulo 2 apresenta os trabalhos relacionados ao tema proposto. O Capítulo 3 apresenta os conceitos fundamentais. No Capítulo 4 é detalhada a metodologia utilizada para o trabalho. O Capítulo 5 apresenta informações sobre os dados que foram armazenados nos bancos de dados, além de apresentar os modelos desenvolvidos para este trabalho. No Capítulo 6 é visto uma análise sobre os resultados obtidos. Por fim, o Capítulo 7 conclui a dissertação apresentando os principais resultados e os desdobramentos para trabalhos futuros. 


\section{Capítulo 2}

\section{Trabalhos relacionados}

Neste capítulo serão apresentados os trabalhos relacionados com o tema proposto percorrendo brevemente o histórico de cada tema e elencando os pontos pendentes a serem vistos nesta dissertação.

\subsection{O modelo relacional e o modelo não relacional}

A diversidade de modelos NoSQL originou estudos que analisam os quatro modelos principais de NoSQL: Chave/Valor, orientado a colunas, orientado a documentos e orientado a grafos. Essas pesquisas apresentaram as características e os aplicativos que atendem a cada modelo, porém sem definir qual o melhor para um determinado problema [Abramova 2014a; Abramova 2014b; de Souza 2015; Sharma 2015].

Sobre o modelo orientado a grafos, foram feitos estudos que comparam as implementações existentes abordando diversas características [Angles 2008; Angles 2012; Jouili 2013; Escobar 2014].

Em um estudo comparativo sobre o desempenho do algoritmo do menor caminho entre o modelo relacional e o modelo orientado a grafos, foi visto que a escolha do NoSQL é mais plausível [Miler 2014]. A eficácia e o desempenho dos aplicativos em grafos foram constatados por [Cheng 2009; McColl 2014].

[Shi 2010; Hecht 2011; Lourenço 2015] informam que a escolha do modelo NoSQL depende da aplicação e sua finalidade. Não existe um modelo genérico que atenda bem a todos os problemas.

Em estudos comparando banco de dados NoSQL com banco de dados relacional, o critério de desempenho das consultas foi estudado por [Boicea et al. 2012; Li and Manoharan 2013; Parker et al. 2013; Politowski 2014; Shalini 2014; Schmid 2015]. Esses estudos adotaram o banco de dados NoSQL MongoDB [MongoDB 2016] e o compararam com os seguintes modelos de banco de dados relacional: Oracle [Oracle 
2016], [Microsoft 2016] e PostgreSQL [Momjian 2001; PostgreSQL 2016]. Em todos os estudos o MongoDB obteve melhores resultados, principalmente quando era utilizado um grande volume de dados, somente em funções agregadas que o desempenho não foi superior.

\subsection{Integração entre o modelo relacional e o modelo não relacional}

[Cavoto 2014] apresentou uma revisão dos trabalhos sobre a integração de modelos de banco de dados. Conforme visto, muitas propostas evitam modificações impactantes nos esquemas e sistemas. As soluções propostas são: implementar grafos em bancos relacionais, implementar um módulo de integração entre os bancos por meio de uma interface de acesso unificado aos modelos e por fim uma arquitetura em camadas, na qual um modelo de banco de dados é implementado como uma aplicação que opera sobre outro modelo.

[Curé 2011] apresenta duas soluções de integração entre modelos de banco de dados diferentes. Na primeira, de 2011, ele propõe uma integração entre o modelo relacional e o NoSQL por meio de caminhos de acesso baseados em mapeamento. Porém são necessários vários passos de transformação para que se obtenham resultados a partir dos dados armazenados em cada uma das fontes. Os resultados preliminares apontam que a sobrecarga desses passos de transformação não afeta o desempenho de uma consulta. Os modelos estudados foram o orientado a documentos e o orientado a colunas.

No trabalho publicado em 2012, [Curé 2012] propõe outra abordagem para a integração, baseada em ontologia - Ontology Based Data Access (OBDA). As funcionalidades fornecidas pelo OBDA superaram as expectativas, porém, a priori, existe um grande trabalho árduo para que ocorra uma integração entre OBDA e NoSQL.

\subsection{Redes de colaboração científica}

No âmbito acadêmico, as redes de colaboração são muito relevantes como fonte de aprendizado, constituindo o melhor instrumento para o compartilhamento de ideais e pesquisa. Trabalhos referentes à atuação dessas redes são realizados desde 1978 [Beaver and Rosen 1978], nos quais nota-se que a colaboração científica envolve metas comuns que acabam gerando trabalhos científicos e pesquisas com responsabilidade compartilhada.

Por meio da otimização na rede de colaboração científica, a melhora nos resultados 
e o potencial das pesquisas e publicação de artigos são ampliados [Weisz and Roco 1996]. Nesse contexto, a internacionalização no meio acadêmico tem grande importância para o reconhecimento fora dos limites locais.

Tendo em vista o aumento do conhecimento e das opções das ferramentas de pesquisa dessas redes e considerando que o processo de produção científica requer associações e estratégias para interligar o maior número de elementos possíveis, constata-se que pesquisadores que não pertencem a uma rede de colaboração, tendem a ser menos produtivos [Silva 2002].

Com o passar dos anos, a evolução da internet é um fator de impacto nas redes de colaboração, facilitando o surgimento de redes sociais virtuais voltadas à pesquisa em comum. O estudo dessas novas redes de colaboração tem aumentado, com agrupamentos tanto entre instituições como grupos de pesquisa e países [Glanzel 2001, Kretschmer 2004, Cronin 2005].

Ao se estudar as redes de colaboração científica considerando os coautores e os produtos gerados, além dos motivos dessas redes terem surgido, abre-se um leque significativo de possibilidades. Tem-se afirmado que a coautoria de publicações é um indicador de colaboração [Cronin 2005, Kim 2006], com isso diversos estudos têm sido feitos tendo como métrica as diferentes características de publicações.

Todos esses fatos acerca do armazenamento de dados estão relacionados com o tema a ser analisado. Os dados sobre as redes de colaboração, que disponibilizam dados que permitem a descrição de como os indivíduos são armazenadas em diferentes modelos de dados [Ahuja 2013].

Ao se estudar as redes de colaboração científica considerando os coautores e os produtos gerados, é importante saber os motivos que levaram à configuração dessa rede, e assim estudar o comportamento desde um pesquisador até diversos grupos de pesquisa de diversas áreas de conhecimento [Autran 2015].

[Cronin 2005; Kim 2006] afirmam que a coautoria de publicações é um indicador de colaboração, com isto vários estudos têm sido realizados utilizando como métrica as diferentes características de publicações [Maia 2008, Hayashi et al 2012, Oliveira 2014, Sidone 2014].

Também é notado em estudos, que conforme as redes de colaboração em coautoria, pode ocorrer um aumento da produtividade dos pesquisadores e em estudos sobre trabalhos teóricos e de natureza experimental, o primeiro produz artigos com menos 
autores [Cronin 2005].

As conclusões desses trabalhos mostram que as colaborações entre autores têm aumentado, porém não é um fator constante conforme as áreas de pesquisa; por exemplo, nas ciências naturais o número de artigos em coautoria e o número de autores por artigo é maior do que nas ciências sociais [Yoshikane and Kageura 2004].

\subsection{Internacionalização}

O Estudo sobre a rede de colaboração científica tem sido alvo de várias pesquisas, [Newman 2001; Balancieri 2005; Matheus and Silva 2006; Hayashi; Hayashi and Lima 2008; Maia and Caregnato 2011], e a utilização de banco de dados em grafos, segundo [Vicknair 2010], é mais eficiente em vários aspectos, e já amplamente estudado no meio acadêmico [Angles 2012, 2008]. Porém nenhuma trata da relação que pode existir entre a internacionalização e a quantidade e qualidade da produção científica utilizando uma abordagem de busca por similaridades com bancos de dados orientados a grafos.

Conforme o estudo apresentado em [Alves 2014], desenvolvimento científico e tecnológico é alavancado pela cooperação e a internacionalização sendo fundamental existir uma cooperação entre os pesquisadores visando aumentar a visibilidade de suas pesquisas.

É visto que a ciência no Brasil tem tido um crescimento bem expressivo no qual podese notar um aumento na participação de autores nacionais em publicações científicas em bancos de dados internacionais. É importante ressaltar que o crescimento da produção científica do Brasil superou a média internacional [Alves 2014]. Em 2011, o Brasil ficou em $13^{\mathrm{a}}$ posição [SCImago 2012] referente à quantidade de publicações, estando à frente de países como Holanda, Suécia e Suíça. [Alves 2014].

Essa evolução na quantidade de publicações amplia o interesse em analisar as redes de colaborações, e com isso diferentes características e objetivos começam a ser analisados. As atividades científicas provenientes das coautorias de publicações se tornam reconhecidamente um indicador de colaboração [Kim 2006; Cronin 2005; Newman 2001]. [Newman 2001; Glanzel 2001] estudaram as características de colaboração em disciplinas, já [Kim 2006; Glanzel 2001] pesquisaram as colaborações relacionadas às instituições ou aos países [Kim 2006; Glanzel 2001].

Assim, a colaboração científica entre autores ou instituições considera a relação de hipóteses e objetivos centrais de um projeto, o estabelecimento de uma divisão de 
trabalho, a interação entre os investigadores, o compartilhamento de informações e a coordenação dessas diferentes relações do investimento conjunto [Gómez 2008; Alves 2014].

Trabalhos como [Oliveira 2009] mostram que os relacionamentos nas instituições podem ser divididos em intra e interinstitucional. Formando três grupos marcantes, um com muita colaboração interna e pouca com outras instituições, outro com pouca colaboração interna e moderada colaboração interinstitucional e por fim um grupo com grande colaboração interinstitucional e pouca colaboração interna. Assim, são poucas as instituições que atuam de forma mais independente, existindo mais coautorias internas. A maioria atua com outras instituições.

Relacionado ao problema proposto por este projeto, quando os trabalhos possuem cooperação internacional, ocorre um maior impacto e com isto, visibilidade [Glanzel 2002].

O compartilhamento de informações tendo a junção de competências e a união de esforços de pesquisadores na busca de metas em comum impulsiona a produção de conhecimento agilizando o tempo de pesquisa e a obtenção de recursos financeiros para os projetos, sendo esse muito estimulado pelas agências financiadoras de pesquisa [Balancieri et al. 2005].

Apesar de inúmeros estudos [Maia 2008; Hayashi et al 2012; Oliveira 2014; Sidone 2014], um trabalho que permita a descrição histórica das áreas de pesquisa, que possuem publicações com autores estrangeiros, em um período de quase duas décadas e que estabeleça uma correlação entre a quantidade de coautores estrangeiros e o número e qualidade de publicações com citações por meio do Web of Science e que tenha uma sustentação computacional automatizada e eficiente ainda é um desafio a ser superado.

A isto, é somada a importância em investir na internacionalização em uma instituição de ensino superior que requer o conhecimento do retorno do investimento e quais os resultados obtidos para a instituição. Ao se saber as relações existentes, considerando o fator de internacionalização como um impacto na qualidade das publicações, pode-se saber mais sobre as áreas de conhecimento e grupos de pesquisa que se beneficiam e assim medir a qualidade da pesquisa do grupo. 


\section{Capítulo 3}

\section{Conceitos fundamentais}

Uma das principais dificuldades encontradas no modelo relacional para utilização em aplicações de redes de colaboração é a escalabilidade. É possível escalar um modelo relacional por meio da distribuição em várias máquinas, contudo, não é fácil de ser implementado tendo em vista a dificuldade em se organizar os dados em um sistema distribuído [Pokorny 2011].

Em 1998 Carlos Strozzi apresentou o termo Not Only SQL (NoSQL). O termo se referia a um novo modelo de banco de dados no qual a responsabilidade pela gestão da modelagem e de relacionamento dos dados foi deslocado do SGBD para o espaço de aplicação [Sattar 2013].

O modelo NoSQL surgiu com o propósito de ser o banco de dados que atendesse esta lacuna do modelo relacional. Com a flexibilidade oferecida por esse modelo, muitos serviços, como [Chang 2006; DeCandia et al 2007], optaram por ele.

Outras características do NoSQL são a escalabilidade, disponibilidade, processamento de grandes volumes de dados, controle de concorrência e a distribuição de sistemas em escala global [Diana 2010]. As principais categorias de bancos de dados NoSQL são: orientados a documentos, chave/valor, orientado a colunas e orientado a grafos [Sattar 2013].

\subsection{Banco de dados Relacional}

Um banco de dados pode ser definido com uma coleção de dados inter-relacionados que podem ser armazenados de forma centralizada ou distribuída, tendo ou não um controle de redundância [Elmasri and Navathe 2005]. Essa coleção de dados representa as características do mundo real.

Como as entidades armazenadas precisavam se relacionar, por exemplo, os autores e publicações que participaram, a complexidade do banco de dados começou a aumentar para que fosse permitido o relacionamento entre todas as entidades. Tendo em vista esse 
problema, a IBM investiu em pesquisas na década de 60 de modo a solucionar as demandas dos bancos de dados digitais.

Em junho de 1970, o pesquisador da IBM Edgar Frank Codd apresentou um modelo no qual os usuários pudessem armazenar e utilizar quantidades expressivas de dados mesmo com pouco conhecimento técnico [Codd 1970]. O artigo possibilitou a evolução dos bancos de dados, permitindo que outros pesquisadores evoluíssem a criação de um modelo de banco de dados relacional. Na proposta é apresentado um modelo que utiliza conjuntos de relações matemáticas para representar os dados com uma linguagem baseada em teoria de conjuntos e lógica de primeira ordem para acessá-los [Cood 1970].

No final da década de 70 foi criado a linguagem de consulta estruturada (SQL Structured Query Language) que se tornou a linguagem padrão para bancos de dados relacionais. Na década seguinte surgiram outros bancos de dados, tais como o da a empresa IBM que lançou o SQL/DS [Sumathi 2007] sendo o primeiro sistema de gerenciamento de dados relacional comercializado [Sumathi 2007], e o da empresa Oracle [Oracle 2007].

Para que esses bancos de dados pudessem ser administrados, foi desenvolvido o Sistema de Gerenciamento de Bancos de Dados (SGBD) ou Database Management System (DBMS) [Patterson 1971]. Esse sistema é uma coleção de dados interrelacionados e uma coleção de programas para acesso a esses dados. O SGBD proporcionou um ambiente eficiente e homogêneo para recuperação e armazenamento em banco de dados [Silberschatz 1999].

Dentre as funcionalidades do SGBD, está o controle de redundância, compartilhamento de dados, restrições de acesso multiusuários, representação de relacionamentos complexos de dados, restrições de integridade e funcionalidades de backup e restauração. As propriedades transacionais mais conhecidas são Atomicidade, Consistência, Isolamento e Durabilidade (ACID) [Elmasri 2005]:

Atomicidade: as transações são atômicas (indivisíveis) no processamento. Ou todas as modificações de uma transação são executadas com sucesso, ou nenhuma delas é executada.

Consistência: todas as modificações serão efetuadas no banco de dados se forem consistentes, quando todos os dados de uma transação forem válidos, caso contrário a transação será cancelada.

Isolamento: a transação não será interferida por nenhuma outra transação 
concorrente. Ela deve ser executada como se estivesse isolada das demais.

Durabilidade: quando uma transação é executada com sucesso todas as suas modificações serão gravadas permanentemente no banco de dados e não devem ser perdidas em caso de uma falha física no equipamento.

O SGBD foi sendo aprimorado desde os sistemas de arquivos de armazenamento em disco até a criação de novas estruturas de dados. As especificações que descrevem como o banco de dados deveria ser estruturado e utilizado começaram a ter diferentes formas de representação, que são os modelos de dados.

Os modelos de dados utilizados pelo SGBD são: modelo hierárquico, modelo em redes, modelo relacional e o modelo orientado a objetos. Sendo que o modelo hierárquico e o de redes são orientados a registros, nos quais qualquer acesso ao banco de dados (consulta, inserção, alteração ou remoção de dados) é feito em um registro por vez.

\subsection{Banco de dados Não Relacional - NoSQL}

Em 2000 o pesquisador Eric Brewer elaborou o Teorema CAP (Consistency, Availability e Partition Tolerance), tendo em mente a conjectura de que não existem garantias de que um sistema computacional distribuído possa ter simultaneamente consistência, disponibilidade e tolerância ao particionamento. Segundo Brewer, um sistema distribuído pode garantir apenas duas dessas três características ao mesmo tempo [Gilbert 2012].

Consistência: é a garantia de que, após a finalização de uma transação, o sistema mantém a integridade dos dados, ou seja, a transação não pode infringir as regras do banco de dados [Wei 2009].

Disponibilidade: é a garantia de que um sistema esteja sempre acessível aos seus usuários. Cada transação deve finalizar com uma resposta esperada.

Tolerância ao particionamento: é a garantia de que um sistema continue operando mesmo após ocorrerem particionamentos na rede. Assim, se um sistema dispuser dessa propriedade, ele deverá ser capaz de realizar operações como leitura e escrita após ocorrerem particionamentos na rede [Gilbert 2012].

Segundo Gilbert [Gilbert 2012], uma aplicação voltada para a Internet pode atender até duas dessas propriedades. Como qualquer estratégia de escalabilidade horizontal é baseada no particionamento de dados, os desenvolvedores devem decidir entre consistência e disponibilidade. 
Nesse contexto, a arquitetura NoSQL possui uma melhor disponibilidade, desempenho e flexibilidade, porém tem uma baixa consistência. O modelo NoSQL utiliza a Consistência Eventual, na qual poucas atualizações são esperadas, e quando elas ocorrem não são propagadas instantaneamente. Esse modelo requer que as atualizações sejam disseminadas para todas as cópias de tempos em tempos. Com isto, quando uma escrita for realizada no banco, não tem como garantir que, daquele momento em diante todos os processos terão acesso ao dado atualizado [Vogels 2008].

Considerando o teorema e as características do NoSQL quanto a consistência, e de que a proposta ACID tem como uma das propriedades principais a consistência, foi elaborado o conceito BASE (Basically Available, Soft state, Eventual consistency). BASE propõe relaxar o requisito de consistência permanente de dados, e enfatizar a disponibilidade e a tolerância ao particionamento. A disponibilidade é obtida por meio do tratamento local de falhas. Quando uma máquina do sistema falha é apenas uma máquina a menos disponível no sistema [Pritchett 2008].

Um Sistema que adote o BASE não demanda a disponibilidade total (Basically Available) não precisando ser continuamente consistente (Soft State).

Desse modo, os modelos de bancos de dados NoSQL possuem as seguintes características: não-relacional, distribuído e escalável horizontalmente, ausência de esquema ou esquema flexível, apoio nativo à replicação de dados nativo e acesso aos mesmos via APIs simples [NoSQL 2016]. As principais categorias de bancos de dados NoSQL são: orientados a documentos, chave/valor, orientado a colunas e bancos de dados de grafos [Sattar 2013].

\subsubsection{Chave/Valor}

O modelo chave/valor utiliza o mesmo princípio do uso de dicionários de dados, no qual os dados são endereçados por uma única chave, que permite trabalhar com os valores por chaves. Esses tipos de bancos de dados são os que têm a maior escalabilidade. Podem conter dados estruturados ou não estruturados e tem muita utilidade para operações simples, baseadas somente em atributos chave. A maioria dos armazenamentos chave/valor mantém seu conjunto de dados em memória, são muito utilizados para cache de consultas SQL [Leavitt, 2010]. Os valores são isolados e independentes devido aos relacionamentos serem tratados na lógica da aplicação. Graças a essa estrutura de dados, os armazenamentos são totalmente livres de esquema. [Hecht 2011].

A estrutura de dados chave-valor proporciona um algoritmo mais eficiente para 
acessar os dados. Como a chave é um valor único pode ser rapidamente localizada, assim permitindo o acesso aos dados [Tiwari 2011].

Existem aplicativos do modelo chave-valor que podem armazenar os dados em memória, melhorando o desempenho do acesso aos dados, ou persistir os dados em discos, assim facilitando escalabilidade. A estrutura chave/valor é vista na Figura 3.1.

\begin{tabular}{|l|l|}
\hline Chave_1 & Valor_1 \\
\hline Chave_2 & Valor_2 \\
\hline Chave_3 & Valor_3 \\
\hline Chave_4 & Valor_4 \\
\hline
\end{tabular}

Figura 3.1: Representação do Modelo Chave / Valor.

Fonte: Autor

\subsubsection{Orientado a Colunas}

O modelo orientado a colunas possui uma estrutura que permite um desempenho melhor para a implementação de sistemas, desde que as agregações sejam processadas sobre a quantidade de dados com características similares. Esse modelo é uma especificidade do modelo chave-valor, já que uma chave corresponde a diversos valores armazenados em sua estrutura [Indrawan-Santiago 2012]. É composto por famílias de colunas e supercolunas. As famílias de colunas agrupam colunas e supercolunas em um dado altamente estruturado. Uma coluna é uma unidade atômica de informação expressa como um par de nome e valor e as supercolunas agrupam colunas associadas, recuperadas pelo disco ou pela associação semântica [Indrawan-Santiago 2012].

Essa estrutura de dados permite uma maior eficácia quanto aos armazenado (Figura 3.2). O modelo orientado a colunas não armazena nulo em uma coluna, com isto economiza espaço [Tiwari 2011]. 


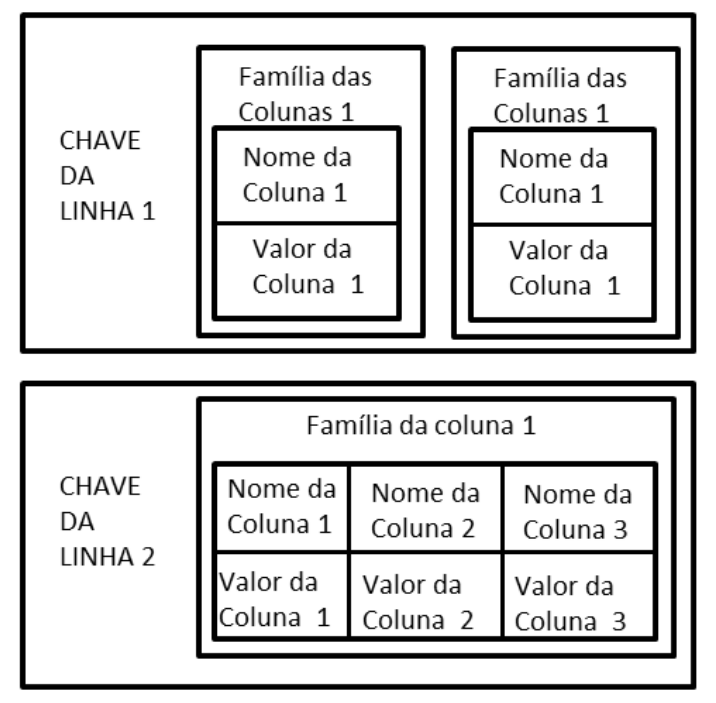

Figura 3.2: Representação do Modelo Orientado a Colunas

Fonte: Autor

\subsubsection{Orientado a Documentos}

O modelo orientado a documentos gerencia, armazena e recupera dados semiestruturados no qual o objeto dos dados é chamado documento. Uma chave única representa o endereçamento do documento no banco de dados. Além de permitir recuperar um documento por meio da pesquisa chave/valor, também é possível recuperar um documento através de uma linguagem de consulta existente no banco. [Leavitt 2010]. Esse modelo de bancos de dados utiliza o JSON (JavaScript Object Notation) sendo que cada documento contém uma chave única que se encontra dentro de uma coleção de documentos, assim o identificando [Hecht 2011].

Esse modelo é considerado uma evolução do modelo chave-valor por permitir estruturas mais complexas com valores escalares. Segundo [Gajendran 2012], os nomes dos atributos podem ser definidos em tempo de execução para cada documento. Uma das vantagens do modelo é que ele considera um documento como única unidade, deste modo não dividindo a sua constituição de pares chave-valor. Com isso é possível indexar o identificador primário dos documentos e as suas propriedades [Tiwari 2011]. Na Figura 3.3 é mostrado uma representação do modelo. 


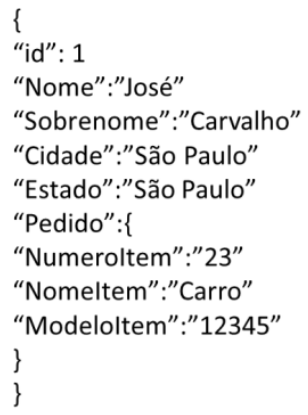

Figura 3.3: Representação da estrutura do modelo Orientado a Documentos

Fonte: Autor

\subsubsection{Orientado a Grafos}

$\mathrm{O}$ modelo de banco de dados orientado a grafos tem como fundamento a teoria dos grafos. Os grafos são descritos por vértices, propriedades e arestas. Os vértices representam as entidades, suas propriedades representam os atributos e as arestas representam as relações [Leavitt 2010].

A aceitação de modelos NoSQL é observada em grandes empresas que desenvolveram e utilizam SGBDs, como exemplo o projeto Dynamo, da Amazon [DeCandia 2007], o Bigtable, do Google [Chang 2006] e o projeto Cassandra, do Facebook [Lakshman 2010]. Atualmente existem vários bancos de dados NoSQL, por exemplo: MongoDB [Chodorow 2013], Redis [Zawodny 2009], CouchDB [CouchDB 2016] e Neo4J[Neo4j 2016].

\subsection{Grafos}

Leonhard Euler (1707-1782) criou a Teoria dos Grafos em 1736, quando ele demonstrou que um problema famoso chamado de desafio das sete pontes de Königsberg não tinha solução. Havia duas ilhas e sete pontes. Seis pontes interligavam as duas ilhas às margens do Rio Pregel e uma que fazia a ligação entre as duas ilhas (Figura 3.4). O problema resumia-se em fazer um passeio pela cidade de forma a atravessar uma única vez cada uma das sete pontes e por fim retornar ao ponto de partida [Harary 1969]. 


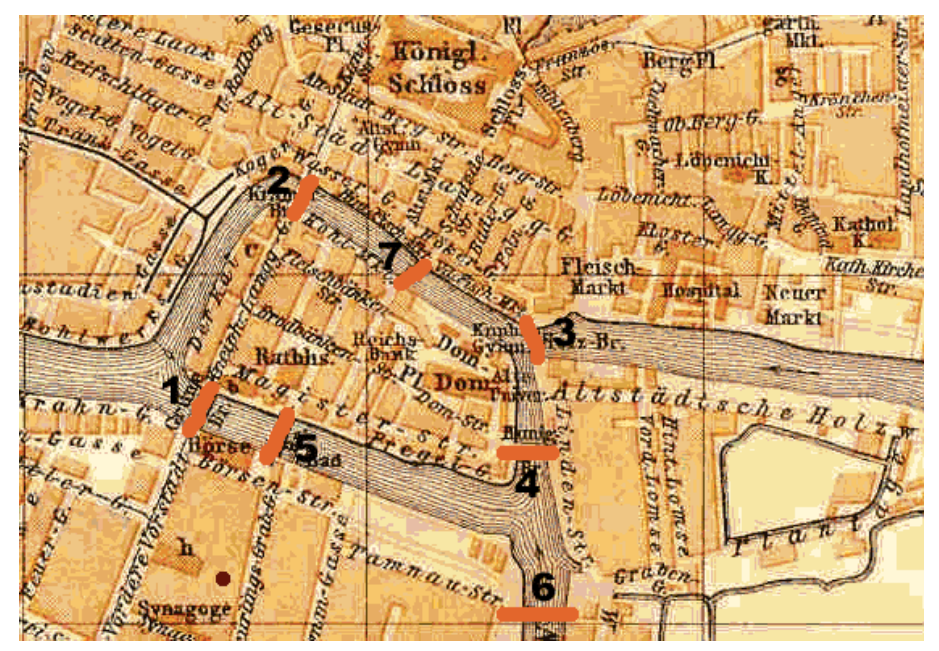

Figura 3.4: Mapa de Königsberg de $1890 \mathrm{com}$ as pontes demarcadas

Fonte: Baedeker, Atlas do Norte da Alemanha, 1890.

Euler conseguiu provar que o problema não tinha solução. Para isto, Euler removeu as informações impertinentes ao problema, como o comprimento e tipo de pontes e o tamanho das ilhas. Com isto, ele acabou representando o problema por um grafo.

A representação gráfica foi feita substituindo cada área de terra por um ponto. Cada uma das sete pontes ligava um destes pontos e foram representadas por uma linha que une os pontos correspondentes (Figura 3.5). Para mostrar que o problema não tinha solução, Euler demonstrou que o gráfico representativo não poderia ser percorrido da maneira solicitada.

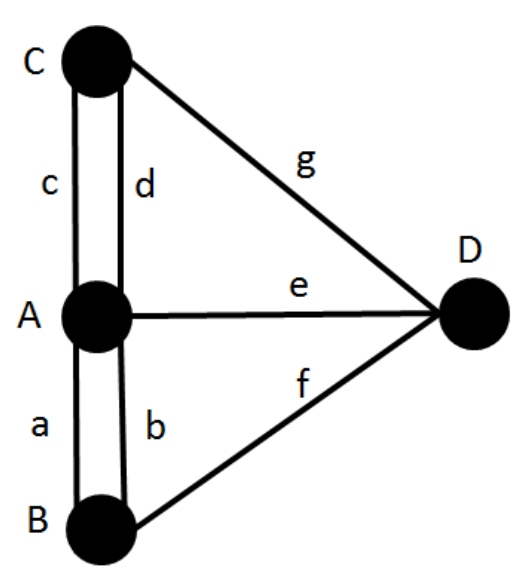

Figura 3.5: Representação das sete pontes de Könisberg

Fonte: Autor

Para isto, Euler determinou o seguinte: para atravessar cada ponto (A,B,C ou D), são necessários duas linhas, uma que entra no ponto e outra que sai. Euler propoz a solução para este problema da seguinte forma, ele se preocupou em descobrir em que tipos de 
grafos se pode fazer esse caminho fechado, passando por todas as arestas uma única vez. Esse tipo de trajeto foi chamado 'caminho de Euler', e um grafo que consiste de um caminho de Euler foi denominado 'grafo de Euler'. Com isto ele concluiu que cada ponto, ou vértice, deve ter grau par de linhas, ou arestas. Um grafo conexo G é um grafo de Euler se e somente se todos os seus vértices são de grau par, e o grafo das pontes de Königsberg tem pontos de grau ímpar. Portanto, o problema não pode ter solução.

\subsubsection{Definição de Grafos}

Um grafo é um conjunto finito $\mathrm{V}$ de vértices e um conjunto finito $\mathrm{E}$ de arestas onde cada elemento E possui um par de vértices que estão conectados entre si e pode ou não possuir um peso $P$. Podendo ser representado por $G=(V, E)$ [Neto 2001]. Os vértices e arestas são também denominados um conjunto de vértices com as relações que os conectam. Dois vértices são considerados adjacentes se existe uma aresta entre eles. Os grafos são de uso geral e expressivo, permitindo a modelagem das entidades como vértices e seus contextos semânticos usando as arestas [Robinson 2013].

A ordem de um grafo é definida pelo número de vértices $|V|$, já o tamanho de um grafo é a quantidade de arestas $|\mathrm{E}|$. O grau de um vértice é o número de arestas incidentes sobre ele, sendo que as arestas internas, que entram e saem do mesmo vértice, são contadas duas vezes [Bondy 2008].

$\mathrm{O}$ caminho em um grafo é uma sequência de vértices $\{\mathrm{v} 1, \ldots, \mathrm{v} n\}$ que estão conectados por arestas, e ciclo é um caminho onde temos que v1 e vn referem-se ao mesmo vértice. A definição de subgrafo é uma parte de um grafo, onde todos os vértices e arestas deste subgrafo estão contidos no grafo origem.

A representação gráfica de um grafo pode ser feita considerando que cada vértice é um círculo, e que cada aresta é representada por uma linha que conecta dois vértices (Figura 3.6). 


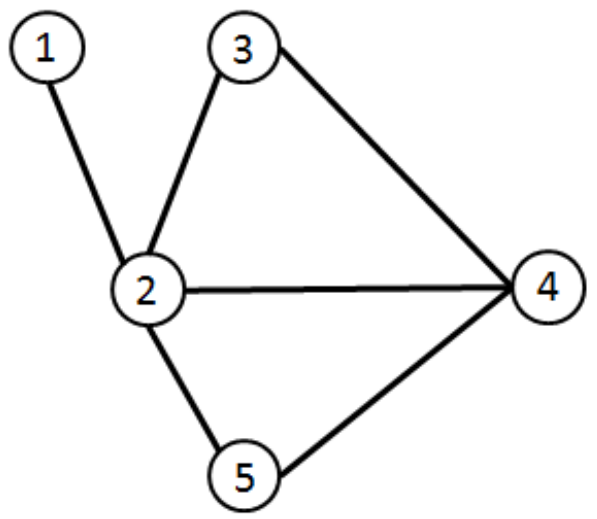

Figura 3.6: Representação de um grafo simples

Fonte: Autor

No grafo da figura 6 temos as seguintes informações:

Vértice $V=\{1,2,3,4,5\}$

Aresta $A=\{(1,2),(2,3),(2,4),(2,5),(3,4),(4,5)\}$

Ordem $|\mathrm{V}|=5$

Tamanho $|\mathrm{A}|=6$

Quando os pares de vértices conectados por uma aresta são ordenados, o grafo é direcionado (dígrafo). Quando os pares de vértices não são ordenados, então é um grafo não direcionado. Neste caso uma aresta que liga dois vértices u e v ter a representação $\{\mathrm{u}, \mathrm{v}\}$ ou $\{\mathrm{v}, \mathrm{u}\}$. Um grafo é completo quando todos os vértices estão conectados por arestas, e conforme a quantidade de arestas entre os vértices, ele pode ser denso ou esparso.

Um grafo simples é quando ele não possui laços, ou seja, arestas que ligam um vértice a si mesmo, ou arestas paralelas, ou seja, duas ou mais arestas que conectam o mesmo par de vértices. Quando os vértices de um grafo podem ser divididos em dois subconjuntos $\mathrm{X}$ e $\mathrm{Y}$ onde toda aresta liga um vértice do subconjunto $\mathrm{X}$ a um vértice do subconjunto $\mathrm{Y}$ é um grafo bipartido [Netto 2003]. As arestas e vértices também podem conter atributos com valores associados, assim permitindo armazenar diversas propriedades de cada aresta ou vértice [Rodriguez and Shinavier 2008]. Angles em [Angles 2012] considera quatros tipos de estruturas de grafos: 
1 - Grafos simples: um grafo simples definido como um conjunto de vértices conectados por arestas, sendo uma relação binária sobre o conjunto de vértices.

2 - Hipergrafos: estende a notação de grafo simples, permitindo a uma aresta se relacionar com um conjunto arbitrário de vértices;

3 - Grafos aninhados: é um grafo cujos vértices podem ser outro grafo;

4 - Grafos de atributos: são grafos em que vértices e arestas podem conter atributos que descrevem as suas propriedades.

O modelo mais utilizado entre os Bancos de Dados Orientados a Grafos atuais é o grafo de atributos. Outra definição sobre esse modelo é de ser um grafo multi-relacional direcionado e com atributos [Rodriguez and Neubauer 2010].

\subsubsection{Representação Computacional}

Para que os grafos pudessem ser processados e utilizados no meio computacional, foram elaboradas diversas formas de representação, possibilitando que algoritmos de grafos pudessem utilizar essa estrutura. A representação computacional de um grafo pode ser feita por listas ou por matrizes [Cormen 2001].

\subsection{Diferenças entre Banco de dados Relacional e NoSQL}

Conforme a pesquisa elaborada por [King 2015], a utilização do modelo de dados relacional é predominante nas empresas. O SQL Microsoft Server e Oracle são utilizados na maioria das organizações, seguidos pelo MySQL, IBM DB2 e MongoDB.

A $5^{a}$ colocação do MongoDB é uma evidência da aceitação da tecnologia NoSQL, particularmente em grandes empresas. A classificação elaborada pelo DB-Engines [DBEngines 2016] atesta o crescimento de popularidade do NoSQL, sendo o MongoDB na posição $4^{\circ}$ na lista, com o Cassandra em $8^{\circ}$ e o Redis em $10^{\circ}$. Nessa classificação da DBEngines, Oracle é o $1^{\circ}$ seguido pelo MySQL e em $3^{\circ}$ o SQL Microsoft Server. Na figura 3.7 é visto como o modelo relacional ainda é predominante, conforme critério de popularidade. 


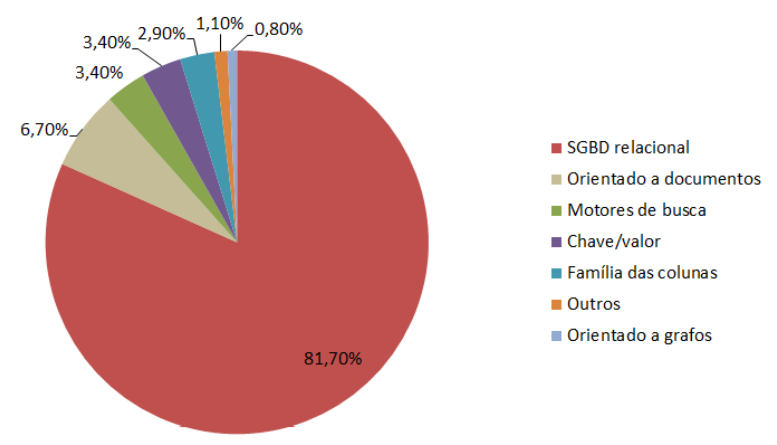

Figura 3.7: Classificação por categoria do DB-Engines, abril de 2016 Fonte: DB-Engines.

Critérios de escalonamento, consistência de dados e disponibilidade devem ser considerados no momento entre decidir entre um modelo de banco de dados relacional e um modelo NoSQL. O escalonamento é importante por ser uma das principais vantagens existentes no modelo NoSQL, que possuem uma flexibilidade maior.

Para suprir a necessidade de aumento da demanda em um sistema, existem duas possibilidades de escalonamento: Escalonamento Vertical (scale up), que é uma melhoria no servidor; Escalonamento Horizontal (scale out) que é o aumento da quantidade de servidores [Brito 2010]. Foi elaborado uma tabela comparativa entre os dois modelos, seguindo o teorema CAP, conforme visto na tabela 3.1.

Tabela 3.12: Análise Comparativa Modelo Relacional x NoSQL [Brito 2010]

\begin{tabular}{|l|l|l|}
\hline Escalonamento & \multicolumn{1}{|c|}{ Relacional } & \multicolumn{1}{|c|}{ NoSQL } \\
& $\begin{array}{l}\text { Possível, mas complexo. } \\
\text { Devido à natureza estruturada } \\
\text { do modelo, a adição de forma } \\
\text { dinâmica e transparente de } \\
\text { novos vértices no grid não é } \\
\text { realizada de modo natural. }\end{array}$ & $\begin{array}{l}\text { Uma das principais vantagens } \\
\text { desse modelo. Por não possuir } \\
\text { nenhum tipo de esquema pré- } \\
\text { definido, o modelo possui maior } \\
\text { flexibilidade o que favorece a } \\
\text { inclusão transparente de outros } \\
\text { elementos. }\end{array}$ \\
& $\begin{array}{l}\text { Ponto mais forte do modelo } \\
\text { relacional. As regras de } \\
\text { consistência presentes } \\
\text { propiciam um maior grau de } \\
\text { rigor quanto à consistência das }\end{array}$ & $\begin{array}{l}\text { Realizada de modo eventual no } \\
\text { modelo: só garante que, se } \\
\text { nenhuma atualização for } \\
\text { realizada sobre o item de dados, } \\
\end{array}$ \\
\hline
\end{tabular}




\begin{tabular}{|l|l|l|}
\hline & informações. & $\begin{array}{l}\text { devolverão o último valor } \\
\text { atualizado. }\end{array}$ \\
\hline Disponibilidade & $\begin{array}{l}\text { Dada a dificuldade de se } \\
\text { conseguir trabalhar de forma } \\
\text { eficiente com a distribuição } \\
\text { dos dados, esse modelo pode } \\
\text { não suportar a demanda muito } \\
\text { grande de informações do } \\
\text { banco. }\end{array}$ & $\begin{array}{l}\text { Outro fator fundamental do } \\
\text { sucesso desse modelo. O alto } \\
\text { grau de distribuição dos } \\
\text { dadospropicia que um maior } \\
\text { seja atendida por parte do } \\
\text { sistema e que o sistema fique } \\
\text { menos tempo não-disponível. }\end{array}$ \\
\hline
\end{tabular}

Além do teorema CAP, outros estudos foram realizados entre os dois modelos. Entre eles foram listados as vantagens e desvantagens entre o modelo NoSQL e o modelo relacional [Nayak 2013]:

Vantagens do modelo NoSQL sobre o modelo Relacional:

- Oferece uma ampla gama de modelos de dados para escolha;

- Escalabilidade com mais facilidade;

- Existem modelos de NoSQL preparados para tratar falhas de disco;

- São mais rápidos, mais eficientes e flexíveis;

- Tem evoluído a um ritmo significativo.

Desvantagens do modelo NoSQL sobre o modelo relacional:

- Ainda em evolução;

- Não existe uma linguagem padrão de consulta;

- Alguns modelos de bancos de dados NoSQL não seguem o modelo ACID;

- Não dispõe de uma interface padrão;

- A manutenção das aplicações exige um grande esforço.

Segundo um estudo realizado por [Näsholm 2012], a maioria dos modelos de SGBDR não são capazes de medir o volume de dados armazenado e processá-lo em um tempo útil. Como os SGBDR foram projetados para escalar verticalmente e não para escalar horizontalmente, sua expansão fica limitada. Para [Tiware 2011] o modelo NoSQL é uma 
evolução do modelo SGBD por permitir a escalabilidade horizontal e garantir uma disponibilidade.

\subsection{Banco de dados Orientado a Grafos}

Os grafos são representados por vértices, propriedades e arestas. Os vértices representam as entidades, suas propriedades são representadas pelos atributos e as arestas representam as relações [Leavitt 2010].

A organização dos grafos ocorre pelos relacionamentos entre os vértices. O modo de se percorrer um grafo é por meio de uma travessia, conforme o grafo é percorrido podem-se identificar os possíveis caminhos [NEO4J, 2016]. Os relacionamentos são constituídos por um vértice inicial e um vértice final, sendo possível existir mais de um relacionamento entre o mesmo par de vértices. Esses diferentes tipos de relacionamentos indicam diferentes relações entre os vértices. Essa implementação permite percorrer os vértices de um grafo selecionando o tipo de aresta desejada.

Existem duas classificações para os bancos de dados orientados a grafos definidas conforme o mapeamento lógico-físico: nativos ou não-nativos.

Os modelos não-nativos utilizam modelos distintos entre o armazenamento de dados físicos e o processamento das consultas. Nesse caso, modelam a parte lógica dos dados como grafos e armazenam os dados através de outros modelos. Como exemplo, temos o sistema SW-Store [Abadi et al. 2009] e o RDF-3X [Neumann and Weikum 2010], que utilizam o modelo relacional para armazenamento. Existe também o HyperGraphDB [Iordanov 2010] que utiliza o modelo chave/valor para o armazenamento físico.

Os modelos nativos utilizam a estrutura de grafos no armazenamento físico dos dados e no processamento das consultas. No armazenamento físico utilizam listas de adjacências vértice a vértice, que permite a exploração do grafo de modo simples e com eficiência quanto ao processamento das consultas. Normalmente esses modelos utilizam listas de adjacência [Aho and Ullman 1995]. Essa propriedade é conhecida como adjacência livre de índices e será vista em uma próxima seção.

Essa forma de armazenamento e pesquisa existente no banco de dados orientado a grafos é um diferencial com relação aos demais modelos de banco de dados. Como os vértices e arestas são armazenados sem o uso de tabelas, podem-se executar consultas através de travessia no grafo, que são mais eficientes, com isto são acessados somente os vértices que pertencem ao escopo da pesquisa, eliminando a necessidade de realizar joins 
desnecessários [Robinson 2013].

Esse armazenamento com os dados estritamente conectados, permite que, ao realizar uma pesquisa através da travessia seja possível percorrer milhões de vértices em questão de segundos [Rodriguez and Neubauer 2010].

Existem atualmente diversos sistemas de armazenamento orientado a grafos, com estudos bem abrangentes de suas características [Kolomicenko 2013]. Foram analisados vários fatores, como custo, tempo de busca no grafo e tempo gasto para a construção do grafo. Um relatório técnico sobre os modelos de banco de dados com sistemas abertos foi apresentado por [McColl et al. 2013], analisando o processamento de consultas e consultas e atualizações.

Foi realizado um estudo comparativo quanto ao desempenho por meio de um benchmark [Ciglan et al. 2012] analisando os cinco sistemas: Neo4J [Neo4j 2016], DEX [Martínez-Bazan 2011], OrientDB [OrientDB 2016], Repositório Nativo RDF (NativeSail) e um protótipo de pesquisa SGDB.

Os estudos quanto a escalabilidade e mecanismos de persistência comparando o desempenho relativo, em termos do uso de memória e tempo de execução feitos por [Barmpis 2014] compararam as implementações Neo4J e OrientDB [OrientDB 2016]. A conclusão dos estudos foram que consultas nativas fornecem resultados de desempenho muito boa, além de proporcionarem uma fácil manutenção.

O banco de dados orientado a grafos que foi selecionado para o estudo foi o Neo4J. A implementação Neo4J possui um desempenho muito superior às demais implementações, tem sua própria linguagem e permite transações ACID, além de ter uma melhor documentação e suporte [Jouli 2013; Escobar 2014].

\subsubsection{Neo4J}

O Neo4j é um banco de dados orientado a grafos desenvolvido em Java [Neo4j 2016]. Foi desenvolvido pela empresa Neo Technology (neotechnology.com) e sua primeira versão foi lançada em fevereiro de 2010 com a licença GNU Public License version 3 (GPLv3). Conforme pesquisa realizada em maio de 2016, é o banco de dados orientado a grafos mais utilizado [DB-Engine 2016]. Possui duas versões de licenciamento, uma de código aberto e outra proprietária, com código fechado e suporte aos seus usuários, além de possuir outros recursos que garantem o desempenho para aplicações maiores. Sendo um banco de dados de navegação, e devido a funcionalidade de travessia, permite percorrer de um vértice para outro [Neo4j 2016]. 
Pode-se definir o limite da navegação de uma travessia, ou permitindo que ela percorra todo o grafo, ou informando até que nível deve ser executada [Neo4J 2016].

Por convenção, neste trabalho a nomenclatura adotada pelo Neo4J vai ser: "nodes" são os vértices e "relationships" as arestas.

Cada vértice e aresta possuem atributos que armazenam as suas propriedades. Conforme o grafo, cada aresta conecta dois vértices, permitindo-lhe ser direcionado ou não. Os atributos são pares chave/valor, sendo que o valor pode ser unitário ou uma matriz de valores [Neo4j 2016]. Um exemplo de modelo Neo4J é visto na (Figura 3.8).

Esse modelo de banco de dados tem como uma de suas principais características garantir a propriedades de atomicidade, consistência, isolamento e durabilidade (ACID), existente nos bancos de dados relacionais, e base para a consistência dos dados. Para garanti-la, o Neo4j faz com que toda operação que modifique algum dado esteja contida em uma transação [Neo4j 2016].

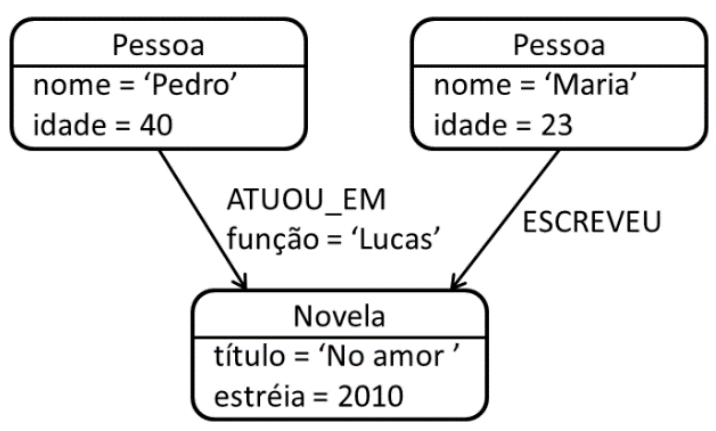

Figura 3.8: Representação de um grafo simples em Neo4J.

Fonte: adaptado da Neo4J.

Outra característica é a escalabilidade, que lhe permite tratar bilhões de vértices e arestas relacionados, através do recurso de consulta em um framework chamado travessia, que percorre o grafo pesquisando suas informações. $\mathrm{O}$ alto desempenho em consultas, graças a utilização da travessia entre os vértices, é outra de sua propriedade.

É um banco de dados transacional que dispõe de dois tipos de arquitetura, uma centralizada e a outra distribuída com apoio a replicação. Apesar de uma instância em um banco de dados orientado a grafos conseguir ser armazenado em um único diretório contendo bilhões de vértices e arestas relacionadas, existe a possibilidade de que o banco de dados ser implantado de forma distribuída em um conjunto de servidores. Essa arquitetura replica todos os dados em todas as instâncias, e é denominada Neo4j High 
Availability (HA). Assim garantindo a propriedade de alta disponibilidade [Neubauer 2010].

$\mathrm{O}$ modelo Neo4J permite que os vértices e as arestas tenham atributos diferentes adicionados para o mesmo tipo de objeto, com isto a recuperação das informações pode ser feita por dois meios: o próprio identificador do objeto e por um conjunto de valores indexados que possui alguns atributos específicos [Robnson et al. 2013].

Quanto à instalação, o Neo4J pode tanto ser instalado em um ambiente multisservidor quanto ser executado em um programa Java. Como exemplo o programa Eclipse [Eclipse 2016] e o armazenamento físico pode ser tanto em disco quanto em memoria, sendo que o modelo físico tem como base repositórios chave/valor.

O framework Cypher Query Language [NEO4J, 2016] permite que o Neo4J possa escrever consultas utilizando uma linguagem de consulta proprietária Cypher e permite suporte ao SPARQL (SQL for linked data). A linguagem Cypher possui um recurso existente na linguagem SQL que é permitir cláusulas encadeadas que utilizam os resultados previamente obtidos. Dentre as cláusulas, as mais utilizadas para consultas são match e where. Match é utilizada para descrever a estrutura da consulta utilizando como base os relacionamentos e where é utilizado para incluir restrições adicionais.

Apesar disso, as funcionalidades Stored Procedures e Triggers não são possíveis no Neo4J. Para suprir essa demanda foi desenvolvido, utilizando a linguagem de programação Java, uma Interface de Programação de Aplicação (API). Por meio dela, pode-se criar uma estrutura do banco de dados e adicionar vértices com seus atributos e relacionamentos.

Quanto à propriedade de travessia, essa API contém classes que permitem a execução da mesma, possibilitando a navegação entre os vértices de um grafo. A seguir, apresentamos algumas das classes que são direcionadas para a função de travessia [Neo4j 2016]:

Pathexpanders: define o que será percorrido, normalmente quanto à direção relacionamento e tipo;

Uniqueness: vértices visitados (relações, caminhos) somente uma vez;

Evaluator: decidir quando parar e retornar, e se deve parar ou continuar com a travessia para além da posição atual;

Starting nodes: local no qual a travessia inicia. 
O Neo4J pode ser incorporado em um aplicativo Java, disponibilizando as bibliotecas jar. Com isso um desenvolvedor pode utilizar qualquer ferramenta do Java Development Kit (JDK) para desenvolver suas aplicações. Temos, como exemplo, o framework Eclipse [Eclipse 2016] e o NetBeans [NetBeans 2016]. A versão Eclipse Luna (eclipse.org/luna/) já vem integrado ao Maven [Maven 2016].

Maven é uma ferramenta da Apache de gerenciamento de projetos de software. Baseado no conceito de um modelo de objeto de projeto (POM) [POM 2016], pode-se gerenciar a construção de um projeto, na elaboração de relatórios e documentação.

O framework Lucene [NEO4J, 2016] possibilita que os vértices e arestas sejam indexados de forma prática e eficiente. Esse banco de dados também já possui os algoritmos implementados: All Simple Paths, Dijkstra, Shortest Path [Cormen 2001], entre outros.

\subsubsection{Usabilidade de bancos de dados orientados a grafos}

Diversas finalidades podem ser atendidas por um banco de dados orientado a grafos, sendo este modelo o modo mais simples de se armazenar dados entre as possibilidades de estruturas de dados.

Segundo (Patil, 2014), empresas de grande porte, como a Google, Cisco, Linkedin, Facebook, Huwai, Adobe já utilizam este modelo com diferentes objetivos. Desde gerenciamento de redes sociais como gerenciamento de dados e de redes de computadores, além de atuação na área de bioinformática com o sequenciamento de DNA ou no armazenamento de informações de enzimas e proteínas.

\subsection{Adjacência livre de índices (index-free adjacency)}

Uma das características do modelo de banco de dados orientado a grafos é a propriedade chamada adjacência livre de índice (index-free adjacency). Essa propriedade significa que cada vértice o mantém referências diretas aos seus vértices adjacentes; ou seja, cada vértice atua como um micro-índice dos outros vértices próximos, assim tendo melhor desempenho do que os índices globais [Robinson 2013].

Segundo [Stonebraker 2010], a adjacência livre de índice é um fator importante que 
diferencia bancos de dados relacionais de bancos de dados não relacionais, já que cada elemento contém um apontador para o elemento adjacente e não necessita da indexação de cada elemento.

Quando o banco de dados utiliza adjacência livre de índice, então temos que o tempo de consulta será independente do tamanho total do grafo, o tempo será proporcional ao tamanho do grafo de busca. Para o processamento nativo de grafos, a adjacência livre de índice é crucial para garantir uma travessia eficiente pelo grafo.

Em outras palavras, cada vértice carrega a informação sobre seus vizinhos e não existe índice global de acessibilidade entre os vértices. Como resultado, o percurso de uma borda de um vértice é independente do tamanho dos dados e pode ser testado em tempo constante. Isso garante que a análise local pode ser realizada de forma muito eficiente no GDBMS e isso torna esses sistemas adequados em cenários onde o tamanho dos dados aumenta rapidamente.

Devido à sua ênfase em consultas globais, o mecanismo do banco de dados orientado a grafos é otimizado para digitalizar e processar grandes quantidades de informações em lotes e, nesse aspecto, são semelhantes a outras tecnologias de análise de lote, como mineração de dados e OLAP, em uso em análises de relacionamento.

Um modelo de banco de dados orientado a grafos também pode não ter essa característica nativa em sua estrutura. Nesse caso, ele irá utilizar índices globais para relacionar os vértices que estão em conjunto. Esses índices adicionam uma camada temporária para cada travessia, gerando maior custo computacional.

Um banco de dados orientado a grafos tem como prioridade as relações existentes entre seus vértices. Com isto este banco de dados não utiliza chave estrangeira para relacionar uma informação com outra. Como resultado as modelagens são simples e mais expressivas do que uma mesma modelagem em outro modelo de banco de dados.

Processamento nativo de grafos (adjacência livre de índices) beneficia o desempenho em consultas de travessia, porém não apresenta muitas vantagens ao se fazer consultas que não sejam de travessia ou com uso intenso de memória (Marek et al. 2012). Nas situações em que é possível alocar toda a estrutura na memória, o resultado obtido quanto ao tempo de execução é satisfatório.

Conforme Robinson [Robinson 2013], com adjacência livre de índice, as cláusulas de JOIN bidirecionais são eficientemente pré-computadas e armazenadas no banco de dados como relacionamento. Em contraste com os bancos relacionais, onde índices são 
utilizados para simular conexões entre as tuplas, deste modo não existindo relacionamentos armazenados no banco.

$\mathrm{O}$ uso de índices globais em bancos de dados relacionais cria dois problemas. $\mathrm{O}$ primeiro é que os algoritmos para travessia são mais custosos. Um índice típico tem o custo de $\mathrm{O}(\log (\mathrm{n}))$ no tempo, enquanto que utilizando a adjacência livre de índice teremos um custo de $\mathrm{O}(1)$.

O outro problema é que utilizando índices para simular as relações é um problema quando se tenta a travessia na direção oposta da qual o índice foi construído. Com o uso de adjacência livre de índice, associações bidirecionais são calculadas e armazenadas no banco de dados como relacionamentos. Com isso, é mais fácil e mais eficiente percorrer o grafo em qualquer uma das direções. Caso não se adote essa técnica, não existe nenhuma relação real de armazenado no banco de dados. Sendo assim, ao se percorrer um grafo na direção contrária à qual o índice foi construído se torna menos eficiente e mais complexa.

\section{7 Índices em banco de dados orientado a grafos}

Uma análise sobre as técnicas de índice existentes nos bancos de dados orientados a grafos foi realizada por (Mpinda, 2015). Devido a técnica de índice de adjacência, o uso de índice não é uma condição decisiva para a otimização de uma consulta em um grafo. Com esta técnica, operações de travessia podem ser feitas com uma máxima eficiência do que se fosse utilizado dados com um índice global (Mpinda, 2015).

O banco de dados Neo4J permite navegar no grafo em busca de um vértice ou relacionamento utilizando a indexação, e com isto é mais preparado para tratar as solicitações. Desde a versão 2.0, o Neo4J disponibiliza uma característica referente ao uso dos rótulos que identificam os vértices, com eles é possível criar grafos menores de modo mais rápido e eficiente, deste modo podendo ser utilizados para indexação.

Pode-se então criar índices nos bancos de dados orientados a grafos para pesquisas posteriores. Na medida em que se sabe antecipadamente que o valor de um identificador de um vértice ou relação será único, pode-se adicionar uma restrição que cria um índice exclusivo, e isto é mais rápido do que um índice padrão (Mpinda, 2015). 


\section{Capítulo 4}

\section{Metodologia}

Neste capítulo será descrita a metodologia utilizada neste trabalho, além de detalhar, caracterizar e delimitar os dados para geração do banco de dados.

\subsection{Caracterização dos Dados}

O conjunto de dados utilizados neste trabalho envolveu as seguintes fontes de dados: Sistemas Corporativos da Universidade de São Paulo, Web of Science e Plataforma Sucupira (Figura 4.1). Para cada um deles foi utilizado um método de extração de dados que foi desenvolvido em conjunto com os analistas do sistema da Divisão de Sistemas da Superintendência de Tecnologia da Informação da Universidade de São Paulo.

Informações Fonte

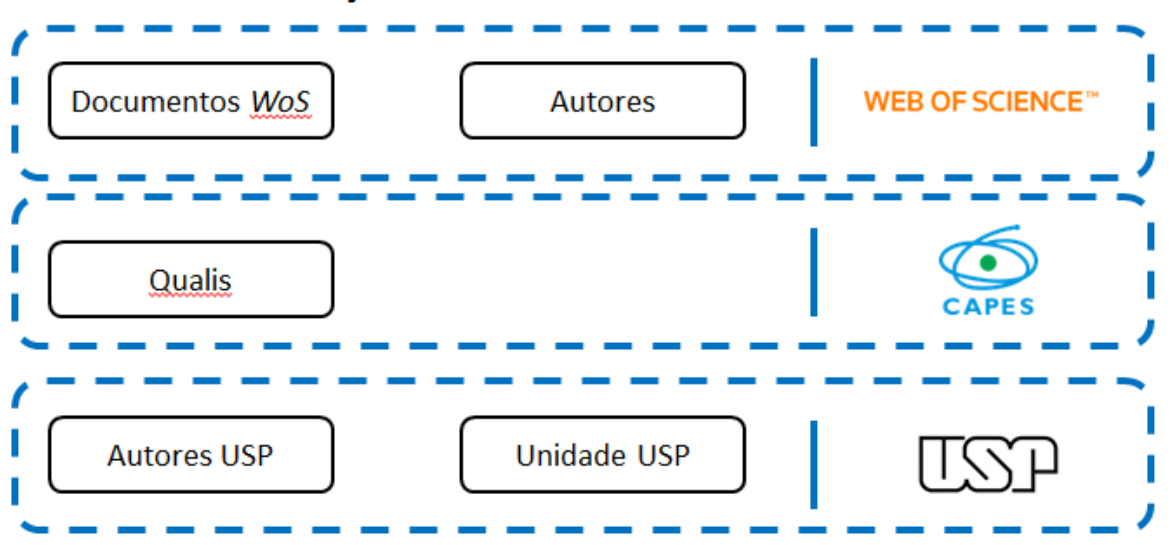

Figura 4.1: Fonte dos dados

Fonte: Autor

\subsubsection{Elementos de autoria: Autor e Coautor}

O autor principal é o indivíduo que idealizou e definiu os objetivos de um trabalho, independente de sua natureza, decidiu qual o material a ser estudado e qual o método a ser empregado e também, em geral, é o responsável pela análise final dos resultados obtidos. Para a inclusão de coautores, esses devem ter um envolvimento importante no 
trabalho, conhecimento de seu conteúdo e participação na sua redação [Montenegro 1987].

A coautoria é um indicador da atividade de colaboração científica e possui como vantagens: constituir-se de dados objetivos que podem ser ratificados por estudos de outros pesquisadores e constituir-se de uma metodologia viável para quantificar a colaboração. Desse modo, a análise de coautoria expressa o compartilhamento existente entre os pesquisadores e cuja métrica é o número de publicações em colaboração com outros autores, instituições ou países assim permitindo mapear os diferentes níveis de cooperação. Por meio dos dados dos autores é possível obter a instituição e o país ao qual estão vinculados.

\subsection{2 Órgão Classificador: Capes}

A Coordenação de Aperfeiçoamento de Pessoal de Nível Superior (Capes), fundada pelo Ministério da Educação (MEC), atua na expansão e consolidação da pós-graduação stricto sensu (mestrado e doutorado) no Brasil. A avaliação da pós-graduação stricto sensu foi criada em 1976, sendo um instrumento de grande importância à concessão de auxílios, tanto por parte das agências de fomento nacionais, como dos organismos internacionais [Capes 2016].

\subsubsection{Elementos para Classificação: ISSN e Qualis}

O International Standard Serial Number (ISSN) é um identificador único de uma publicação. É um código numérico que constitui um identificador unívoco para cada título de publicação em série, que é constituído por dois grupos de quatro dígitos separados por hífen. O oitavo dígito corresponde a um caractere de controle calculado por um algoritmo sobre os números precedentes, sendo que quando o valor é igual a dez é utilizado o dígito ' $\mathrm{X}$ '. As publicações em série compreendem as revistas, os periódicos, as publicações anuais, as séries monográficas, as memórias, as atas de sociedades, qualquer que seja o seu suporte [ISSN 2016].

A classificação das publicações é feita segundo o estrato Qualis, que é o conjunto de procedimentos utilizados pela Capes para estratificação da qualidade da produção intelectual. Tal processo foi concebido para atender às necessidades específicas do sistema de avaliação e é baseado nas informações fornecidas por meio da Plataforma Sucupira. Como resultado, disponibiliza uma lista com a classificação dos veículos utilizados pelos programas de pós-graduação para a divulgação da sua produção [CAPES 
2016].

Por meio da análise da qualidade dos periódicos científicos é possível medir a qualidade do artigo e identificar a estratificação da qualidade dessa produção pelo Qualis. A classificação de periódicos é realizada pelas áreas de avaliação e passa por um processo, antes trienal e desde 2013, realizada a cada 4 (quatro) anos. Os periódicos recebem estratos indicativos da qualidade, sendo estes: A1; A2; B1; B2; B3; B4; B5; C, no qual o A1 é estrato de maior peso e o C é o de menor peso.

\subsubsection{Web of Science}

Várias fontes de informação contêm dados sobre as redes colaborativas, como a plataforma Lattes, o Scopus e o Web of Science. Neste trabalho foi utilizado o banco de dados da Web of Science, que é um produto da Thomson Reuters Institute of Scientific Information (ISI), e que surgiu de uma evolução do Science Citation Index, criado por Eugene Garfield em 1960 [Chadegani 2013], se tornando uma rede de relacionamento colaborativa amplamente aceita pela comunidade científica. Cada publicação em série já publicada, em publicação ou a publicar num futuro previsível que foi coletada possui o ISSN de sua publicação. O Web of Science possui mais de 59 milhões de registros que datam desde 1898.

O Web of Science é um banco de dados internacional composto por um banco de dados de periódicos multidisciplinar contendo informações de várias áreas do conhecimento. Os periódicos são classificados com indicadores bibliométricos, como o fator de impacto e o índice de citações. O Web of Science apresenta uma rede de coautorias entre autores de uma publicação sendo o relacionamento dos autores verificada em cada artigo.

Cada identificador de um documento no Web of Science é único, mantendo a relação dos autores que participaram dele. Com isto foi possível garantir a deduplicação dos documentos que contém mais de um autor da instituição.

\subsubsection{Periódico Qualis}

As informações do Periódico Qualis contendo os estratos por ano de avaliação Capes foram obtidos diretamente pela Plataforma Sucupira (https://sucupira.capes.gov.br/sucupira/) na opção de menu "Consulta" e depois selecionando "Periódico Capes". Até 2012 a avaliação dos periódicos era trienal e depois 
passou a ser quadrienal, englobando os anos de 2013, 2014, 2015 e 2016.

Os anos de avaliação que se encontram disponibilizados na Plataforma Sucupira e foram extraídos são: 2012, 2013 e 2014, sendo que a avaliação referente ao ano de 2012 é uma consolidação para o triênio 2010, 2011 e 2012. Já as avaliações de 2013 e 2014 são complementares, pois a classificação de periódicos passa por processo anual de atualização. A plataforma permite a exportação de um arquivo no formato Excel contendo as seguintes informações: ISSN do periódico, título, área de avaliação e o estrato. Na Figura 4.2 é visto uma parte do arquivo.

Foram obtidas as informações de 108.272 periódicos classificados em 2012, 40.916 em 2013 e por fim, 44.582 periódicos classificados em 2014.

Quanto ao triênio 2007, 2008 e 2009, o banco corporativo da Universidade de São Paulo dispunha de 54.316 avaliações Qualis dos periódicos, deste modo não foi necessário extrair os dados da Plataforma Sucupira.

Sobre as classificações de 2013 e 2014 foram integradas em um único arquivo, removendo todas as informações com duplicidade e o ano de referência foi definido como 2014. No final tivemos 62.365 periódicos com estrato em 2014.

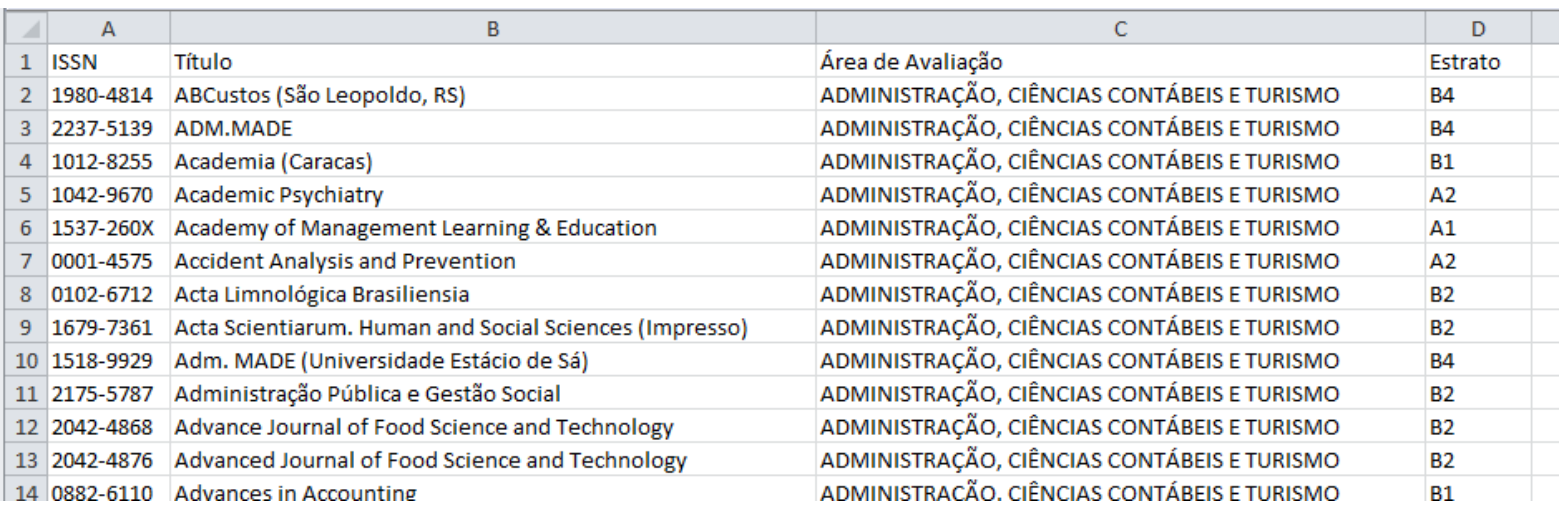

Figura 4.2: Trecho do arquivo com os periódicos Qualis obtido pela Plataforma Sucupira.

Fonte: Autor

Em um mesmo ano um periódico (ISSN) pode ter mais de um estrato pois cada área de avaliação pode ter um estrato diferente. Este trabalho relaciona uma publicação do Web of Science ao seu estrato, assim não é possível determinar em qual área de avaliação o mesmo deve ser corretamente relacionado.

Mesmo se fosse considerado o programa em que o autor da Universidade de São Paulo se encontrava credenciado durante a avaliação do periódico, teríamos o caso em que um mesmo autor poderia pertencer a mais de um programa no mesmo período de 
avaliação Capes. Desse modo adotamos sempre o mais bem avaliado estrato que um periódico obteve em um ano de avaliação.

Por exemplo, se um periódico obteve estrato B2 na área de Ciência da Computação e o mesmo periódico obteve estrato A1 na área de Medicina II, então consideramos que o estrato obtido por aquele periódico naquele ano foi A1.

Para identificar qual estrato considerar para cada ano, foi desenvolvido um procedimento onde era selecionado o maior estrato de um periódico em um determinado ano de avaliação. Por fim obteve-se 63.174 periódicos, que representam o melhor estrato que cada um deles poderia obter em cada um dos anos de avaliação: 2009, 2012 e 2014.

\subsubsection{Banco de dados Corporativo da Universidade de São Paulo}

A instituição de ensino superior adotada para os estudos deste trabalho foi a Universidade de São Paulo (USP). A USP é uma das instituições de ensino superior mais conceituadas da América Latina.

Através do acesso aos bancos de dados corporativos da Universidade de São Paulo, foi possível obter as informações sobre os docentes e as unidades a que estão vinculados, além de outras informações, como por exemplo se o docente esta ativo ou desligado da instituição.

O acesso a esses bancos de dados foi possível graças a um trabalho conjunto com a Superintendência de Tecnologia da Informação da Universidade de São Paulo, que disponibilizou as informações solicitadas em formato Comma-separated values (csv).

Em dezembro de 2015 a USP possuía o registro de 12.384 docentes ativos e aposentados associados à instituição e distribuídos nas unidades de ensino. Desse modo foram obtidos os dados desses docentes e de 75 unidades que incluem os Centros e Institutos Especializados, Ensino e Pesquisa, Entidades Associadas, Hospitais e Serviços Anexos e Museus.

Os tipos de unidade existentes, conforme as normas e regimento da Universidade de São Paulo, são:

- Ensino e Pesquisa: São as unidades que tem como finalidade formar profissionais por meio de cursos de graduação, pós-graduação e de extensão universitária, realizar pesquisas científicas e tecnológicas e prestar serviços de interesse da comunidade e do desenvolvimento do País. Por exemplo o Instituto de Matemática e Estatística (IME) ou a Faculdade de Odontologia (FO); 
- Centros e Institutos especializados: são órgãos de integração: Os centros são institutos especializados e órgãos de integração da Universidade de São Paulo (USP). A USP já teve 12 centros, hoje são 6 os centros ativos, como exemplo o Centro de Biologia Marinha (CEBIMar) e o Centro de Energia Nuclear na Agricultura (CENA);

- Entidades Associadas: aão as entidades que não pertencem a instituição, porém oferecem cursos ou prestam serviços de interesse da comunidade. Como exemplo o Instituto de Medicina Social e de Criminologia de São Paulo (IMESC) e o

- Instituto de Pesquisas Energéticas e Nucleares (IPEN);

- Museus: São órgãos de integração da universidade. São quatro os museus: Museu de Arte Contemporânea, Museu Paulista, Museu de Zoologia e Museu de Arqueologia e Etnologia;

- Hospitais e Serviços anexos: O Hospital de Reabilitação de Anomalias Craniofaciais (HRAC) e o Hospital Universitário (HU) são Órgãos Complementares da Universidade de São Paulo (USP). Com a finalidade de promover o ensino, a pesquisa e a extensão de serviços à comunidade;

- Órgãos Centrais - Direção e Serviço: São órgãos com a finalidade administrativa na instituição. Por exemplo a Reitoria, Prefeitura do Campus ou as Superintendências.

Destes 12.384 docentes ativos e aposentados, foram identificados 4.215 (34,04\%) $(34,04 \%)$ no banco de dados do Web of Science. Nas Figuras 4.3 e 4.4 são mostrados exemplos dos arquivos recebidos. 


\begin{tabular}{|r|r|l|r|r|}
\hline \multicolumn{1}{|c|}{ A } & \multicolumn{1}{|c|}{ B } & \multicolumn{1}{|c|}{ D } \\
\hline 1 & nusp & Nome docente & status & unidade \\
\hline 2 & 5332372 & Rogério Carrazedo & Ativo & 18 \\
\hline 3 & 48445 & Maria do Rosario Dias de Olive & Ativo & 6 \\
\hline 4 & 1492328 & Pietro Sampaio Baruselli & Ativo & 10 \\
\hline 5 & 74726 & José Djair Vendramim & Ativo & 11 \\
\hline 6 & 70826 & Artur de Jesus Motheo & Ativo & 75 \\
\hline 7 & 1217507 & Paulo Simionatto Polito & Ativo & 21 \\
\hline 8 & 174888 & Alberto Queiroz Farias & Ativo & 5 \\
\hline 9 & 604320 & Ana Cristina Victorino Krepisch Ativo & 41 \\
\hline 10 & 2549718 José Maurício Simões Bento & Ativo & 11 \\
\hline 11 & 464102 & Cassia Baldini Soares & Ativo & 7 \\
\hline 12 & 7933702 Houtan Noushmehr & Ativo & 17 \\
\hline 13 & 2872716 Diego Antonio Falceta Gonçalv Ativo & 86 \\
\hline 14 & 85200 & Jose Reynaldo Anselmo Setti & Ativo & 18 \\
\hline 15 & 72297 Mario Hiroyuki Hirata & Ativo & 9 \\
\hline 16 & 60189 & Marisa de Cassia Piccolo & Ativo & 64 \\
\hline 17 & 3061366 & Leonardo De Boni & Ativo & 76 \\
\hline 18 & 1400231 Miguel Cooper & Ativo & 11 \\
\hline & & & \\
\hline & & & \\
\hline
\end{tabular}

Figura 4.3: Informações extraídas dos docentes da USP.

Fonte: Autor

\begin{tabular}{|c|c|c|c|c|c|c|c|}
\hline 4 & A & B & c & D & $\mathrm{E}$ & $\mathrm{F}$ & G \\
\hline 1 & Código Unidade & Tipo unidade & Nome unidade & Silga unidade & Exatas & Biológica & sHumanas \\
\hline 2 & 30 & Centros e Institutos Especializados & Centro de Biologia Marinha & CEBIMar & $\mathrm{N}$ & $\mathrm{N}$ & $\mathrm{s}$ \\
\hline 3 & 64 & Centros e Institutos Especializados & Centro de Energia Nuclear na Agricultura & CENA & $\mathrm{s}$ & $\mathrm{N}$ & $\mathrm{N}$ \\
\hline 4 & 40 & Centros e Institutos Especializados & Centro de Medicina Nuclear & $\mathrm{CMN}$ & $\mathrm{N}$ & $\mathrm{N}$ & $\mathrm{s}$ \\
\hline 5 & 86 & Ensino e Pesquisa & Escola de Artes, Ciências e Humanidades & EACH & $\mathrm{N}$ & $\mathrm{s}$ & $\mathrm{N}$ \\
\hline 6 & 27 & Ensino e Pesquisa & Escola de Comunicações e Artes & ECA & $\mathrm{N}$ & $\mathrm{s}$ & $\mathrm{N}$ \\
\hline 7 & 39 & Ensino e Pesquisa & Escola de Educação Física e Esporte & EEFE & $\mathrm{N}$ & $\mathrm{N}$ & s \\
\hline 8 & 90 & Ensino e Pesquisa & Escola de Educação Física e Esporte de Ribeirão Preto & EEFERP & $\mathrm{N}$ & N & s \\
\hline 9 & & Ensino e Pesquisa & Escola de Enfermagem & $\mathrm{EE}$ & $\mathrm{N}$ & $\mathrm{N}$ & $\mathrm{s}$ \\
\hline 10 & 22 & Ensino e Pesquisa & Escola de Enfermagem de Ribeirão Preto & EERP & $\mathrm{N}$ & N & s \\
\hline 11 & 88 & Ensino e Pesquisa & Escola de Engenharia de Lorena & EEL & s & $\mathrm{N}$ & $\mathrm{N}$ \\
\hline 12 & 18 & Ensino e Pesquisa & Escola de Engenharia de São Carlos & EESC & $\mathrm{s}$ & $\mathrm{N}$ & $\mathrm{N}$ \\
\hline 13 & & Ensino e Pesquisa & Escola Politécnica & EP & $\mathrm{s}$ & $\mathrm{N}$ & $\mathrm{N}$ \\
\hline 14 & 11 & Ensino e Pesquisa & Escola Superior de Agricultura Luiz de Queiroz & ESALQ & $\mathrm{N}$ & $\mathrm{s}$ & s \\
\hline 15 & 16 & Ensino e Pesquisa & Faculdade de Arquitetura e Urbanismo & FAU & $\mathrm{N}$ & $\mathrm{s}$ & $\mathrm{N}$ \\
\hline
\end{tabular}

Figura 4.4: Informações extraídas das unidades da USP.

Fonte: Autor

Um sumário de todas as informações utilizadas neste trabalho é visto na tabela 4.1.

Tabela 4.1: Sumário dos dados

\begin{tabular}{|l|r|}
\hline Total de docentes & 12.384 \\
\hline Total de docente identificado no Web of & \\
Science & 4.215 \\
\hline Total de publicações & 65.631 \\
\hline Total de autores & 352.642 \\
\hline Total de países & 152 \\
\hline Total de ISSN & 40.901 \\
\hline Total de áreas de avaliação Capes & 47 \\
\hline
\end{tabular}




\subsection{Extração dos Dados}

Para poder usufruir das vantagens existentes em cada modelo, é necessário integrar a estrutura de dados do modelo relacional com o modelo orientado a grafos bem como manter o sincronismo entre elas. Deste modo, inicialmente foi gerado o banco de dados relacional e por meio dele foi obtido o banco de dados orientado a grafos. As etapas do processo de obtenção dos dados são vistas na Figura 4.5 e apresentados a seguir.

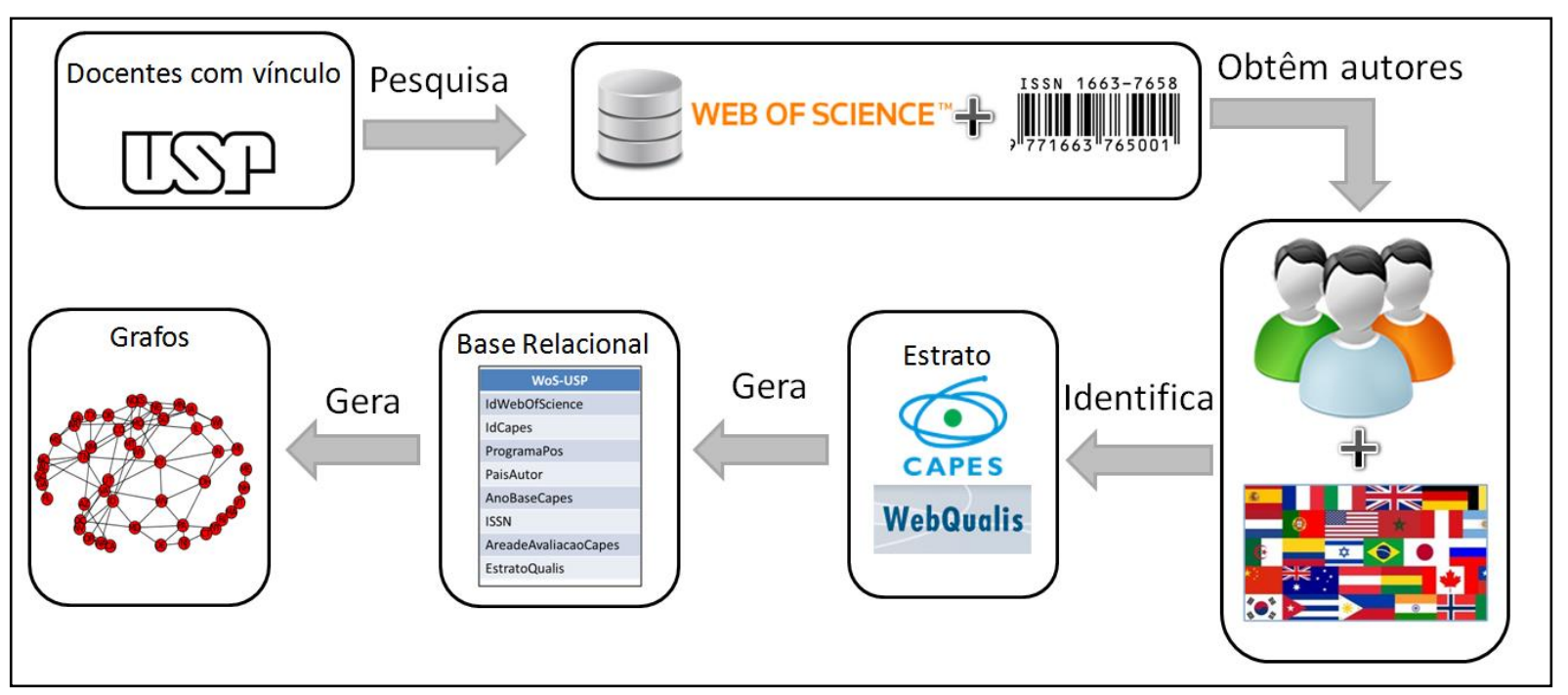

Figura 4.5: Etapas para extração dos dados

Fonte: Autor

O primeiro passo foi obter uma lista de identificadores Web of Science dos docentes da Universidade de São Paulo. Esta lista está em constante atualização já que não é estática e novos cadastros podem ser feitos pelos docentes da USP. Deste modo, no segundo semestre de 2016 foi obtido uma lista com 12.384 docentes, dos quais 4.215 possuíam identificador Web of Science.

Para a coleta dos dados, a extração foi realizada utilizando uma API disponibilizada pelo próprio Web of Science e assim permitindo analisar a sequência de entrada para determinar sua estrutura segundo uma gramática formal determinada dos arquivos XML (eXtensible Markup Language) de cada publicação. A extração e armazenamento dos dados da pesquisa ocorreram no segundo semestre de 2016. Este serviço foi disponibilizado através de um contrato firmado entre a Universidade de São Paulo e a Thomson Reuters.

O campo de entrada deste serviço é o identificador ResearcherID e a saída são todos 
documentos relacionados a este identificador. Para cada documento identificado como da Universidade de São Paulo, foram extraídas informações sobre o título, citações e dados dos autores, como o país da instituição a que estavam vinculados quando o documento foi publicado. A lista de todas as informações de cada publicação que podem ser extraídas é apresentada na Tabela 4.2.

Desenvolveu-se um script para automatizar a busca, extração e compilação dos dados dos autores que tinham relação com a Universidade de São Paulo através do uso deste Web Service.

Tabela 4.2: Informações disponíveis pelo serviço web da Thomson Reuters.

\begin{tabular}{|c|c|}
\hline Campo & Exemplo \\
\hline $\begin{array}{l}\text { Identificador único para cada } \\
\text { documento reconhecido pela } \\
\text { Thomson Reuters. }\end{array}$ & WOS:000260007300017 \\
\hline Título do artigo & $\begin{array}{l}\text { Persistent alterations in cognitive function and prefrontal } \\
\text { dopamine D2 receptors following extended, but not limited, } \\
\text { access to self-administered cocaine }\end{array}$ \\
\hline Número do periódico & 12 \\
\hline Páginas do artigo & $2969-2980$ \\
\hline Mês da publicação & $\mathrm{NOV}$ \\
\hline Ano da publicação & 2008 \\
\hline Título da publicação & NEUROPSYCHOPHARMA COLOGY \\
\hline Volume & 33 \\
\hline \multirow[t]{7}{*}{ Nome dos autores } & Briand, Lisa A. \\
\hline & Flagel, Shelly B. \\
\hline & Garcia-Fuster, M. Julia \\
\hline & Watson, Stanley J. \\
\hline & Akil, Huda \\
\hline & Sarter, Martin \\
\hline & Robinson, Terry E. \\
\hline \multirow[t]{6}{*}{ Palavra-chave do artigo } & self-administration \\
\hline & Attention \\
\hline & Addiction \\
\hline & dopamine receptor \\
\hline & medial prefrontal cortex \\
\hline & orbital frontal cortex \\
\hline Número do ResearcherID & E-1234-2010 \\
\hline Documento DOI & 10.1038/npp.2008.18 \\
\hline Número do artigo & ARTN 064319 \\
\hline ISI & 359SB \\
\hline ISSN & 0893-133X \\
\hline ISBN & $0-89603-417-8$ \\
\hline
\end{tabular}


Apesar de não constar na tabela de informações disponíveis pela Thomson Reuters, as informações sobre a instituição de cada autor com o endereço completo também são fornecidas pelo serviço web.

Dessas informações, o nome da instituição não segue um padrão, por exemplo Universidade de São Paulo aparece como "USP”, “UNIV SAO PAULO” ou "Univ de Sao Paulo".

Esse problema de uma mesma instituição possuir mais de uma grafia do nome foi resolvido internamente pelo Web of Science, para isto eles possuem um banco de dados com o mapeamento dos nomes preferenciais de organizações e de suas variantes de nome. Assim uma pesquisa pelo nome preferencial da instituição retorna todos os registros que contêm o nome preferencial e todos os registros que contêm suas variantes de nome [Web of Science 2016].

Esse banco de dados com o mapeamento dos nomes das instituições e suas variantes não é de livre acesso e nem foi encaminhado pelo serviço web. Tendo o interesse em analisar o país da instituição de cada autor e como este se mantém independente da grafia do nome da instituição, não armazenamos os nomes das instituições, apenas os países em que estão localizadas.

O campo de entrada do serviço web foi uma lista contendo 4.215 identificadores ResearcherID referentes aos docentes da Universidade de São Paulo que foram localizados. Através desta lista foram obtidos 65.631 documentos Web of Science que possuem pelo menos um autor da Universidade de São Paulo. Todos esses artigos possuem ISSN informado e contém ao todo 352.642 autores distribuídos em 152 países distintos. Foram identificadas 47 áreas de avaliação Qualis contendo 40.901 ISSN associados no ano de 2014.

Para cada documento obtido do Web of Science foram identificados os nomes de todos os autores, instituição a que estavam associados durante a publicação, país da instituição, ano de publicação, título dos periódicos, número de autores do artigo, ISSN e o estrato Qualis vinculado.

A Capes disponibiliza a classificação Qualis através da Plataforma Sucupira. Para cada área de avaliação é fornecido o ISSN do periódico e o seu estrato. Por meio destas informações e do ISSN obtido pelo serviço web foi possível obter os estratos de cada documento extraído, além das áreas de avaliação Capes da publicação.

Após a finalização da extração de dados, as informações foram armazenadas em um 
banco de dados relacional denominado BD3 e por meio dele foi gerado o banco de dados orientado a grafos.

\subsection{Criação dos bancos de dados}

Utilizamos o banco de dados com as informações originalmente extraídas (BD3), como modelo para gerar outros quatro bancos de dados relacionais. Sendo dois bancos de dados com um número menor de informações e dois outros bancos com informação maior do que o banco BD3. Estes bancos foram denominados BD1, BD2, BD4 e BD5 respectivamente.

Para criar os dois bancos de dados menores, foram extraídos os dados dos autores do banco de dados original juntamente com os documentos correspondentes. Criando assim dois bancos de dados com 1.000 e 10.000 autores, que denominamos BD1 e BD2 respectivamente.

Nos bancos de dados maiores multiplicamos o número de documentos do Web of Science em dez e cem vezes, com isto o número de autores também foi multiplicado na mesma proporção. Para efetuar esta repetição, desenvolvemos um script que fez com que cada documento existente do Web of Science fosse repetido 10 e 100 vezes, alterando o identificador único dele. Conforme já informado, os bancos foram nomeados BD4 e BD5.

Deste modo obtivemos os 5 bancos de dados para estudos em MySQL: BD1, BD2, BD3, BD4 e BD5 com aproximadamente 2.700, 20 mil, 560 mil, 5 milhões e 50 milhões de registros, respectivamente. A tabela 4.3 apresenta o tamanho e o número de registros nos cinco bancos de dados MySQL.

Tabela 4.3: Discriminação dos bancos de dados relacionais.

\begin{tabular}{|l|r|r|}
\hline \multicolumn{1}{|c|}{ Banco } & \multicolumn{1}{|c|}{ Registros } & \multicolumn{1}{c|}{ Tamanho (em MB) } \\
\hline BD1 & 2.757 & 0,21875 \\
\hline BD2 & 20.603 & 2,046875 \\
\hline BD3 & 562.470 & 39,140575 \\
\hline BD4 & 5.053 .803 & 303,56238 \\
\hline BD5 & 49.967 .133 & 2900,56248 \\
\hline
\end{tabular}

Os bancos de dados orientados a grafos foram gerados com as informações extraídas destes bancos de dados relacional. Esses bancos também foram denominados BD1, BD2, BD3, BD4 e BD5. A nomenclatura foi mantida igual já que dispunham das mesmas 
informações só que com outra modelagem dos dados.

Quanto ao armazenamento em disco, o Neo4j é organizado em arquivos baseados em registros por estrutura de dados, sendo que cada vértice e bloco de registro de relacionamento é diretamente endereçável por seu identificador [Neo4J 2016].

Os blocos têm tamanhos diferentes para acomodar os diferentes tipos de dados que contêm:

- Registros de nó: rótulos, ponteiro para o primeiro relacionamento, ponteiro para o primeiro bloco de propriedade.

- Registros de relacionamento: tipo de relacionamento, ponteiros para vértice de início e vértice de extremidade, primeiro bloco de propriedade, próximo relacionamento e relação anterior para vértices de início e de fim

- Registros de propriedade: até quatro entradas de propriedade, cada uma com um ID de propriedade-chave e um valor de propriedade codificado / comprimido ou ponteiro para string ou lista de armazenamento de matriz

A descrição destes bancos de dados está resumida na tabela 4.4.

Tabela 4.4: Discriminação dos bancos de dados orientados a grafos.

\begin{tabular}{|l|r|r|r|}
\hline Banco & No de vértices & № de relações & Tamanho (em MB) \\
\hline BD1 & 1.395 & 973 & 12,5828 \\
\hline BD2 & 13.958 & 9.563 & 12,5828 \\
\hline BD3 & 456.556 & 385.526 & 62,9144 \\
\hline BD4 & 4.565 .560 & 3.855 .260 & 557,8410 \\
\hline BD5 & 45.655 .600 & 38.552 .600 & 5528,0792 \\
\hline
\end{tabular}

As informações sobre o modelo relacional e o orientado a grafos, além dos detalhes sobre cada tabela e como o banco orientado a grafos foi desenvolvido é mostrado em detalhes no Capítulo 5.

\subsection{Metodologia dos Experimentos}

Após a etapa de criação dos bancos de dados, foi proposto que seriam executados experimentos similares em cada banco de dados e os resultados destes experimentos seriam armazenados em planilhas Excel. Um esquema que apresenta como as informações foram obtidas para cada experimento é visto na Figura 14.

O computador utilizado para realizar as comparações tem as seguintes características: 
Sistema Operacional: Debian GNU/Linux 7;

Processador: Intel(R) Xeon(R) CPU E7- 2870 @ 2.40GHz;

Memória RAM: 8 gigabytes;

Dez experimentos foram elaborados de modo a verificar a relevância do número de indireções, cláusulas e volume de dados em cada busca. Com isso, as alterações foram realizadas em cada consulta para poder estudar e assim poder estimar o impacto dos parâmetros quando uma consulta era realizada no modelo relacional e quando era realizada no modelo orientado a grafos, conforme visto na Figura 4.6.

Cada experimento era composto de uma consulta que foi executada em cada um dos cinco bancos de dados do modelo relacional e em cada um dos cinco bancos do modelo orientado a grafos.

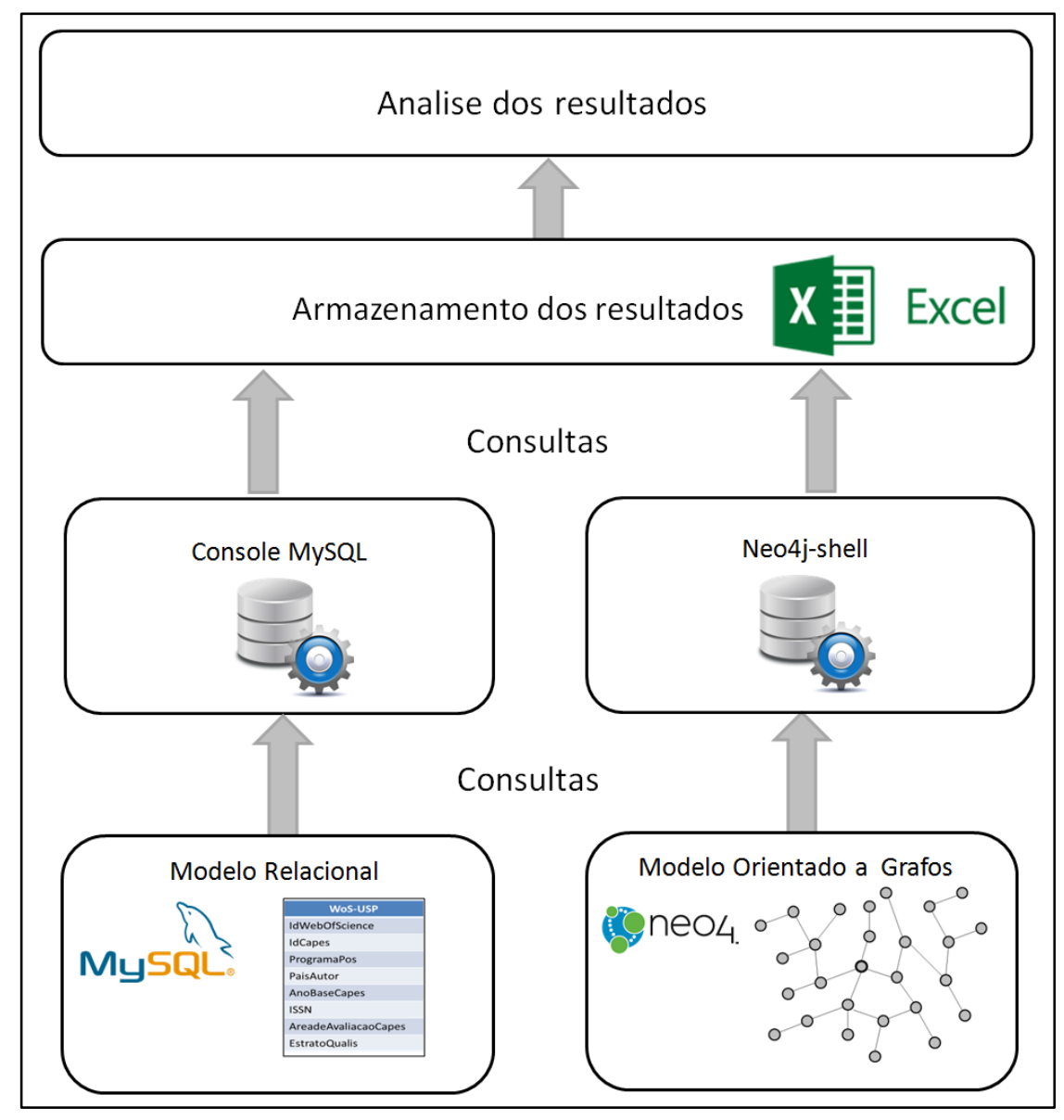

Figura 4.6: Esquema da proposta de pesquisa.

Fonte: Autor

Os experimentos foram elaborados de modo a aumentar a ordem de complexidade, 
sendo que o experimento1 era o mais simples e o experimento 10 o mais complexo.

Tivemos como premissa iniciar cada experimento com o menor número de indireções entre as tabelas no modelo relacional e ir aumentando o número de JOINs envolvidos a cada experimento. Desse modo os experimentos 1 e 2 possuem 1 JOIN, os experimentos 3, 4 e 5 possuem respectivamente 2, 3 e 4 JOINs. Os experimentos 6 até 9 possuem 5 JOIN e por fim, o experimento 10 possui 9 JOINs.

Com o intuito de comparar o impacto das cláusulas nos experimentos, algumas cláusulas foram incluídas em alguns dos experimentos. A cláusula GROUP BY, que tem a função de agregar grupos de um conjunto de tuplas, foi utilizada em 6 experimentos. Junto com esta cláusula foi utilizado a cláusula ORDER BY, possibilitando expor os resultados de uma consulta conforme uma ordem pré-definida das tuplas.

Em dois experimentos, incluímos o operador IN. Esse operador é utilizado em buscas em uma tabela, realizando um filtro no valor de um de seus campos a partir de uma lista com as possibilidades desejadas. Também foram utilizadas condições de seleção, para definir alguns parâmetros de busca.

As características de cada um dos experimentos que foram utilizados como métrica para avaliar os modelos de bancos de dados é visto a seguir:

Experimento 1: uma consulta SELECT com um JOIN e uma condição de seleção que retorna uma contagem de ocorrências.

Experimento 2: variação do experimento 1 com a inclusão das cláusulas GROUP BY e ORDER BY e como retorno temos os grupos de ocorrência para cada situação encontrada.

Experimento 3: uma consulta SELECT com dois JOINs, incluindo as cláusulas GROUP BY e ORDER BY e uma condição de seleção. O retorno é uma lista.

Experimento 4: uma consulta SELECT com três JOINs, incluindo a cláusula GROUP BY e uma condição de seleção. O retorno são os grupos de ocorrência para cada situação encontrada.

Experimento 5: uma consulta SELECT com quatro JOINs, incluindo as cláusulas GROUP BY e ORDER BY e uma condição de seleção. Essa consulta também tem a cláusula IN. O retorno são os grupos de ocorrência para cada situação encontrada.

Os quatro próximos experimentos possuem cinco JOINs e utilizam todas as seis tabelas do modelo relacional. A finalidade destes experimentos foi verificar a 
influência das cláusulas além das indireções.

Experimento 6: foi feita uma consulta SELECT com cinco JOINs e três condições de seleção. O retorno são os grupos de ocorrência para cada situação encontrada.

Experimento 7: variação do experimento 6, com a inclusão das as cláusulas GROUP BY e ORDER BY.

Experimento 8: variação do experimento 7, alterando uma das condições de seleção.

Experimento 9: variação dos experimentos 7 e 8, trocando uma condição de seleção pela cláusula IN.

Experimento 10: uma consulta SELECT com 9 JOINs, incluindo as cláusulas GROUP BY e ORDER BY e uma condição de seleção. Essa consulta também tem a cláusula IN. O retorno são os grupos de ocorrência para cada situação encontrada.

Um resumo destas características de cada consulta é visto nas tabelas 4.5 e 4.6.

Tabela 4.5: Característica de cada experimento.

\begin{tabular}{|l|c|c|c|c|c|}
\hline Experimento & $\begin{array}{c}\text { No de } \\
\text { JOIN }\end{array}$ & Condição de seleção & GROUP BY & $\begin{array}{c}\text { ORDER } \\
\text { BY }\end{array}$ & IN \\
\hline E1 & 1 & 1 & & & \\
\hline E2 & 1 & 1 & $X$ & $X$ & \\
\hline E3 & 2 & 1 & & $X$ & \\
\hline E4 & 3 & 1 & $X$ & & \\
\hline E5 & 4 & 1 & $X$ & $X$ & $X$ \\
\hline E6 & 5 & 3 & & & \\
\hline E7 & 5 & 3 & $X$ & $X$ & \\
\hline E8 & 5 & 3 & $X$ & $X$ & \\
\hline E9 & 5 & 2 & $X$ & $X$ & $X$ \\
\hline E10 & 9 & 4 & $X$ & $X$ & $X$ \\
\hline
\end{tabular}

As relações envolvidas em cada uma das consultas estão na Tabela 4.6, sendo que os experimentos de 6 a 10 envolvem todas as tabelas existentes no modelo relacional.

\subsection{Consultas MySQL}

Para cada experimento, foram elaboradas consultas SQL no modelo relacional, utilizando o MySQL para executá-las. O objetivo foi elaborar consultas que atendessem a cada um dos itens analisados. Essas consultas em SQL são vistas no Apêndice A. 
Tabela 4.6: Relações existentes em cada experimento.

\begin{tabular}{|l|c|c|c|c|c|c|}
\hline \multirow{2}{*}{ Experimento } & \multicolumn{6}{|c|}{ Tabelas do Modelo Relacional } \\
\cline { 2 - 7 } & autorwos & documentowos & pais & Qualis & unidadeusp & tipo_unidade \\
\hline E1 & $\mathrm{X}$ & - & $\mathrm{X}$ & - & - & - \\
\hline E2 & $\mathrm{X}$ & - & $\mathrm{X}$ & - & - & - \\
\hline E3 & $\mathrm{X}$ & $\mathrm{X}$ & $\mathrm{X}$ & - & - & - \\
\hline E4 & $\mathrm{X}$ & $\mathrm{X}$ & $\mathrm{X}$ & $\mathrm{X}$ & - & - \\
\hline E5 & $\mathrm{X}$ & $\mathrm{X}$ & - & $\mathrm{X}$ & $\mathrm{X}$ & $\mathrm{X}$ \\
\hline E6 & $\mathrm{X}$ & $\mathrm{X}$ & $\mathrm{X}$ & $\mathrm{X}$ & $\mathrm{X}$ & $\mathrm{X}$ \\
\hline E7 & $\mathrm{X}$ & $\mathrm{X}$ & $\mathrm{X}$ & $\mathrm{X}$ & $\mathrm{X}$ & $\mathrm{X}$ \\
\hline E8 & $\mathrm{X}$ & $\mathrm{X}$ & $\mathrm{X}$ & $\mathrm{X}$ & $\mathrm{X}$ & $\mathrm{X}$ \\
\hline E9 & $\mathrm{X}$ & $\mathrm{X}$ & $\mathrm{X}$ & $\mathrm{X}$ & $\mathrm{X}$ & $\mathrm{X}$ \\
\hline E10 & $\mathrm{X}$ & $\mathrm{X}$ & $\mathrm{X}$ & $\mathrm{X}$ & $\mathrm{X}$ & $\mathrm{X}$ \\
\hline
\end{tabular}

\subsection{Consultas Neo4J}

As consultas no banco de dados Neo4J foram elaboradas utilizando a linguagem de pesquisa em grafos Cypher [Neo4J 2016] que é uma linguagem declarativa inspirada em SQL para descrever padrões em grafos. Sobre as consultas desenvolvidas com a linguagem Cypher, é importante o que se segue [Neo4J 2016]:

MATCH: comando equivalente ao SELECT do SQL. É responsável por montar um padrão de busca no Neo4J, sendo o padrão principal:

MATCH (vértice origem)-[relacionado]->(vértice final).

WHERE: parte de MATCH. Permite adicionar restrições a um padrão ou filtrar o resultado intermediário passando por WITH.

WITH: este comando armazena o resultado prévio de um MATCH para ser utilizado por um outro MATCH ou um RETURN com restrições mais complexas. O WITH permite dividir consultas mais elaboradas em consultas menores.

ORDER BY: similar ao ORDER BY utilizado na linguagem SQL. O complemento DESC é quando a ordenação é decrescente.

RETURN: comando que retorna os resultados das consultas. Permite retornar desde um número, linhas até um grafo completo. Permite também adicionar outros comandos, como exemplo contagem, soma ou média.

As consultas na linguagem Cypher se encontram no Apêndice B. 


\section{7 Índices nas Tabelas}

Índices são estruturas de dados que recebem uma propriedade de registro como entrada e localiza os registros com essa propriedade de modo mais otimizado. Deste modo os índices são estruturas auxiliares com a finalidade de tornar mais eficiente o acesso aos registros e assim encontrar um registro de forma eficiente e sem a necessidade de examinar todos os dados de uma tabela.

\subsubsection{Criando índices no MySQL}

No modelo relacional, o uso de índices é indicado quando a consulta envolve várias tabelas por meio de joins, ou nas condições da cláusula WHERE. O uso da cláusula ORDER BY e GROUP BY também se utiliza do índice relacional, pois necessita tratar todos os dados requeridos pela consulta.

No Sistema gerencviador de banco de dados MySQL, foram criados índices que foram utilizados nas cinco consultas por meio do comando:

ALTER TABLE <nome_tabela> ADD INDEX <nome_indice> (<coluna_indice $>$ );

Assim tendo por exemplo:

ALTER TABLE autorwos ADD INDEX idx_a_wos (id_wos);

Foram criados os índices para o identificador do documento Web of Science, identificador do país, da unidade, ISSN e tipo de unidade.

\subsubsection{Criando índices no Neo4J}

O Neo4J proporciona a geração de índices tanto nos vértices quanto nas relações para melhorar o tempo de execução do banco de dados. O índice pode ser criado associado ao atributo de todos os vértices que tem o mesmo nome de identificação. O comando para criar o índice é:

CREATE INDEX ON : <identificador_nó> (<nome_atríbuto>)

Assim ao criar o índice para o identificador do autor, temos:

CREATE INDEX ON :Autorwos(autor);

Após a criação dos índices, estes podem ser utilizados na execução dos comandos MATCH, WHERE ou IN por meio da linguagem Cypher. 


\subsection{Análise das Consultas}

Por fim, a análise das consultas tem como finalidade identificar os padrões existentes em cada consulta e decidir qual modelo de dados possui os requisitos para melhor atendêla. Para isso foram analisados:

(i) Número de indireções: o principal parâmetro teórico a ser analisado na consulta é o número de indireções, que exige inúmeros joins no modelo relacional para ser atendida.

(ii) Número de atributos relacionais: a necessidade de fazer "selects e joins" na estrutura de dados. Todas as consultas em tese podem ser representadas por esses dois parâmetros.

(iii) Volume de dados: a quantidade de registros que uma tabela possui e quanto de espaço físico no banco de dados ela ocupa. Com esses dados é possível fazer estimativas sobre o tempo de execução de uma consulta.

Através dessa análise será possível verificar se é pertinente ou não integrar o modelo orientado a grafos ao modelo relacional. Através desta etapa, poderemos verificar se, em casos onde o nível de indireção é pequeno em relação ao número de operações no modelo relacional, se é interessante executar toda a consulta no modelo relacional. Caso ocorra o inverso, toda a consulta deverá ser executada no modelo orientado a grafo.

Desse modo, estaremos utilizando toda a capacidade de recuperação adjacente no modelo de grafos e toda a capacidade de recuperação relacional no modelo relacional.

\subsection{Integração entre os Bancos de Dados}

Por fim, a análise das consultas tem como finalidade identificar os padrões existentes em cada consulta e decidir qual modelo de dados possui os requisitos para melhor atendêla. 


\section{Capítulo 5}

\section{Modelagem e armazenamento dos dados}

Neste capítulo serão apresentados o modelo conceitual tanto para o modelo relacional quanto para o modelo orientado em grafos, além de detalhar o processo para obter os dados no banco de dados relacional e armazená-los no SGBD orientado a grafos. Por fim, descrevemos como os dados foram carregados em cada banco de dados.

\subsection{Modelo dos bancos de dados}

Após ter-se obtido todos os dados necessários para desenvolver o projeto, a próxima etapa foi a definição do modelo conceitual e lógico tanto para o modelo relacional quanto o modelo em grafos e o carregamento das informações nos bancos de dados.

Para o modelo relacional foi adotado o SGBD MySQL. Este é um banco open source bem aceito na comunidade [King 2015, DB-Engine 2016]. A seguinte versão para servidor do MySQL foi instalada:

MySQL - Distribuição 5.6.31 versão 14.04.1 para Ubuntu

\subsection{Modelo conceitual e lógico dos dados}

O primeiro passo para a elaboração do modelo lógico de dados foi a elaboração do modelo conceitual (Figura 5.1), através do qual ficou mais evidente as relações existentes entre os bancos de dados distintos.

Esse modelo foi elaborado de modo a atender ao estudo de caso proposto no problema. Tendo as mínimas informações. O elemento chave é o documento WoS, através dele obtemos os autores e coautores, para cada um identificamos se possuem vínculo com a USP e em caso contrário, qual o país da instituição de origem quando publicaram o documento. Utilizando o ISSN de cada documento obtemos o estrato Qualis associado. 
Após ter definido o modelo conceitual, o próximo passo foi a elaboração do modelo lógico. Nesta etapa o conjunto de informações obtidas em cada banco de dados foi um norteador de quais atributos poderíamos ter para cada entidade.

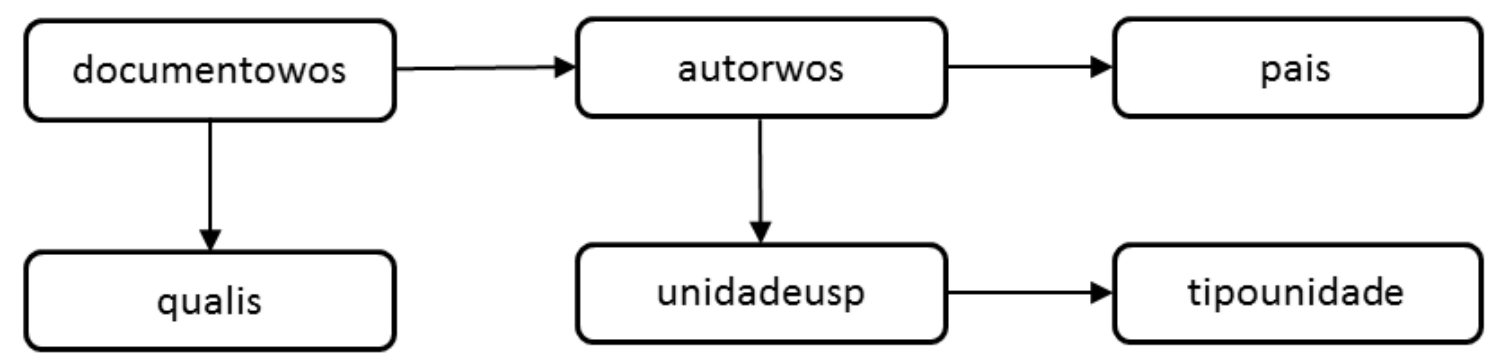

Figura 5.1: Modelo conceitual dos dados.

Fonte: Autor

As regras de normalização do modelo foram seguidas, de modo a atender corretamente a lógica relacional. O modelo aprovado é visto na Figura 5.2.

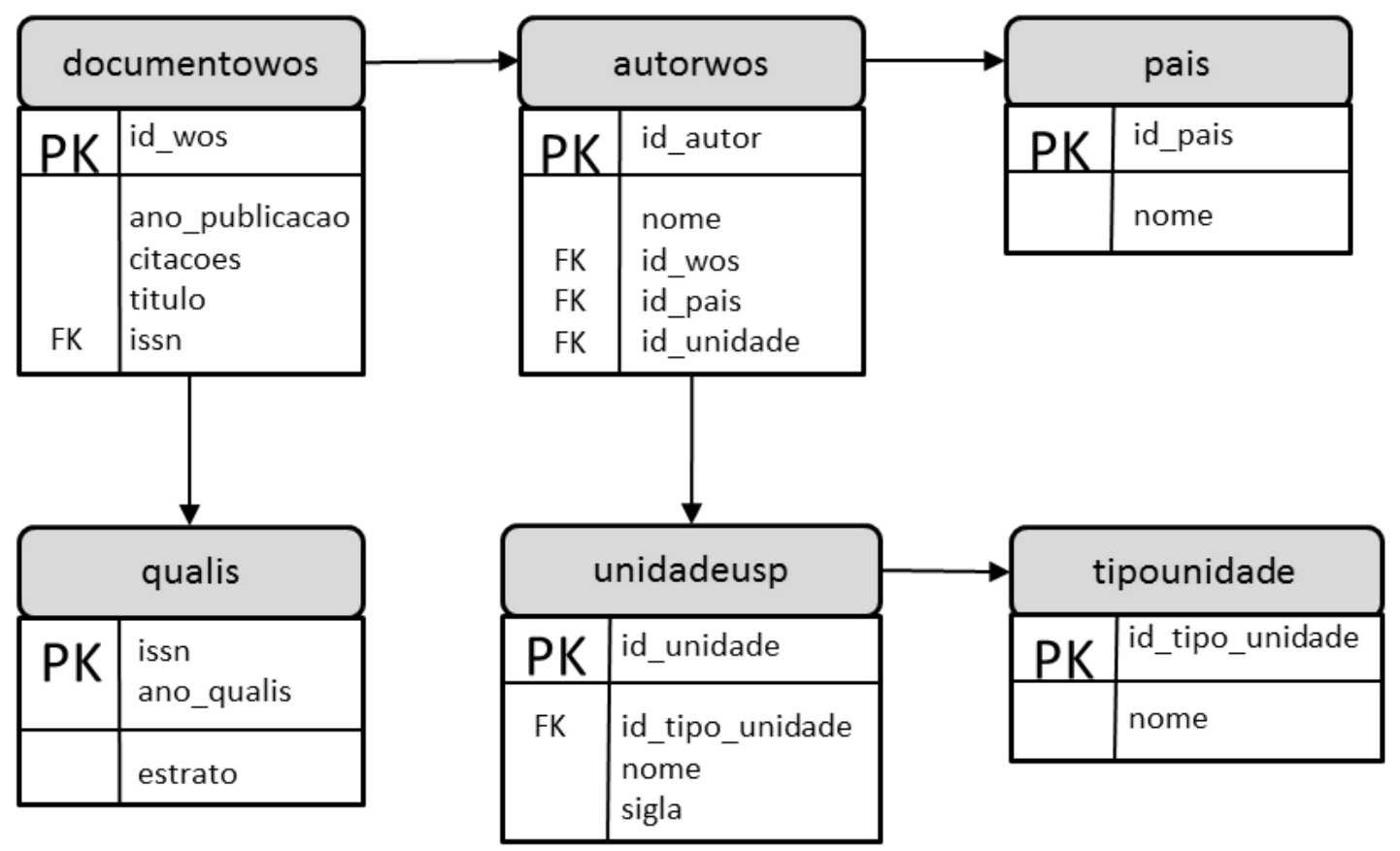

Figura 5.2: Modelo lógico relacional.

Fonte: Autor

\subsubsection{Descrição das tabelas}

A seguir são descritos todos os atributo das tabelas. 
A tabela documentowos contém todos os documentos obtidos pela Web of Science que tinham ISSN, a descrição de seus atributos é vista na Tabela 5.1.

Tabela 5.1: Descrição dos atributos da tabela documentowos

\begin{tabular}{|c|l|}
\hline \multicolumn{2}{|c|}{ Documentowos } \\
\hline Atributo & \multicolumn{1}{c|}{ Descrição } \\
\hline id_wos & $\begin{array}{l}\text { Chave primária da tabela, identificador único de cada } \\
\text { documento. }\end{array}$ \\
\hline ano_publicacao & Ano de publicação do documento. \\
\hline citacoes & $\begin{array}{l}\text { Número de citações que o documento recebeu } \\
\text { desde a sua publicação até a data da extração. }\end{array}$ \\
\hline titulo & Título do documento. \\
\hline issn & Chave estrangeira com o ISSN do documento. \\
\hline
\end{tabular}

Quanto à tabela Qualis, ela contém todas as avaliações de periódicos realizada pela Capes ano a ano. A descrição de seus atributos é vista na Tabela 5.2.

Tabela 5.2: Descrição dos atributos da tabela qualis

\begin{tabular}{|c|l|}
\hline \multicolumn{2}{|c|}{ Qualis } \\
\hline Atributo & \multicolumn{1}{c|}{ Descrição } \\
\hline issn & Chave primária da tabela, ISSN do documento. \\
\hline ano_qualis & $\begin{array}{l}\text { Ano de avaliação do periódico realizada pela } \\
\text { Capes. }\end{array}$ \\
\hline estrato & Estrato do periódico no ano de avaliação. \\
\hline
\end{tabular}

A tabela autorwos contém todos os autores e coautores identificados em cada um dos documentos. Foi feito uma associação entre o autor e os dados geográficos da instituição em que ele estava vinculado quando o documento foi publicado.

Nesta tabela existem colunas especificas para quando o autor pertence ao quadro docente da Universidade de São Paulo. Para cada autor nesta situação, dispomos de suas informações corporativas, como nome do autor e unidade a que está vinculado.

A descrição da tabela e de seus atributos é visto na Tabela 5.3.

Tabela 5.3: Descrição dos atributos da tabela autorwos

\begin{tabular}{|c|l|}
\hline \multicolumn{2}{|c|}{ Autorwos } \\
\hline Atributo & \multicolumn{1}{c|}{ Descrição } \\
\hline id_autor & Chave primária do autor. \\
\hline nome & Nome do autor. \\
\hline id_wos & Chave estrangeira do documento que o autor publicou. \\
\hline id_pais & $\begin{array}{l}\text { Chave estrangeira do país, identificador único de cada } \\
\text { país. }\end{array}$ \\
\hline
\end{tabular}




\section{id_unidade}

Chave estrangeira da unidade onde o autor USP se encontra vinculado.

A tabela pais é bem simples, contendo apenas a chave e o nome do país. Foi mantido o nome conforme registrado no Web of Science. A descrição de seus atributos é vista na Tabela 5.4.

Tabela 5.4: Descrição dos atributos da tabela pais

\begin{tabular}{|c|l|}
\hline \multicolumn{2}{|c|}{ pais } \\
\hline Atributo & \multicolumn{1}{|c|}{ Descrição } \\
\hline id_pais & $\begin{array}{l}\text { Chave primária da tabela, identificador único de cada } \\
\text { país. }\end{array}$ \\
\hline nome & Nome do país. \\
\hline
\end{tabular}

Quanto à tabela unidade, descreve as informações sobre a unidade a que o autor USP esta vinculado. Neste trabalho foram considerados, além da unidade de Ensino e Pesquisa, os seguintes tipos de unidade; Centros e Institutos Especializados, Entidades Associadas, Museus, Hospitais e Serviços Anexos e Órgãos Centrais - Direção e Serviço. O detalhamento do tipo de unidade já foi visto na Tabela 5.5.

Tabela 5.5: Descrição dos atributos da tabela unidadeusp

\begin{tabular}{|c|l|}
\hline \multicolumn{2}{|c|}{ Unidadeusp } \\
\hline Atributo & \multicolumn{1}{|c|}{ Descrição } \\
\hline id_unidade & $\begin{array}{l}\text { Chave primária da tabela, identificador único de cada } \\
\text { unidade. }\end{array}$ \\
\hline id_tipo_unidade & Chave estrangeira do tipo de unidade. \\
\hline nome & Nome da unidade. \\
\hline Sigla & Sigla da unidade. \\
\hline
\end{tabular}

A tabela tipounidade informa qual o tipo de cada unidade. A descrição da tabela tipo unidade é mostrada na Tabela 5.6.

Tabela 5.6: Descrição dos atributos da tabela tipounidade

\begin{tabular}{|c|l|}
\hline \multicolumn{2}{|c|}{ tipounidade } \\
\hline Atributo & Descrição \\
\hline id_tipo_unidade & Chave primária da tabela, tipo de unidade. \\
\hline nome & Nome do tipo de unidade. \\
\hline
\end{tabular}

\subsubsection{Criação da base de dados e das tabelas}

Após finalizar a modelagem lógica de todas as tabelas, o próximo passo foi a criação de cada uma das tabelas no SGBD MySQL. Para isso foram definidos os tipos de variáveis e as tabelas. O script da criação da base de dados no MySQL e de cada uma das 
tabelas é visto a seguir:

Criando a base de dados "mestrado" no MySQL informando que o encode é UTF8:

CREATE DATABASE `mestrado`DEFAULT CHARACTER SET utf8 COLLATE utf8_general_ci;

Criando o usuário e liberando as permissões:

CREATE USER 'wos'@'localhost' IDENTIFIED BY 'wospwd1';

GRANT ALL PRIVILEGES ON *.*TO 'wos'@'localhost' IDENTIFIED BY '<senha>';

Como todo o acesso ao banco de dados foi feito diretamente pelo servidor onde o MySQL está instalado, não foi liberado o acesso ao MySQL para uso externo. Adotou-se a criação de chave primária composta para atender as tabelas em que existe uma repetição de valores.

Uma chave primária composta é criada utilizando dois campos, assim passando a utilizar a junção dos dados destes dois campos para formar um valor único e com isto bloquear a ocorrência de duplicidade. Foi utilizado o Constraint pois a chave primária é uma restrição, assim garantindo a unicidade da chave. Em todos os casos foi adotado o nome pk_id para a restrição.

O script utilizado para a criação das tabelas no banco de dados MySQL seguindo a mesma ordem de apresentação do modelo lógico se encontra no Apêndice C.

\subsection{Carregamento dos dados}

O MySQL disponibiliza um comando que permite que um arquivo externo no formato de texto seja carregado com mais eficiência: LOAD DATA. Através deste comando, cada linha de texto corresponde a um registro na tabela sendo que as colunas são separadas por uma tabulação contendo os valores a serem inseridos. A ordem das colunas no arquivo deve ser a mesma da tabela a ser populada.

O comando é executado após se conectar ao servidor MySQL e selecionar a base de dados. No prompt "mysql>", deve-se digitar:

LOAD DATA LOCAL INFILE <local_arquivo>/<nome_arquivo.txt> INTO TABLE $<$ nome tabela> GO;

Sendo que o campo INFILE deve conter o caminho exato de onde se encontra o arquivo. Como o arquivo foi criado utilizando um editor de textos do Windows, então foi especificado o fim de linha "\r|n" utilizando a seguinte sintaxe: 
LOAD DATA LOCAL INFILE <local_arquivo>/<nome_arquivo.txt> INTO TABLE <nome tabela> LINES TERMINATED BY 'Irın' GO

Ao final da execução do comando, aparece uma mensagem informando que os dados foram corretamente carregados e quantas linhas foram inseridas. Os scripts que foram executados se encontram no Apêndice D.

\subsection{Carregamento dos dados no modelo orientado a grafos}

Dos bancos de dados orientados a grafos existentes, foi adotado o Neo4J. Esse banco de dados é open source e a seguinte versão para servidor do Neo4J foi instalada:

Neo4J - Distribuição 3.0.5 para Ubuntu.

Após gerar o modelo de banco de dados relacional, o próximo passo foi extrair as informações necessárias para se obter o modelo correspondente em banco de dados orientado a grafos. Para isso foi preciso criar uma consulta que retorna as informações para gerar os vértices e outra consulta que retorna as informações para as relações.

Os passos para a criação do modelo orientado em grafos com base dos dados do modelo relacional foram:

1 - Definir o modelo orientado em grafos: vértices e Relações juntamente com os atributos;

2 - Elaborar as consultas no banco relacional que retornam os atributos dos vértices e das relações;

3 - Executar o comando para obter um arquivo csv com os valores dos vértices e relações;

4 - Configurar o cabeçalho dos vértices e arestas;

5 -Importar os arquivos para criar e popular o banco de dados Neo4J.

A seguir veremos em detalhes cada um destes passos.

\subsubsection{Definir o modelo orientado em grafos}

Com o modelo conceitual dos dados no MySQL, foi elaborado o modelo a ser desenvolvido em grafos. A relação de interesse foi a dos autores com relação aos documentos que publicaram. Onde as informações como estrato, país, unidade se tornaram atributo de cada um destes vértices. 
O modelo de bancos de dados possui três tipos de elementos: vértices, arestas e propriedades. Sendo que os vértices se referem às instâncias de dados, as arestas são os relacionamentos mantidos entre estas instâncias, e por fim as propriedades são os atributos contidos nas instâncias.

No caso a ser estudado, teremos dois vértices, um representando os autores com a informação dos países das instituições de vinculação, e o outro representando as publicações do Web of Science, tendo como arestas a nacionalidade da instituição de cada um dos autores, sendo esta separada em nacional e em estrangeiro. Esse modelo irá facilitar o estudo das relações em diversos tamanhos e disposições de grupos de estudos, e assim facilitar a identificação das relevâncias entre a quantidade de publicação e a qualidade delas com relação à existência de coautores estrangeiros.

A estrutura do banco de dados para atender as relações mencionadas é apresentada na figura 5.3. Nele são vistos os seguintes vértices: Autorwos e Documentowos. Conforme já mencionado, estes vértices estão conectados pelas relações: NACIONAL e

\section{ESTRANGEIRO.}

A composição da relação por esses dois tipos é que o país da instituição é um item que vai ser utilizado nas consultas a serem feitas nos dois bancos de dados, sendo um fator recorrente. Com isso todos os autores que são de instituição nacional foram vinculados aos documentos de sua autoria pela relação NACIONAL, já para todos os demais casos a relação foi ESTRANGEIRO. Desse modo, das 385.526 relações, obtivemos 211.915 (54,97\%) relações NACIONAL e 173.611 (45,03\%) relações ESTRANGEIRO.

Os atributos existentes nos vértices foram definidos a fim de atender aos experimentos propostos neste trabalho.

Este é um modelo que se aproxima bem do modelo relacional, onde os atributos são as propriedades de cada nó. No modelo em grafos as relações substituem as chaves estrangeiras. Na Figura 5.3 vemos o modelo lógico.

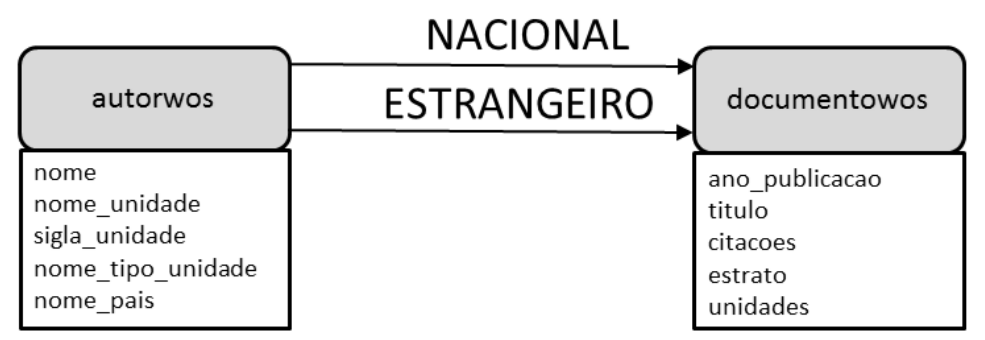

Figura 5.3: Modelo lógico orientado a grafos.

Fonte: Autor 


\subsubsection{Elaborando as consultas para extração}

Com a definição do modelo orientado a grafos, foram elaboradas consultas no banco de dados relacional que devolve os dados que permitirão criar o novo banco de dados.

Como um periódico pode ter um estrato diferente em cada período de avaliação (2009, 2012 ou 2014), e como cada publicação está relacionada a um ISSN e com um único ano de publicação, então foi criado uma chave única para cada identificador de um documento do Web of Science e seu estrato correspondente.

O ano da avaliação foi inserido no final do ISSN, assim além dos 8 caracteres, temos também o ano no qual a avaliação foi feita. Para os documentos foi adotado o mesmo critério, porém como tínhamos anos de publicação contidos nos intervalos, foi adotado o seguinte:

- Caso o documento tivesse o ano de publicação anterior a 2010, então os periódicos foram avaliados pelo Qualis correspondente ao ano de 2009 e o ano colocado no final do identificador Web of Science foi 2009;

- Se o ano fosse entre 2010 e 2012 inclusive, então o periódico foi avaliado pelo Qualis 2012 e o ano colocado no final foi 2012;

- Caso o documento tivesse o ano de publicação igual ou posterior a 2013, então o qualis de avaliação foi 2014 e o ano colocado foi 2014.

Por exemplo, um documento Web of Science com identificador '000305403400002' e com ano de publicação 2012, teve o seu novo identificador '0003054034000022012'.

No modelo, temos dois vértices e uma aresta. $\mathrm{O}$ vértice autorwos contém todas as informações referentes ao autor enquanto o vértice documentowos contém todas as informações dos documentos da Web of Science. As consultar para se obter os dados para popular estes vértices são:

\section{autorwos:}

SELECT a.id_autor_wos, a.nome, (select un.nome from unidadeusp as un where un.id_unidade = a.id_unidade) as unidade, (select uni.sigla from unidadeusp as uni where uni.id_unidade = a.id_unidade) as sigla, (select t.nome from unidadeusp as und, tipo_unidade as t where und.id_unidade $=$ a.id_unidade and t.id_tipo_unidade =und.id_tipo_unidade) as tipo, (select p.nome from pais as $p$ where p.id_pais = a.id_pais) as pais FROM autorwos as a; 


\section{documentowos:}

SELECT d.id_wos, d.ano_publicacao, d.titulo, d.citacoes, q.estrato, (select count(a.id_unidade) from autorwos as a where d.id_wos = a.id_wos and a.id_unidade $<>0)$ FROM documentowos as d INNER JOIN qualis as q ON (d.issn = q.issn and d.ano_publicacao = q.ano_qualis);

Já as consultas para se obter as informações das relações foram:

\section{NACIONAL:}

SELECT d.id_wos,d.ano_publicacao, a.id_autor_wos FROM autorwos as a INNER JOIN documentowos as d ON (d.id_wos = a.id_wos) INNER JOIN qualis as q ON (d.issn = q.issn and d.ano_publicacao $=$ q.ano_qualis) INNER JOIN pais as p ON (a.id_pais = p.id_pais AND p.nome $=$ 'Brazil');

\section{ESTRANGEIRO:}

SELECT d.id_wos,d.ano_publicacao, a.id_autor_wos FROM autorwos as a INNER JOIN documentowos as d ON (d.id_wos = a.id_wos) INNER JOIN qualis as q ON (d.issn = q.issn and d.ano_publicacao $=$ q.ano_qualis) INNER JOIN pais as p ON (a.id_pais = p.id_pais AND p.nome <> 'Brazil');

\subsubsection{Exportar informações para arquivo csv}

Tendo definido todas as consultas que permitem obter os elementos que irão compor o modelo orientado a grafos, tem-se que gerar estas consultas em formato de arquivo csv.

Nesta etapa do trabalho iremos utilizar a ferramenta disponível no Linux SED. Esta ferramenta é uma linguagem para manipulação, modificação e substituição de arquivos texto.O SED lê linha por linha de um arquivo e aplica a expressão do parâmetro a cada uma delas.

O comando MySQL que iremos adotar para obter o resultado de uma consulta é: mysql -u <usuário > -p <banco de dados > -e "<comando>;"

Fazendo com que sua saída seja utilizada como entrada do SED e assim aplicando as modificações e transformações do resultado, obtemos o arquivo csv quase pronto para ser utilizado pelo Neo4J:

sed 's/;:/g;s/t///g;s/n//g' > <endereço do arquivo > /<arquivo de saida.csv>

Onde os campos <usuário> e <banco de dados> são as informações de acesso ao banco de dados relacional, o <comando> é a consulta SQL que se deseja fazer para exportar o resultado, e o <endereço do arquivo> o local onde o arquivo de saída se 
encontra e por fim <arquivo de saida.csv> é o nome do arquivo de saída.

Para isto, o MySQL dispõe de comandos que, alinhados permitem executar uma consulta e exportar o resultado em um arquivo csv:

Assim temos o exemplo completo para obtenção dos documentos Web of Science:

mysql -u wos -p mestrado -e "SELECT d.id_wos,'@', d.ano_publicacao, q.estrato FROM documentowos as $\mathrm{d}$ INNER JOIN qualis as q ON (d.issn = q.issn and d.ano_publicacao = q.ano_qualis);" | sed 's/;/:/g;s/t///g;s/nn//g' > /home/wos/documentowosF.csv

$\mathrm{O}$ arquivo resultante deve ter a primeira linha excluída, pois ela contém o cabeçalho da consulta e as vírgulas devem ser tratadas antes de substituir o separador ';' por ','.

O comando adotado para remover a primeira linha do arquivo é:

sed -i 1d <nome_do_arquivo >

Neste trabalho adotamos substituir as vírgulas dos resultados por espaço vazio, deste modo o comando adotado para substituir as vírgulas e posteriormente os ponto e vírgulas por vírgulas foi:

sed -e 's/,//g' <nome_do_arquivo> > temporário.txt sed -e 's/;//g' temporário.txt > <nome_do_arquivo >

Com isto geramos os arquivos de entrada no modelo orientado a grafos.

\subsubsection{Preparar arquivos para serem importados}

O formato de entrada esperado pelo comando do neo4J para importação precisa de dois arquivos principais para cada vértice e relacionamento. Para cada nó, um desses arquivos deve conter o cabeçalho onde apresenta as informações sobre o arquivo a ser importado, como identificador principal caracterizado por "autorID:ID(autor)", onde autorID é o nome do identificador e ID é a identificação de que este campo é o identificador de cada vértice e atributos. O cabeçalho do arquivo de relações contém o identificador do vértice de origem, identificado com START_ID(), os atributos da relação e por fim o identificador do vértice destino, ou final, identificado por END_ID():

:START_ID(wos),:END_ID(autor) 
É importante perceber que a referência ao identificador do vértice se dá pelo nome da coluna referenciada pelo ID(), e não pelo nome do identificador principal do vértice.

Os arquivos de cabeçalho, representados com o '-h', possuem a finalidade de indicar quais são os atributos de cada vértice, além do identificar deste vértice e quais são os identificadores de origem e destino para cada relação existente.

A seguir são vistos os cabeçalhos de cada vértice do modelo com as queries que para o carregamento dos dados:

\section{autorwos}

autorID:ID(autor),nome,unidade,sigla,tipo,pais

\section{documentowos}

wosID:ID(wos),publicacao,titulo,citacoes,estrato

Quanto as relações, temos os seguintes cabeçalhos:

\section{NACIONAL}

:START_ID(wos),:END_ID(autor)

\section{ESTRANGEIRO}

:START_ID(wos),:END_ID(autor)

\subsubsection{Importar e criar o banco de dados orientados a grafos}

O Neo4J dispõe de um comando para importação de grandes volumes de dados; a função neo4j-import. Esta função realiza a leitura de dois arquivos texto, sendo um que contém o cabeçalho com as propriedades dos vértices e o outro contém os dados a serem carregados neste nó.

A seguir é visto o comando com a estrutura dos dois arquivos necessários:

neo4j-import --into <local_banco_de_dados $>/<$ nome_banco $>$.db

--nodes:Autorwos <local_arquivo>/autorwos-h.csv, <local_arquivo>/autorwos.csv

--nodes:Wos <local_arquivo>/documentowos-h.csv, <local_arquivo>/documentowos.csv

--relationships:NACIONAL <local_arquivo>/relacaowosNacional-h.csv,

$<$ local_arquivo>/relacaowosNacional.csv 
--relationships:ESTRANGEIRO <local_arquivo>/relacaowosEstrangeira-h.csv, $<$ local_arquivo>/relacaowosEstrangeira.csv

Conforme a sintaxe do comando, o nome do banco de dados Neo4J a ser criado é o mestrado.db e os arquivos que contém os dados sobre os vértices são: autorwos-h.csv, autorwos.csv , documentowos-h.csv e documentowos.csv . Já os arquivos que contém as informações sobre as relações são relacaowosNacional-h.csv, relacaowosNacional.csv e relacaowosEstrangeira-h.csv. 


\section{Capítulo 6}

\section{Experimentos e Resultados obtidos}

O objetivo deste capítulo é apresentar os resultados que foram obtidos ao realizar os experimentos para comparar os dois bancos de dados, seguindo as propostas de analisar as consultas, obtendo informações de quais padrões são melhores atendidos por cada modelo: o relacional e o orientado a grafos.

\subsection{Tempo de carregamento dos dados}

O tempo de carregamento dos dados foi obtido durante a criação dos bancos de dados não relacional. Em todos os bancos de dados utilizados, os índices foram criados somente após a finalização das cargas, assim os tempos mostrados na Tabela 6.1 contêm apenas a criação dos bancos de dados sem índices.

Tabela 6.1: Tempo de importação para o banco de dados orientado a grafos.

\begin{tabular}{|l|r|}
\hline & Tempo de carregamento (em segundos) \\
\hline BD1 & 3,265 \\
\hline BD2 & 3,884 \\
\hline BD3 & 9,606 \\
\hline BD4 & 41,750 \\
\hline BD5 & 386,358 \\
\hline
\end{tabular}

Apesar da diferença do número de vértices e relações entre o BD1 e o BD2, o tempo de carregamento foi muito parecido. Isto porque quando o Neo4J cria um novo banco de dados, ele cria uma estrutura básica inicial. Nesse caso o tempo de carregamento inclui esse tempo para criar esta estrutura também.

O banco relacional é utilizado como fonte de informações para gerar o banco de dados orientado a grafos. Dessa forma o tempo gasto para a carga deste modelo de banco não foi computado por não fazer parte dos experimentos propostos. 


\subsection{Armazenamento em disco}

Os gráficos da Figura 6.1 e a Tabela 6.2 apresentam o espaço em disco que cada um dos bancos de dados ocupou. Em todos os cinco bancos de dados, o Neo4J ocupa mais espaço de disco do que o MySQL. Excetuando-se os bancos menores BD1 e BD2, o banco de dados Neo4J utiliza em media $77,27 \%$ a mais espaço em disco do que o banco de dados MySQL correspondente. Sendo o pior caso para o BD5, quando o banco de dados Neo4J é $88,71 \%$ maior.

Nos bancos BD1 e BD2, devido a estrutura mínima criada pelo Neo4J, o espaço em disco chega a ser até $5600 \%$ maior do que o MySQL.

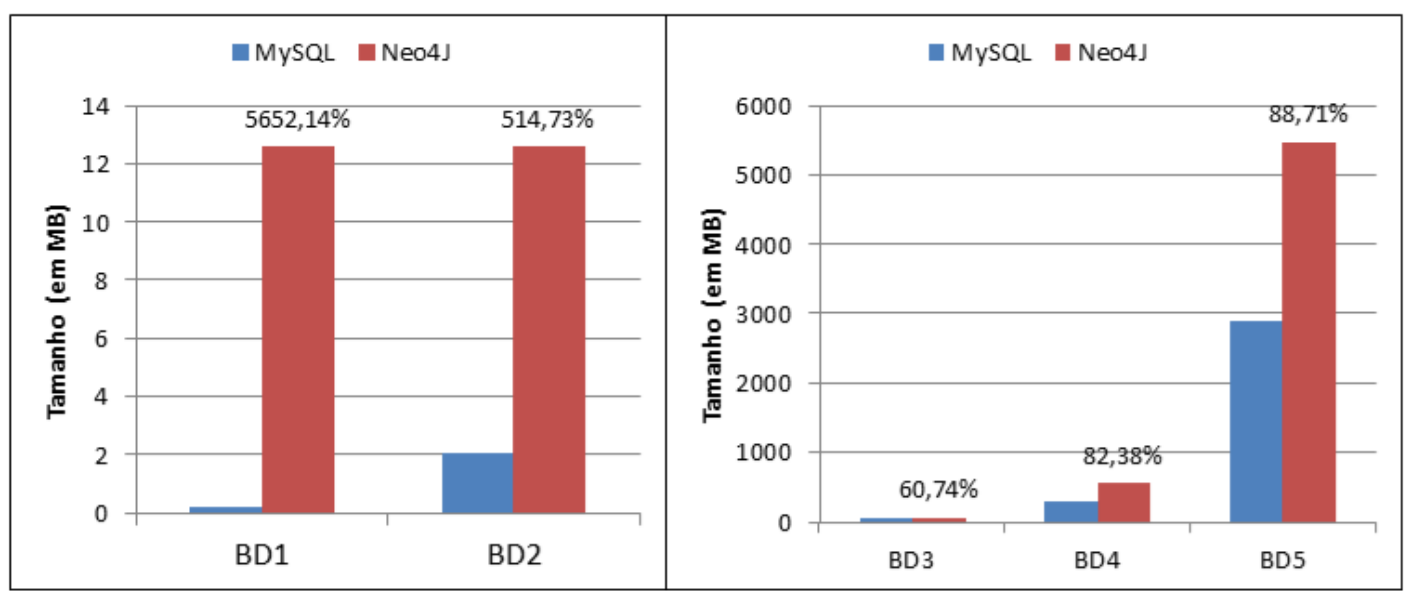

Figura 6.1: Comparação entre os tamanhos dos bancos de dados.

Fonte: Autor

Tabela 6.2: Tamanhos dos bancos de dados.

\begin{tabular}{|l|r|r|}
\hline & MySQL (tamanho em MB) & Neo4J (tamanho em MB) \\
\hline BD1 & 0,21875 & 12,5828 \\
\hline BD2 & 2,046875 & 12,5828 \\
\hline BD3 & 39,140575 & 62,9144 \\
\hline BD4 & 303,56238 & 557,8410 \\
\hline BD5 & 2900,56248 & 5528,0792 \\
\hline
\end{tabular}

Um motivo para este maior espaço de armazenamento é que o Neo4j possui uma organização em arquivos com base em registros por estrutura de dados. Isto para o armazenamento dos vértices, arestas, atributos e rótulos [Neo4J 2016]. Deste modo cada um dos atributos de um vértice contém um ponteiro para cada um dos demais atributos do vértice. No caso das arestas, cada uma possui ponteiros apontando para as arestas 
anteriores e posterior.

Outro motivo para o Neo4J possuir um tamanho maior é devido ao serviço de indexação do Lucene. Por meio dele é armazenado o nome de cada atributo em conjunto com seu valor nos índices. Este tipo de serviço não é encontrado no MySQL.

\subsection{Consumo de memória}

Quanto ao consumo de memória para inicializar os bancos de dados, o Neo4J consome mais memória do que o MySQL em todos os cinco bancos, chegando a tem uma diferença de quase 11 mil \% a mais no BD5 (Figura 6.2).

Essa diferença do uso de memória ocorre devido ao fato de que o MySQL possui um cache estático, enquanto o Neo4J trabalha com paginação de cache, e com isto os dados do Neo4j são armazenados em cache no disco. O objetivo é fazer com que a maioria dos dados do grafo sejam armazenadas em cache na memória, assim evitando o acesso ao disco [Neo4j 2016].

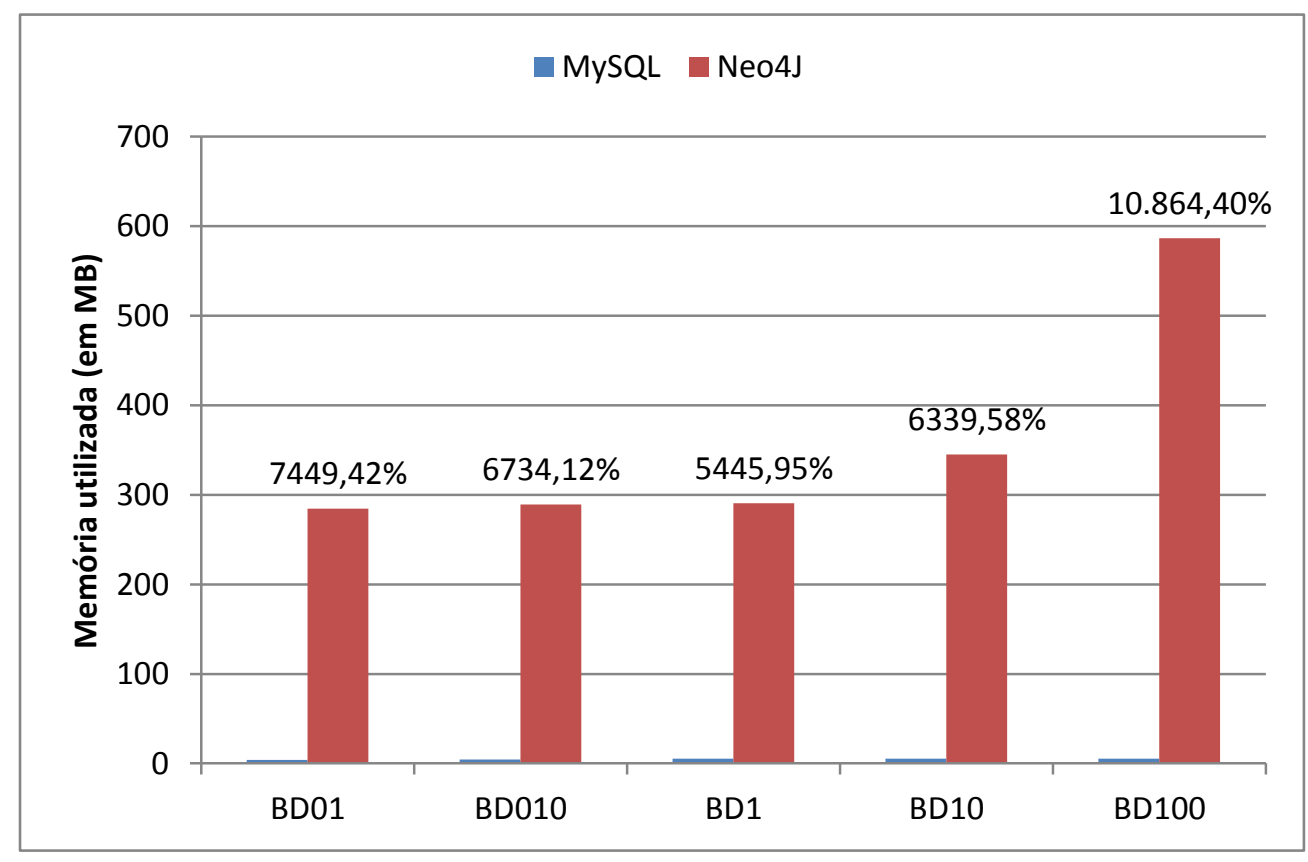

Figura 6.2: Memória utilizada na inicialização dos bancos de dados

Fonte: Autor

\subsection{Resultados dos Experimentos}

Existem muitas variações dos tipos de consulta que podem ser feitas, além de alterações na configuração do MySQL e do Neo4J, de modo a otimizar uma consulta. Este trabalho adotou utilizar os bancos de dados com as configurações padrão, com isto 
garantindo que nenhum dos SGBD tivesse uma melhor configuração que o outro.

Foram obtidos os tempos de execução de cada um dos experimentos. Cada consulta foi executada dez vezes, sendo que o maior e o menor tempo de execução foram descartados, anotando a média dos demais valores restantes.

\section{Experimento 1}

Os resultados do desempenho nos cinco bancos de dados relativos ao experimento1 são vistos na Figura 6.3:

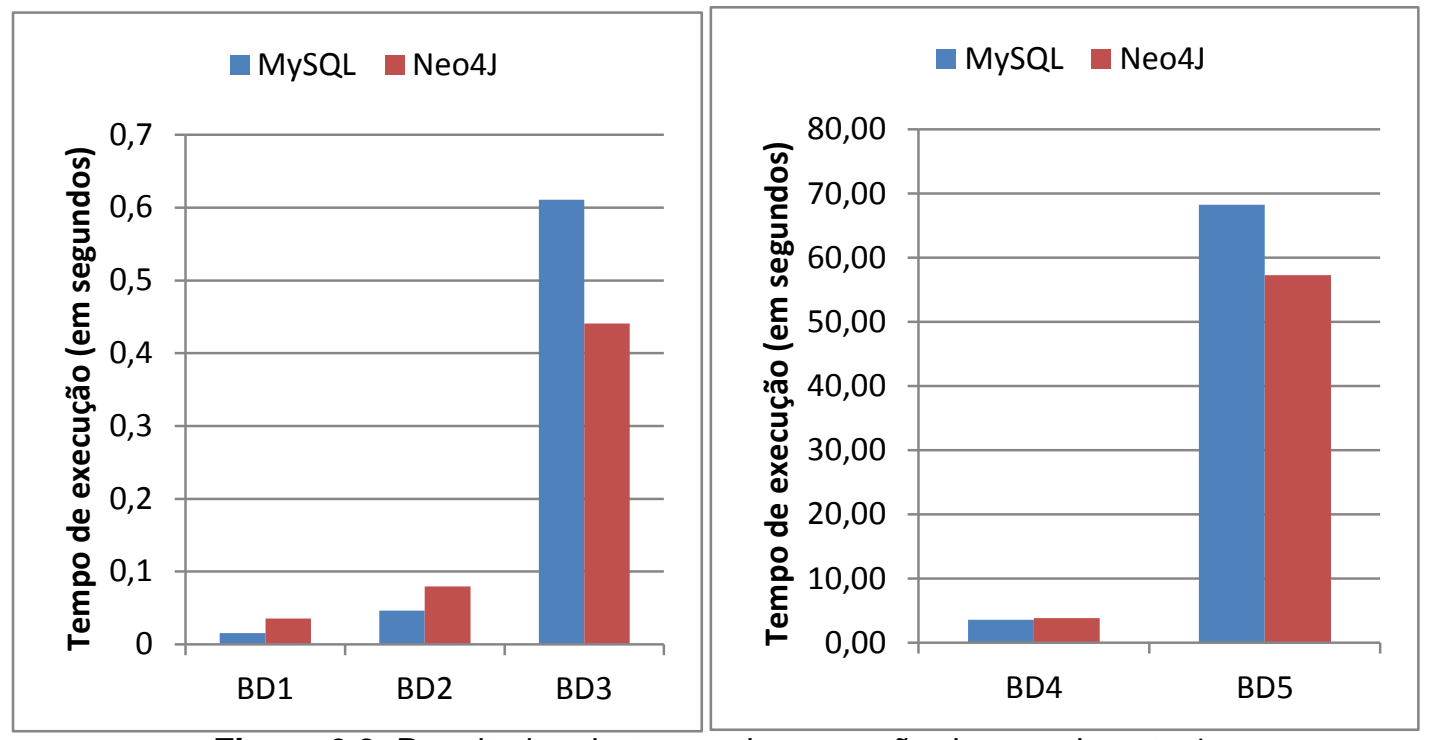

Figura 6.3: Resultados do tempo de execução do experimento 1.

\section{Experimento 2}

Fonte: Autor

Os resultados do desempenho nos cinco bancos de dados relativos ao experimento 2 são vistos na Figura 6.4:

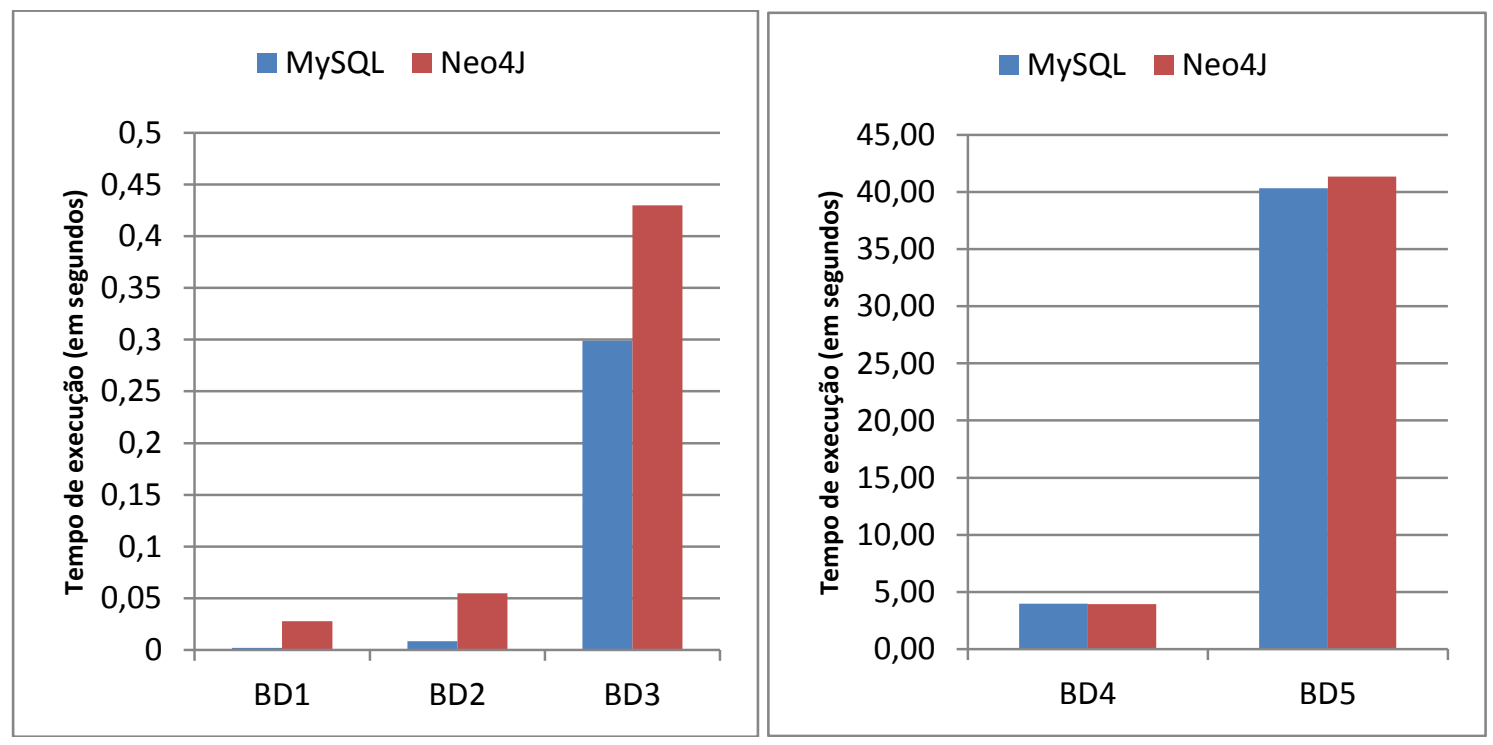

Figura 6.4: Resultados do tempo de execução do experimento 2. 


\section{Experimento 3}

Os resultados do desempenho nos cinco bancos de dados relativos ao experimento 3 são vistos na Figura 6.5:

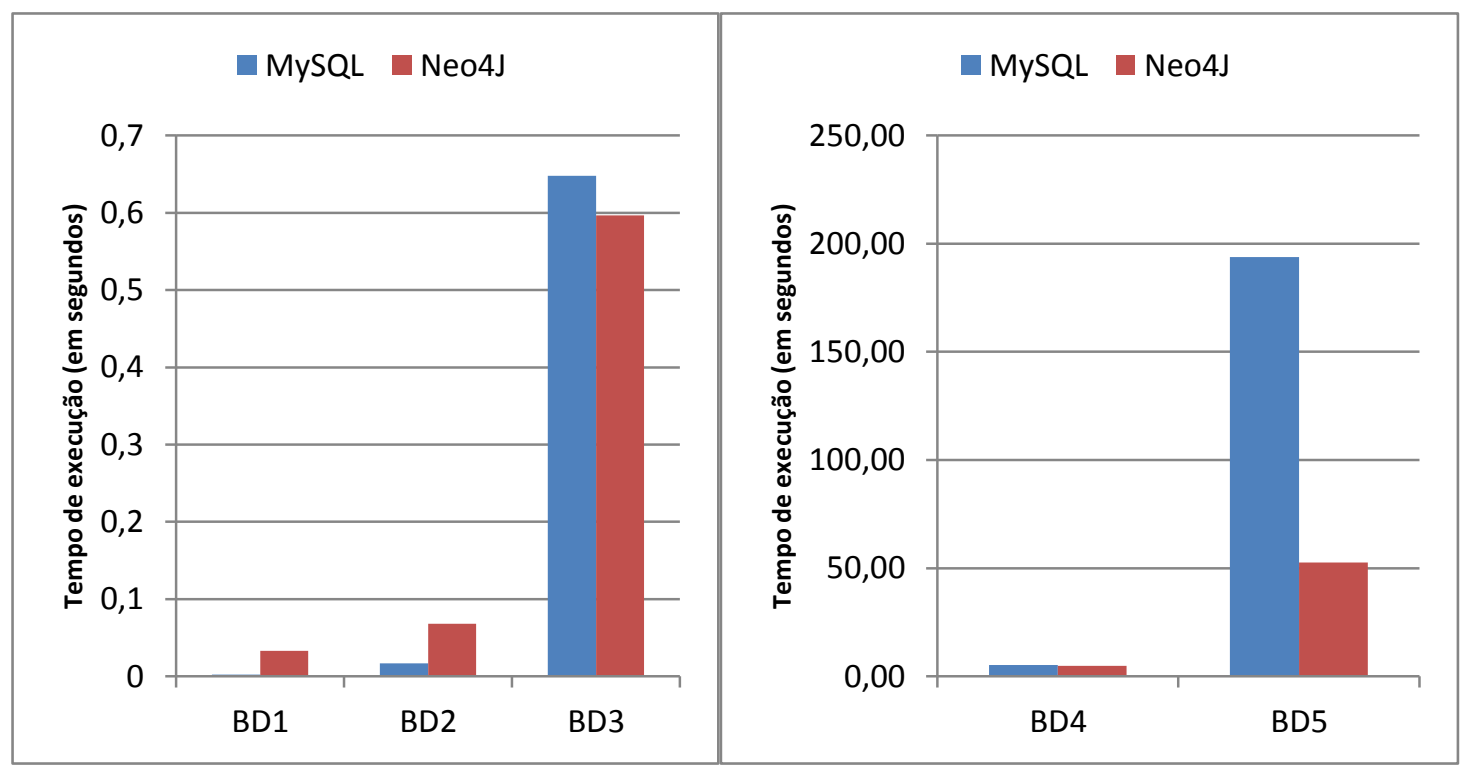

Figura 6.5: Resultados do tempo de execução do experimento 3.

Fonte: Autor

\section{Experimento 4}

Os resultados do desempenho nos cinco bancos de dados relativos à consulta 4 são vistos na Figura 6.6:

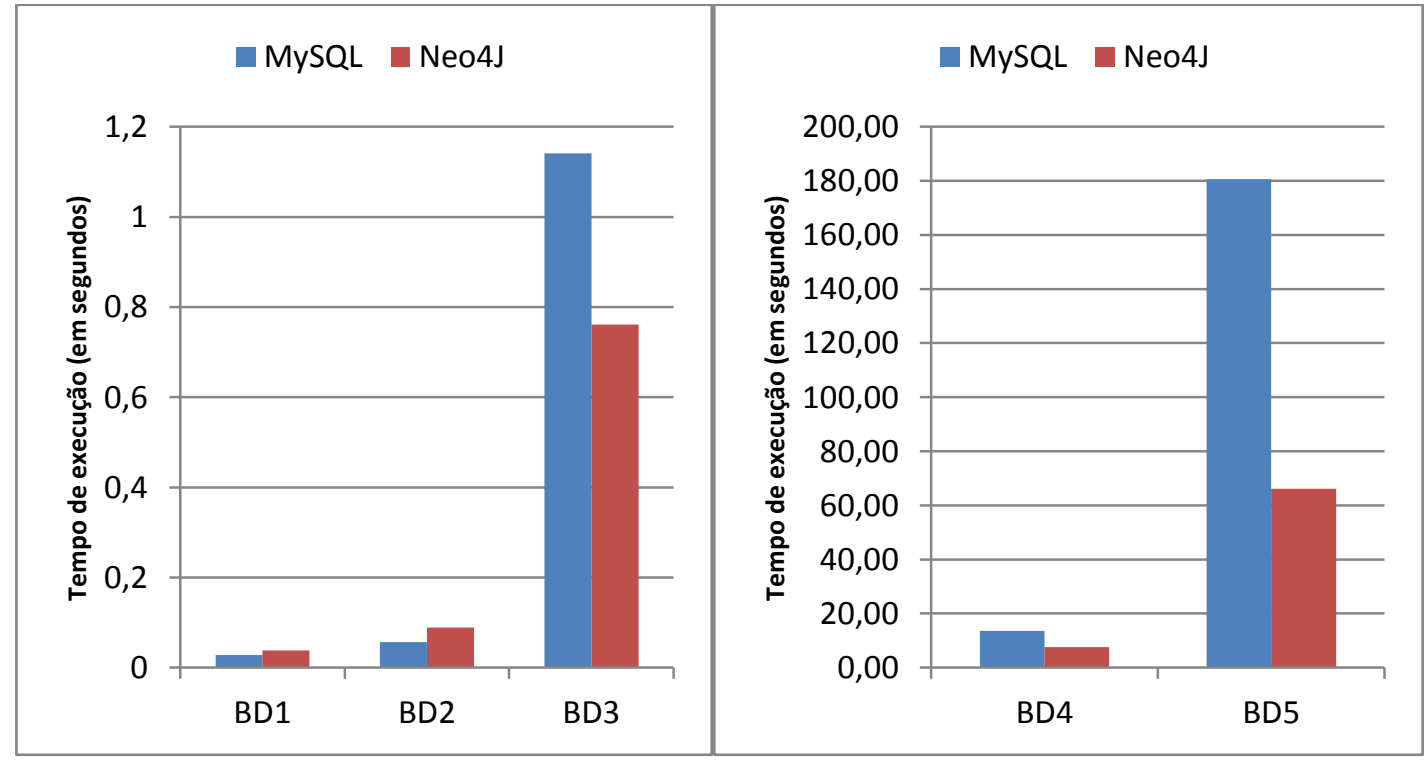

Figura 6.6: Resultados do tempo de execução do experimento 4.

Fonte: Autor 


\section{Experimento 5}

Os resultados do desempenho nos cinco bancos de dados relativos à consulta 5 são vistos na Figura 6.7:

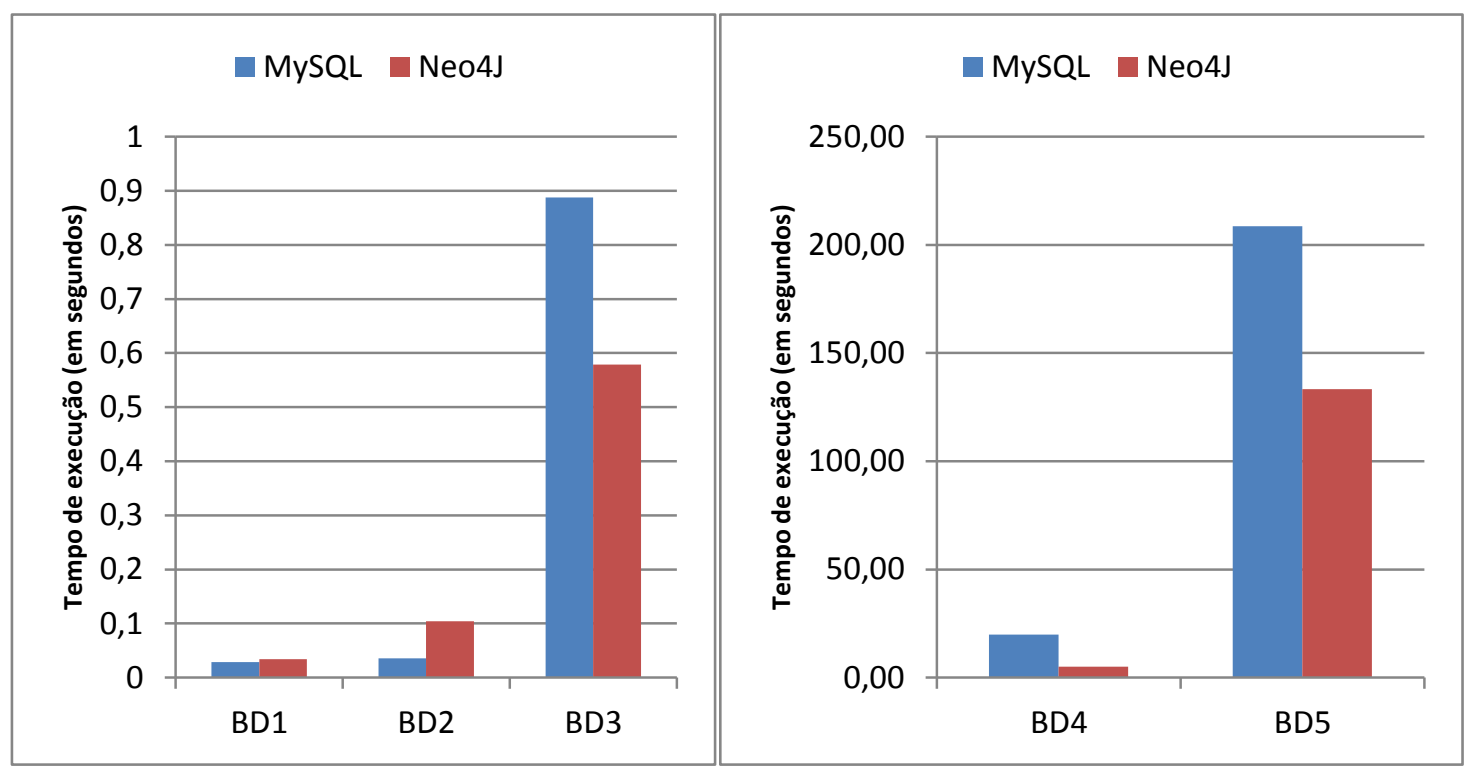

Figura 6.7: Resultados do tempo de execução do experimento 5.

Fonte: Autor

\section{Experimento 6}

Os resultados do desempenho nos cinco bancos de dados relativos à consulta 6 são vistos na Figura 6.8:

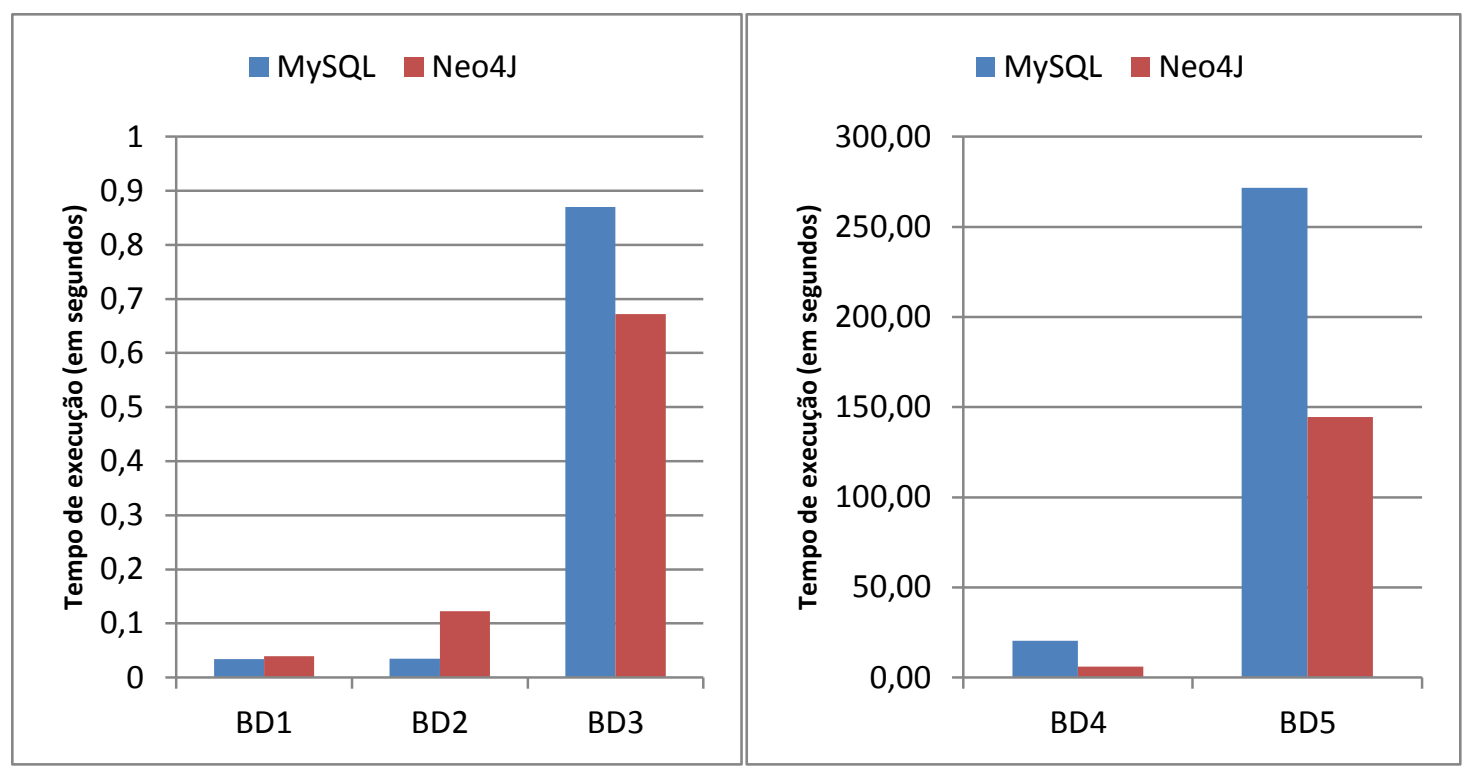

Figura 6.8: Resultados do tempo de execução do experimento 6.

Fonte: Autor 


\section{Experimento 7}

Os resultados do desempenho nos cinco bancos de dados relativos à consulta 7 são vistos na Figura 6.9:

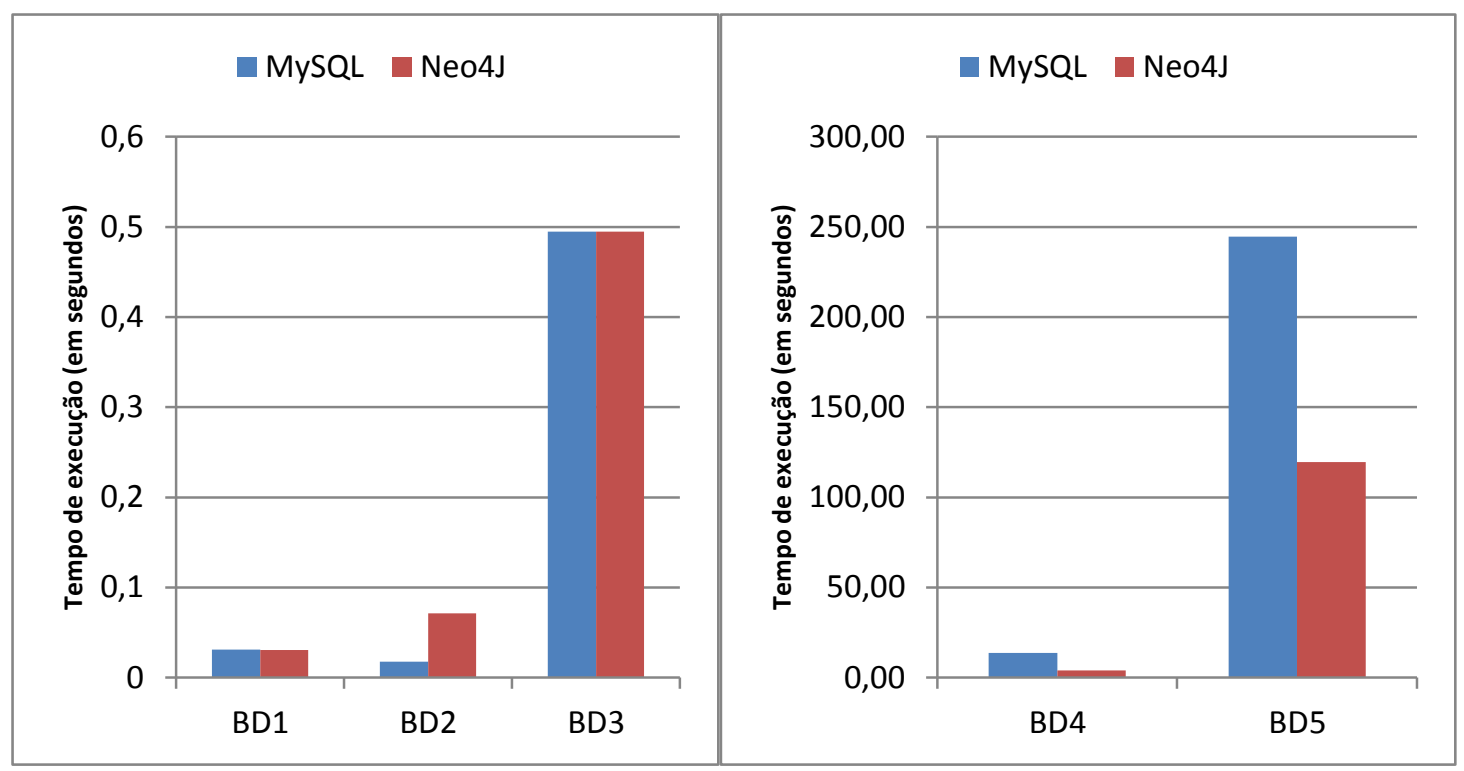

Figura 6.9: Resultados do tempo de execução do experimento 7.

Fonte: Autor

\section{Experimento 8}

Os resultados do desempenho nos cinco bancos de dados relativos à consulta 8 são vistos na Figura 6.10:

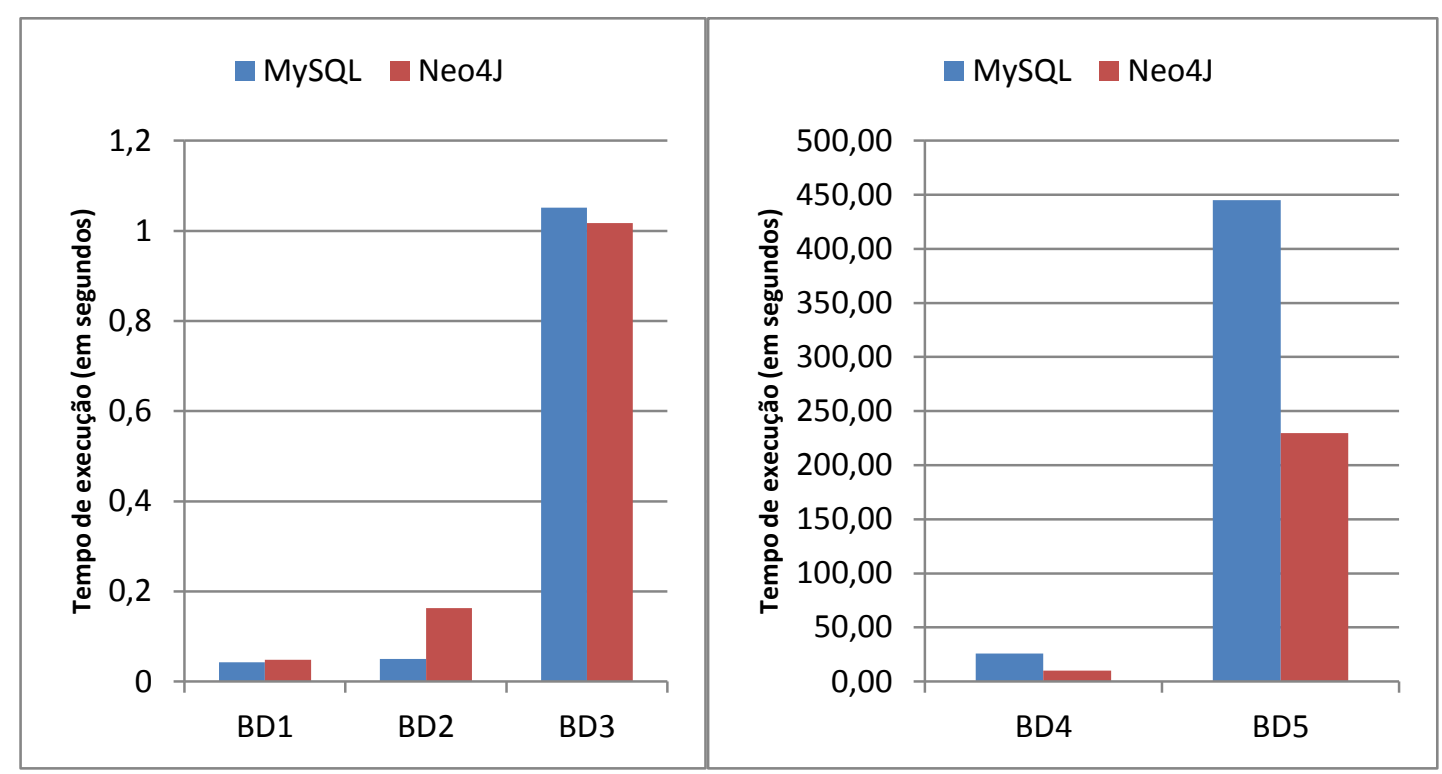

Figura 6.10: Resultados do tempo de execução do experimento 8.

Fonte: Autor 


\section{Experimento 9}

Os resultados do desempenho nos cinco bancos de dados relativos ao experimento 9 são vistos na Figura 6.11:

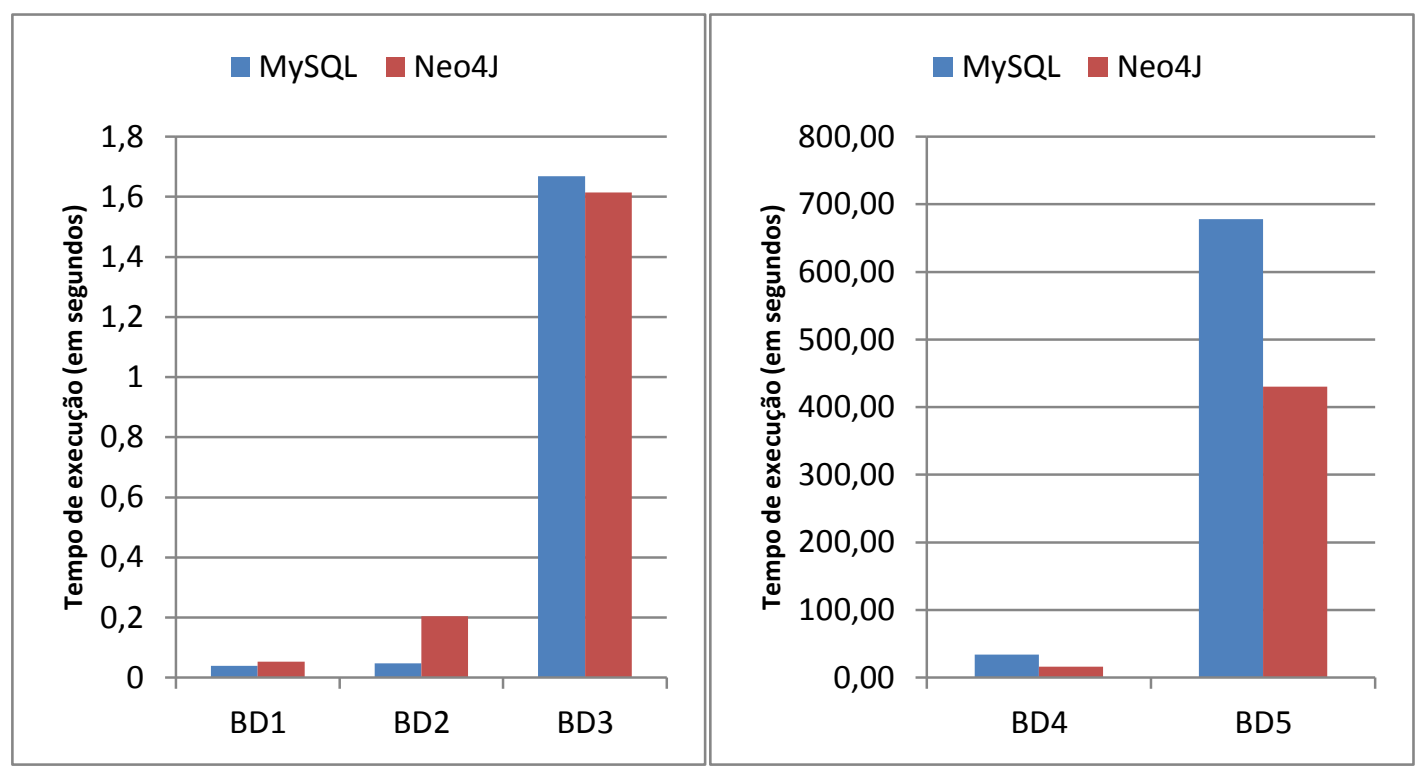

Figura 6.11: Resultados do tempo de execução do experimento 9.

Fonte: Autor

\section{Experimento 10}

Os resultados do desempenho nos cinco bancos de dados relativos ao experimento 10 são vistos na Figura 6.12:

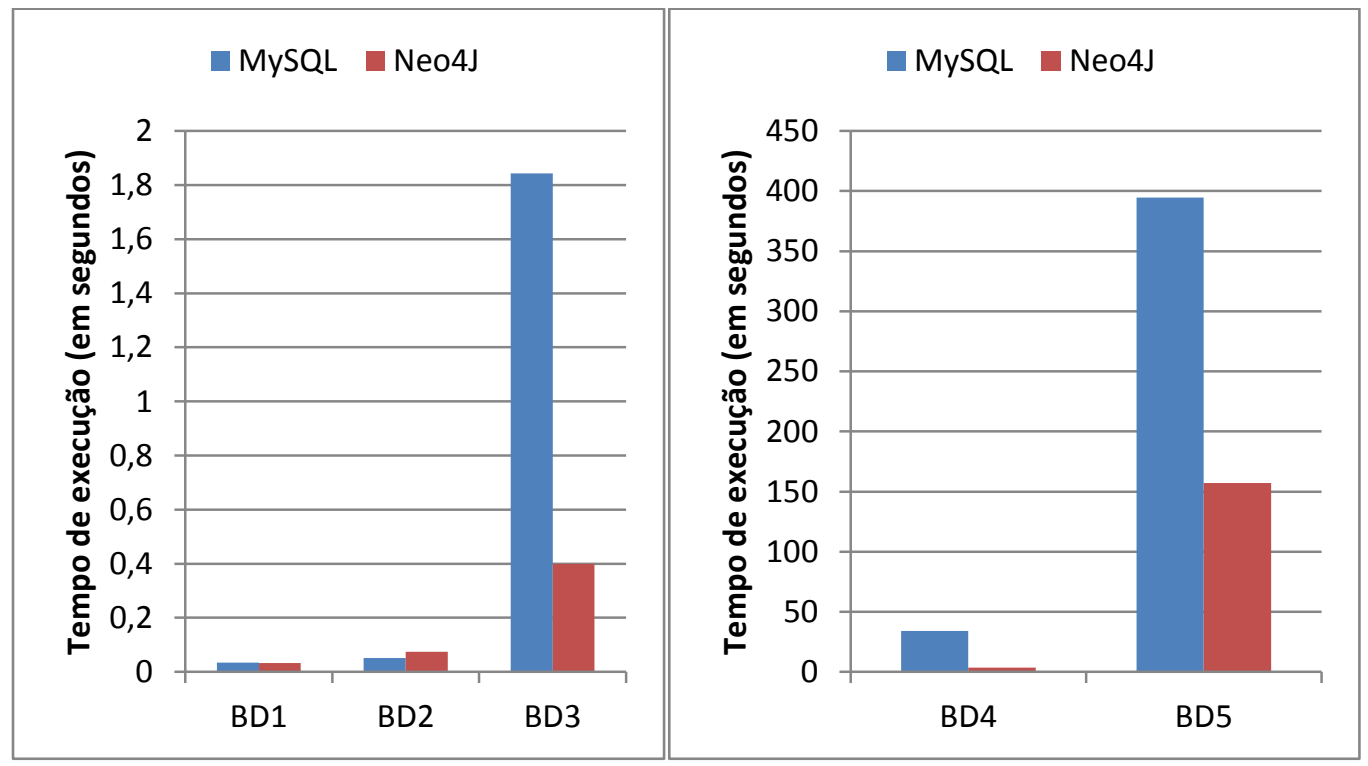

Figura 6.12: Resultados do tempo de execução do experimento 10.

Fonte: Autor 
A tabela 6.3, com os valores em segundos, é vista a seguir:

Tabela 6.3: Resultados em segundos obtidos da média de cada experimento

\begin{tabular}{|l|l|r|r|r|r|r|}
\hline Banco & Experimento & BD1 & \multicolumn{1}{l|}{ BD2 } & \multicolumn{1}{l|}{ BD3 } & BD4 & \multicolumn{1}{l|}{ BD5 } \\
\hline MySQL & E1 & 0,01509 & 0,04628 & 0,61 & 3,60 & 68,25 \\
\hline Neo4J & E1 & 0,0355 & 0,07925 & 0,44 & 3,80 & 57,29 \\
\hline MySQL & E2 & 0,00189 & 0,00843 & 0,30 & 3,95 & 40,35 \\
\hline Ne04J & E2 & 0,02788 & 0,05463 & 0,43 & 3,93 & 41,35 \\
\hline MySQL & E3 & 0,00219 & 0,01691 & 0,65 & 5,19 & 193,74 \\
\hline Ne04J & E3 & 0,033 & 0,06825 & 0,60 & 4,87 & 52,55 \\
\hline MySQL & E4 & 0,02798 & 0,05689 & 1,14 & 13,61 & 180,62 \\
\hline Ne04J & E4 & 0,03775 & 0,08875 & 0,76 & 7,51 & 66,13 \\
\hline MySQL & E5 & 0,02904 & 0,0358 & 0,89 & 19,84 & 208,66 \\
\hline Neo4J & E5 & 0,03375 & 0,10415 & 0,58 & 5,00 & 133,33 \\
\hline MySQL & E6 & 0,03388 & 0,03513 & 0,87 & 20,36 & 271,52 \\
\hline Ne04J & E6 & 0,03915 & 0,12238 & 0,67 & 6,16 & 144,46 \\
\hline MySQL & E7 & 0,03124 & 0,01748 & 0,49 & 13,74 & 244,69 \\
\hline Ne04J & E7 & 0,0305 & 0,07138 & 0,49 & 3,99 & 119,64 \\
\hline MySQL & E8 & 0,0427 & 0,05 & 1,05 & 26,06 & 444,82 \\
\hline Neo4J & E8 & 0,048 & 0,16288 & 1,02 & 9,99 & 229,85 \\
\hline MySQL & E9 & 0,03906 & 0,04679 & 1,67 & 34,22 & 677,84 \\
\hline Ne04J & E9 & 0,0525 & 0,20425 & 1,61 & 16,00 & 430,28 \\
\hline MySQL & E10 & 0,03421 & 0,05172 & 1,843028 & 34,1535 & 394,5652 \\
\hline Ne04J & E10 & 0,03213 & 0,0745 & 0,39925 & 3,64575 & 157,287 \\
\hline
\end{tabular}

\subsection{Análise das consultas}

$\mathrm{Na}$ análise sobre os cinco bancos de dados nota-se que nos bancos de dados BD1 e BD2 o MySQL obteve um resultamos melhor em todas as consultas. Porém conforme o volume de dados vai aumentando, indo para o BD3, BD4 e BD5 o Neo4J obtém um resultado melhor.

Esta diferença a favor do MySQL nos BD1 e BD2 ocorre independente da consulta do experimento, e é devido ao modo como é estruturado internamente o dado em cada um dos bancos de dados.

Nas Figuras 6.13, 6.14, 6.15 e 6.16 são vistos a comparação entre o tempo de execução no MySQL com o Neo4J separado por cada um dos bancos de dados desenvolvidos. 


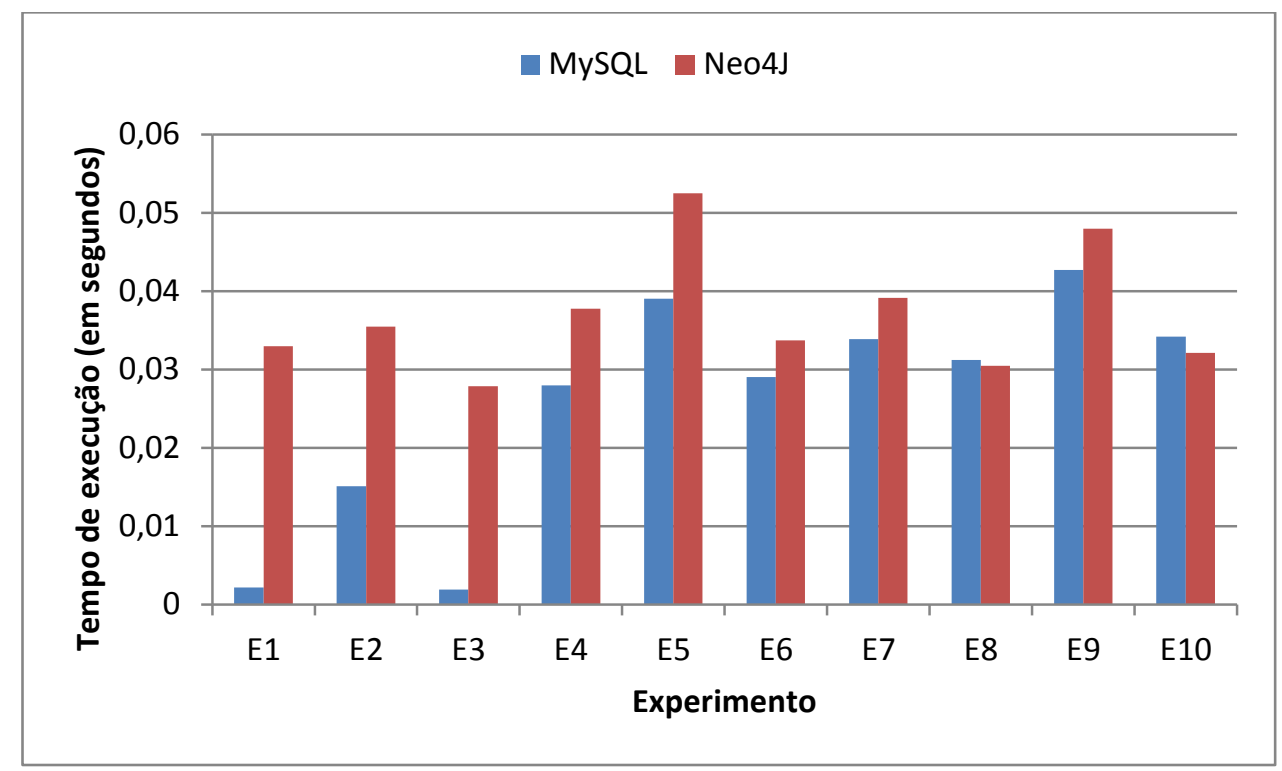

Figura 6.13: Gráfico do tempo de execução no BD1.

Fonte: Autor

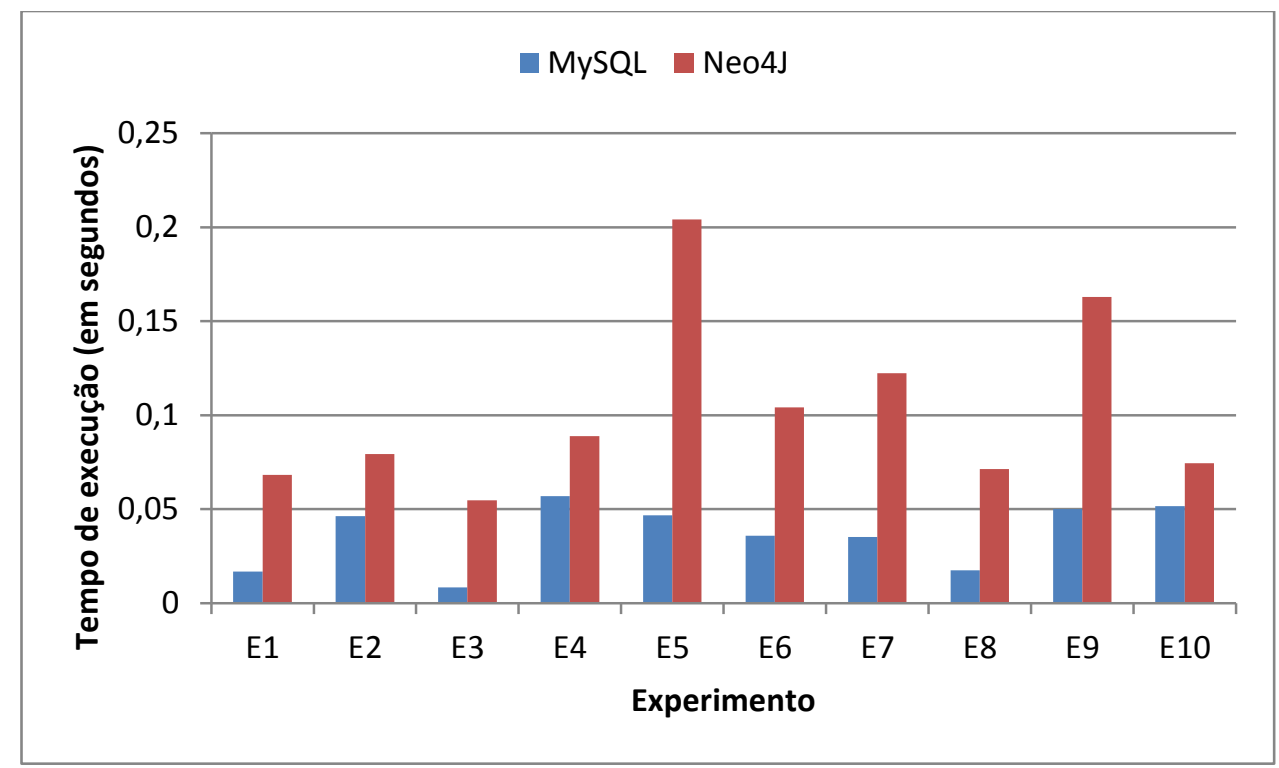

Figura 6.14: Gráfico do tempo de execução no BD2.

Fonte: Autor

A partir do BD3, o Neo4J começa a apresentar tempos de execução próximos do MySQL, sendo que somente no experimento 3, o MySQL obteve um resultado melhor e em 4 consultas o tempo de execução no Neo4J foi melhor. 


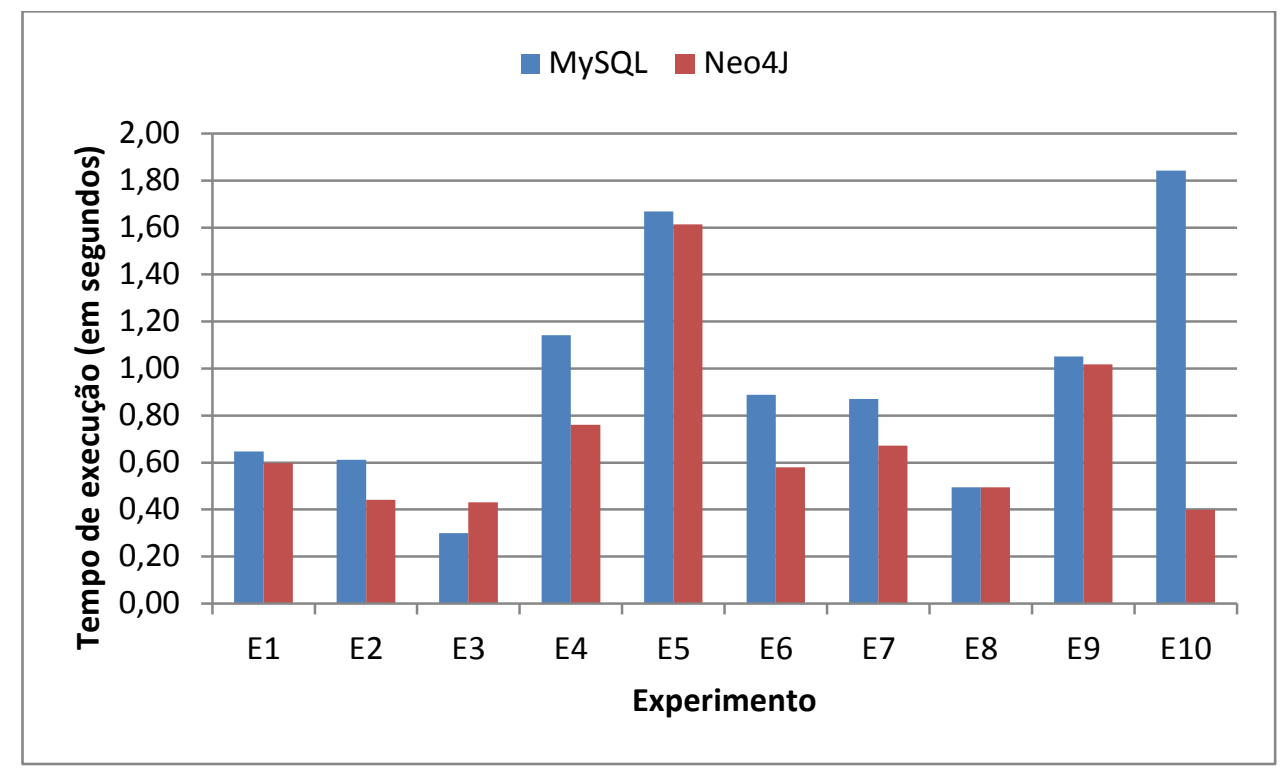

Figura 6.15: Gráfico do tempo de execução no BD3.

Fonte: Autor

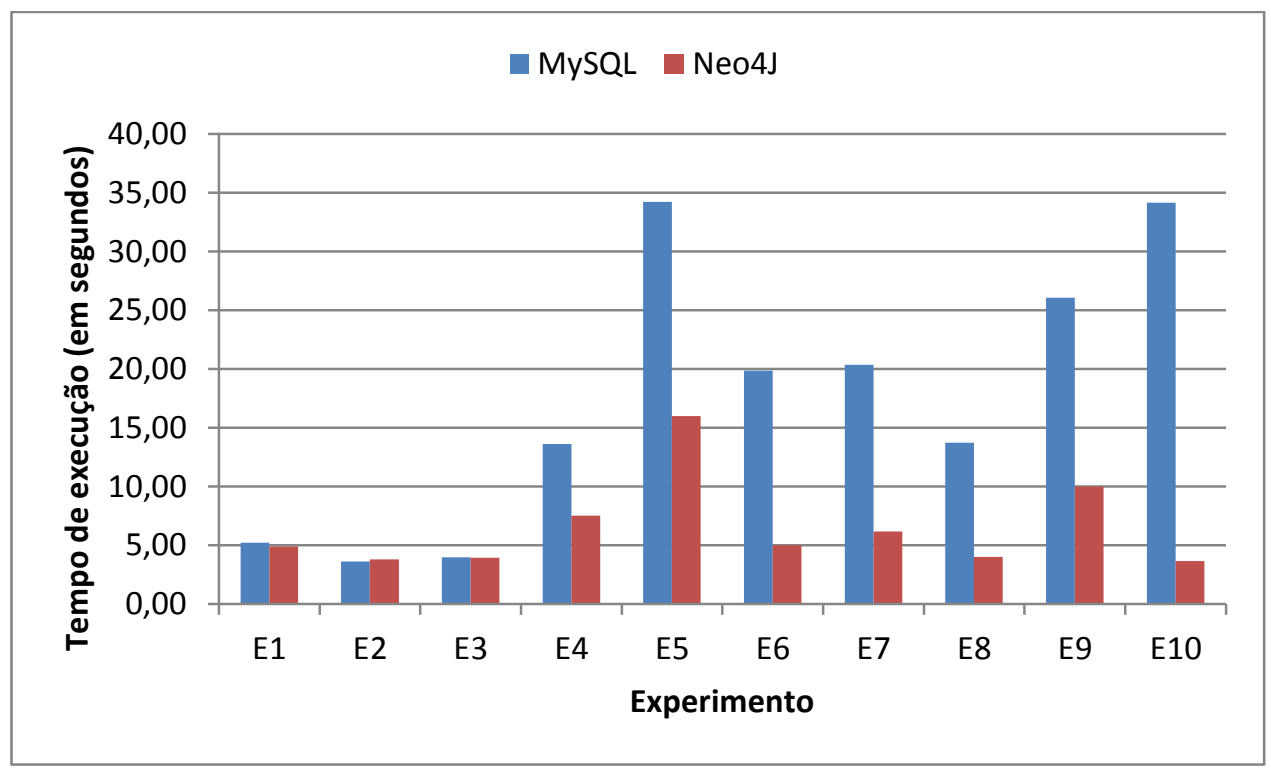

Figura 6.16: Gráfico do tempo de execução no BD4.

Fonte: Autor 


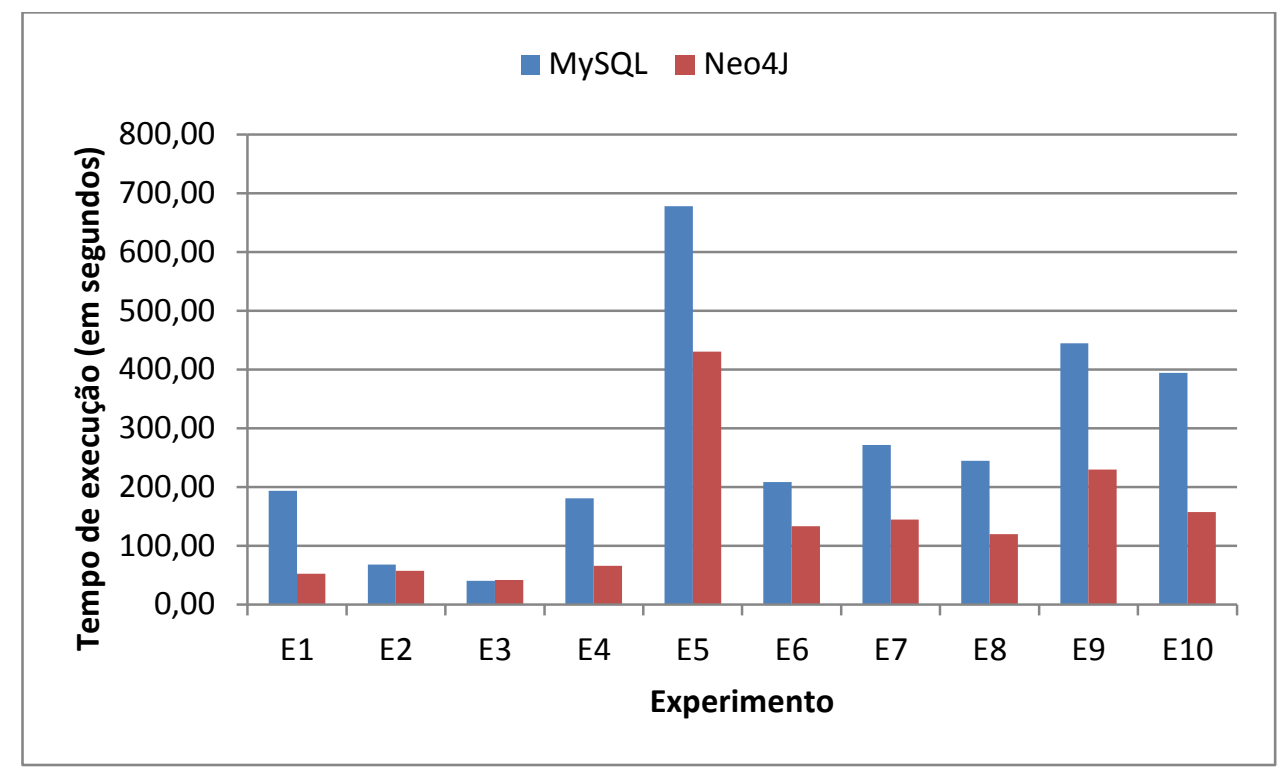

Figura 6.17: Gráfico do tempo de execução no BD5.

Fonte: Autor

$\mathrm{Na}$ média, os experimentos 1 e 2 apresentaram um resultado melhor no banco relacional do que no banco em grafos, porém nos outros oito experimentos o Neo4J obteve um tempo de execução menor. $\mathrm{O}$ Neo4J foi em média $16,63 \%$ mais rápido quando executado no banco BD3, 46,98\% no BD4 e por fim, 46,39\% mais rápido no BD5.

A maior diferença do tempo de execução ocorreu no experimento 6 nos BD3 e BD4, sendo 34,76\% e 74,79\% menor que o tempo de execução do MySQL.

\subsection{Tempo de execução na modelagem orientada a grafos}

Um dos motivos para que o tempo de execução ter sido menor no Neo4J é a divisão das buscas conforme a modelagem dos dados. Como no Neo4J, as relações dos autores com os documentos foram separados em NACIONAL e ESTRANGEIRO, então a consulta já era limitada em aproximadamente 50\% dos casos: 211.915 (54,97\%) relações NACIONAL e 173.611 (45,03\%) relações ESTRANGEIRO, conforme cada busca.

O experimento 5 iguala o número de autores ao fazer uma busca que não considera a nacionalidade da instituição do autor, com isto a busca no Neo4J teve de percorrer todas as duas relações existentes. Apesar disso, o tempo de execução do Neo4J foi 3,29\%, $53,25 \%$ e $36,52 \%$ menor nos bancos BD3, BD4 e BD5 respectivamente. Assim demonstrando que o modelo orientado a grafos teve uma resposta melhor mesmo em situação de igualdade da busca.

O experimento 6 tratava de uma contagem do número de autores nacionais, então 
enquanto o MySQL tinha que percorrer cada um dos autores para identificar qual a nacionalidade da instituição do autor, no caso do Neo4J esta busca já iniciava sabendo quais são estes autores.

Uma das vantagens de integrar o Neo4J ao MySQL é o de poder definir corretamente a modelagem conforme as consultas a serem executadas, desse modo simplificando o modelo para que seja o mais adequado para cada caso.

\subsection{Registros por Experimento}

Para cada um dos experimentos foi verificado o número de registros que tinham que ser percorridos para poder retornar a consulta. Para isso no MySQL foram somados o número de tuplas em cada uma das tabelas conforme a solicitação de cada experimento.

Já para o Neo4J, foram somados a quantidade de vértices dos documentos Web of Science e dos autores, conforme a sua relação NACIONAL e ESTRANGEIRO, assim verificando quantos vértices tinham de ser analisados para retornar a experimento.

Podemos dividir os experimentos em dois grupos, o primeiro com os experimentos $1 \mathrm{e}$ 2, que tiveram o mesmo número de registros consultados, e o segundo, com os experimentos 6 a 9 .

Conforme a análise pelo tempo de execução nesses dois grupos de experimentos, a quantidade de registros idêntica não significa que o tempo de execução vai ser próximo. Comparando os experimentos 6 e 9 temos uma diferença de até 113,18\% no tempo de execução no BD5. Já no grupo 1, a diferença do BD5 no MySQL chega a 380,08\%.

O mesmo ocorre no Neo4J, onde apesar do número de vértices percorridos serem os mesmos nos experimentos 1 até 4 e nos experimentos 6 até 9, o tempo de execução não mantém uma média, demonstrando que outros parâmetros são mais relevantes no tempo de execução de uma consulta.

\subsection{PARÂMETROS DE CONSULTA}

Em alguns experimentos foram realizadas consultas similares quanto ao número de tabelas e registros necessários porém com algumas mudanças quanto aos parâmetros de busca. A influência destes parâmetros nos resultados é vista a seguir.

\subsubsection{Cláusula GROUP BY}

Nos experimentos 1 e 2 e nos experimentos 6 e 7 foram realizadas as mesmas 
consultas quanto ao número de registros e de indireções, e no banco de dados orientado a grafos o número de vértices e tipo de relação manteve-se idêntico.

Em ambos os casos foi feito uma consulta inicial, na qual contava-se o número de ocorrências existentes e no experimento seguinte era adicionada uma cláusula GROUP BY. No MySQL, o impacto da inclusão desta cláusula no tempo de execução foi em média de $176,07 \%$ maior entre a experimento 2 comparado com o experimento 1 e de $10,25 \%$ maior quando comparado o experimento 6 e o 7 .

Já no Neo4J, o aumento do tempo de execução foi em média 29,92\% a mais entre os experimentos 1 e 2 e $15,83 \%$ a mais entre os experimentos 6 e 7.

Em ambos os modelos, a inclusão da cláusula GROUP BY aumentou o tempo de execução, porém o impacto decorrente desta inclusão no modelo relacional foi muito maior do que no modelo não relacional.

Um dos motivos é que a linguagem Cypher não possui o comando GROUP BY. Em seu lugar possui o comando COUNT, que oferece esta funcionalidade. A utilização desse comando é possível devido à estrutura de dados ser diferente, assim proporcionando melhor desempenho.

O modo como o GROUP BY é tratado internamente pelo Neo4J, e devido a sua estrutura, tratar melhor a quantidade de tabelas utilizadas, a diferença começa a ser bem expressivo.

\subsubsection{Operador IN}

O experimento 7 realizou a busca pelos estratos com A1, enquanto que o experimento 8 realizou a mesma busca utilizando o valor de estrato A2. No experimento 9 foi incluído o operador IN tendo as duas possibilidades A1 e A2 como fator de pesquisa.

Apesar do operador IN ser similar a uma busca por igualdade de cada um dos valores existentes nele, tanto no MySQL quanto no Neo4J foi melhor utilizar a cláusula IN do que realizar a busca individualmente e em sequencia, conforme a soma do tempo de execução obtidas.

A utilização o operador IN ainda é preferível do que executar uma busca por igualdade para cada um dos valores existentes dentro desta cláusula. Somando os tempos de execução das consultas 7 e 8, temos um tempo maior do que executando somente uma consulta com IN. Conforme pode ser visto na tabela 6.4: 
Tabela 6.4: Tempo de execução em segundos entre os experimentos 7, 8 e a 9.

\begin{tabular}{|l|l|l|c|c|c|}
\hline & BD1 & BD2 & BD3 & BD4 & BD5 \\
\hline MySQL - Q7 + Q8 & 0,065117 & 0,052605 & 1,36 & 34,1 & 516,21 \\
\hline MySQL - Q9 & 0,042696 & 0,049997 & 1,05 & 26,06 & 444,82 \\
\hline Neo4J - Q7 + Q8 & 0,06965 & 0,19375 & 1,16 & 10,15 & 264,10 \\
\hline Neo4J - Q9 & 0,048 & 0,162875 & 1,02 & 9,99 & 229,85 \\
\hline
\end{tabular}

\subsection{Análise do Número de Indireções}

A proposta dos experimentos foi verificar não somente os parâmetros de consulta, mas também como o número de indireções impacta o desempenho do banco de dados. Para isto a sequência dos 10 experimentos teve um aumento gradual do número de JOIN envolvidos, indo de somente um JOIN até nove JOIN's.

O experimento 1 possuía apenas um JOIN com uma condição de seleção e retornava uma contagem. Era uma consulta de baixa complexidade e que utilizava somente duas tabelas sem utilizar cláusulas adicionais. Nos bancos de dados criados, BD1, BD2, BD3 e BD5, o MySQL obteve um resultado melhor do que o Neo4J.

Apesar da alteração no experimento 2, com a inclusão das cláusulas GROUP BY e ORDER BY, mas mantendo somente um JOIN, tivemos que o Neo4J apresentou menores tempos de execução nos bancos BD3, BD4 e BD5. Isto devido ao modo como atua com estas cláusulas e não devido as indireções.

No experimento 3 tivemos um acréscimo de um JOIN, aumentando a indireção, o mesmo ocorreu no experimento 4 e 5, aumentando uma indireção em cada um destes experimentos. $\mathrm{O}$ experimento 3 teve um resultado dividido entre os dois modelos de dados, porém a partir do experimento 4 , com 3 JOIN, o modelo orientado a grafos começa a se destacar em todos os experimentos.

No experimento 4 o modelo Neo4J apresentou um resultado melhor nos bancos BD3, BD4 e BD5. Chegando a ter um tempo de execução quase duas vezes menor no BD3 e BD4 e 3 vezes menor no BD5.

O experimento 5 foi o que demandou maior tempo de execução, apesar de conter apenas 4 JOINs. Essa consulta tinha como característica não utilizar a condição de país da instituição do autor, deste modo não podendo usufruir de percorrer apenas uma das relações no banco de dados Neo4J e de não pode utilizar o índice de país existente no 
MySQL. Neste experimento o Neo4J obteve um tempo de execução similar ao do MySQL no BD3, contudo foi quase 2 vezes melhor no BD4 e 1,5 vezes melhor no BD5.

Os experimentos de 6 a 9 possuíam o mesmo número de indireções: 5 JOIN, e utilizavam todas as tabelas existentes no modelo relacional. $O$ intuito destes 4 experimentos foi o de verificar a influência das cláusulas de consulta, porém também de verificar a influência de um uso maior de indireções.

Tanto o experimento 1 quanto o experimento 6 realizavam uma consulta que retornava uma contagem. A variação ficou na quantidade de indireções existentes. Nos bancos $\mathrm{BD} 3, \mathrm{BD} 4$ e BD5, comparando o resultado obtidos pelo experimento 6 com resultados do experimento 1 , verificamos que a diferença da inclusão dos JOIN teve um impacto maior no MySQL. Enquanto que no experimento 1 os tempos de execução foram muito similares, no experimento 6 é visível a influência da indireção. A Figura 6.18 apresenta esta diferença do tempo de execução.

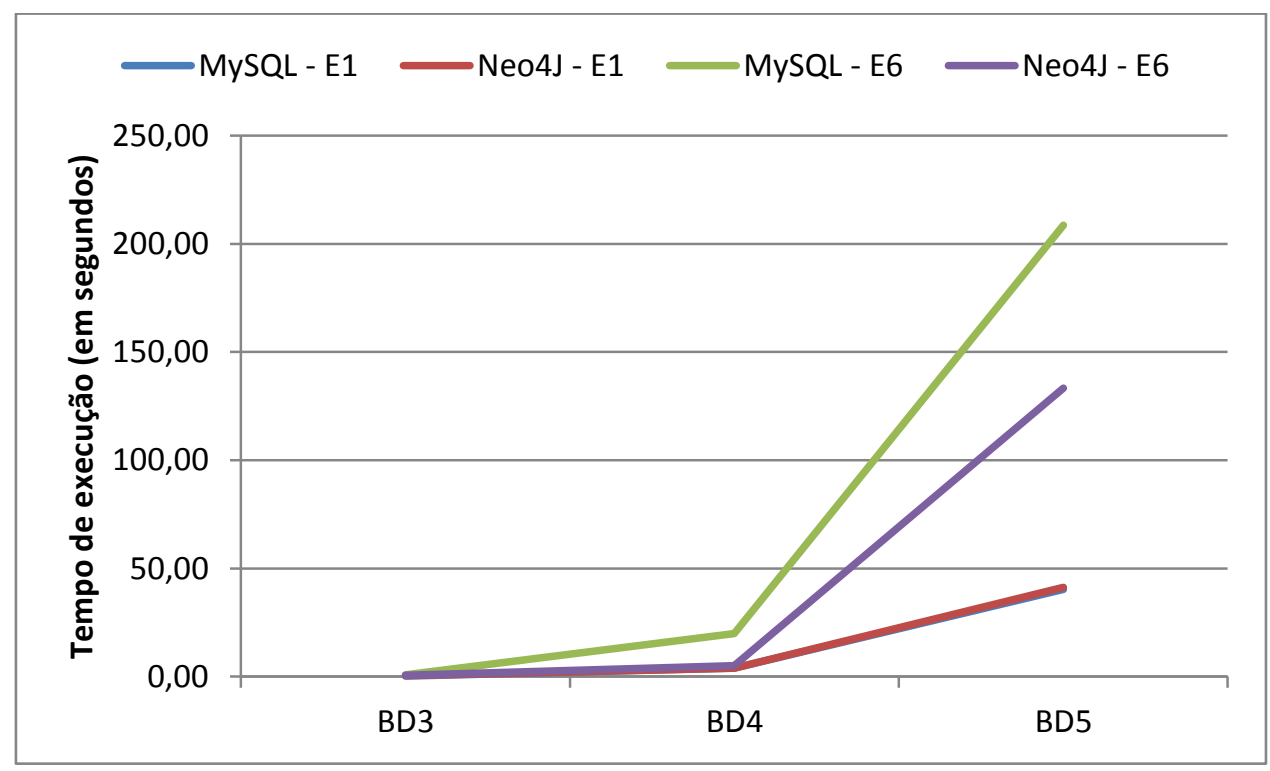

Figura 6.18: Desempenho entre os experimentos 1 e 6 .

Fonte: Autor

Os experimentos 7, 8 e 9 foram elaborados para verificar as influências das cláusulas, principalmente a cláusula IN. Apesar da inclusão desta cláusula de busca, o Neo4J também teve um resultado melhor do que o MySQL nos bancos de dados BD3, BD4 e BD5.

No experimento 10 foram utilizados um maior número de indireções, 9 JOIN's. Com isto permitindo estudar como os dois modelos de bancos de dados atuam em situações 
mais complexas. No caso do BD4, o Neo4J executou o experimento quase 10 vezes mais rápido do que o MySQL. Já no BD5 foi mais de 2,5 vezes melhor e por fím no BD3 mais de 4,5 vezes melhor.

\subsection{Considerações finais}

Os estudos propostos foram muito relevantes para perceber as características de cada uma das consultas nos dois modelos de bancos de dados.

Verificou-se que quanto ao armazenamento e o uso de memória, o banco de dados relacional necessita de menos espaço e memória do que o banco de dados orientado a grafos, isto devido a estrutura interna de cada um dos modelos e ao modo como foram implementados.

Quanto ao tempo de execução, conforme os volumes de dados, nas situações em que o número de registros era bem pequeno, como no $\mathrm{BD} 1$ e no $\mathrm{BD} 2$, o modelo relacional obteve um resultado melhor, independente do tipo de consulta ou da quantidade de indireções envolvidas. Porém, conforme o volume de dados foi aumentando, o desempenho do modelo relacional foi ficando mais lento, conforme a comparação com o tempo de execução obtido pelo modelo em grafos.

Nos bancos de dados BD3, BD4 e BD5, que possuíam um volume de dados maior, constatou-se que, para consultas que tinham mais de três JOIN, o uso de um banco de dados orientado a grafos é mais indicado. Nestas situações o tempo de execução do Neo4J se sobressaiu em relação ao tempo obtido pelo modelo relacional, devido principalmente ao uso da adjacência livre de índice.

Graças a essa característica do Neo4J e também à possibilidade de se modelar o banco orientado a grafos conforme a necessidade, permitiu-se usufruir inteiramente da estrutura em que o banco de dados orientado a grafos foi desenvolvido. Isso ficou evidente conforme o aumento do número de indireções e conforme o uso de algumas cláusulas, como o GROUP BY, que são tratadas de modo diferenciado no Neo4J.

Conforme a Tabela 6.5 , que contém a variação entre os tempos médios obtidos nos bancos de dados BD3, BD4 e BD5, e considerando o experimento 4 em diante, 3 JOIN ou mais, percebe-se que o Neo4J se destaca, tendo uma média de diferença de tempo de $25,09 \%$ melhor para o BD3, 66,37\% no BD4 e 48,91\% de diferença no BD5. 
Tabela 6.5: Variação do tempo médio nos experimentos.

\begin{tabular}{|c|r|c|c|}
\hline Experimento & \multicolumn{1}{|c|}{ BD3 } & BD4 & BD5 \\
\hline E4 & $33,30 \%$ & $44,80 \%$ & $63,39 \%$ \\
\hline E5 & $3,29 \%$ & $53,25 \%$ & $36,52 \%$ \\
\hline E6 & $34,76 \%$ & $74,79 \%$ & $36,10 \%$ \\
\hline E7 & $22,71 \%$ & $69,77 \%$ & $46,79 \%$ \\
\hline E8 & $-0,04 \%$ & $70,98 \%$ & $51,10 \%$ \\
\hline E9 & $3,28 \%$ & $61,66 \%$ & $48,33 \%$ \\
\hline E10 & $78,34 \%$ & $89,33 \%$ & $60,14 \%$ \\
\hline
\end{tabular}

Por meio do experimento 10 pode-se perceber o quanto o número de indireções maior influenciou na execução das consultas existente no experimento. Sendo 78,34\% menor no BD3 e 60,14\% no BD5. Considerando que neste experimento o tempo médio de execução no Neo4J foi de 157,287 segundos já no MySQL tivemos 394,565 segundos, ou seja, um aumento de aproximadamente 2 minutos e meio para 6 minutos e meio. 


\section{Capítulo 7}

\section{Conclusões}

Neste capítulo são apresentadas as conclusões do trabalho. Encontra-se dividido em três seções: contextualização, contribuições e trabalhos futuros.

\subsection{Contextualização}

O objetivo deste trabalho foi propor um método de integração entre o banco de dados relacional e o banco de dados orientado a grafos, no qual se mantenha integro as informações existentes no modelo relacional e por meio deste banco gerar bancos de dados orientados a grafos com a finalidade de atender a demanda da parte analítica das informações.

Para esta proposta ser viável era necessário verificar em quais situações o modelo não relacional se sobressai ao modelo relacional. Como utilizamos um caso de testes real, com as particularidades próprias de cada tabela e dados, as conclusões são direcionadas a mais a este caso, podendo não gerar resultados similares em outros estudos com bancos de dados diferentes.

Como o Neo4J utiliza a adjacência livre de índice, esta propriedade é um diferencial quando se executa consultas de travessia ou cujos dados podem ser alocados na memória. Deste modo aproveitando esta característica do Neo4J aplicada ao MySQL.

Conforme os resultados obtidos, fazer uma integração entre o modelo relacional e o modelo orientado a grafo é pertinente quando o volume de dados for significativo, o número de indireções for relativamente grande (no caso maior que 3 JOIN) e o sincronismo imediato entre o dado operacional e analítico não seja um fator crítico.

Nessas situações o modelo orientado a grafos atende bem a necessidade de realizar consultas relacionais com alto grau de indireção com um tempo de retorno menor.

Outro fator importante é que uma boa modelagem do banco de dados orientado a grafos deve ser feita, de modo a atender a todas as consultas possíveis, pois qualquer variação não prevista acarretará um custo no tempo de execução. 
Este trabalho delimitou e caracterizou que bancos de dados orientados a grafos possuem muito mais vantagens para trabalhar com redes de colaboração do que o modelo relacional, isto devido a sua estrutura e modo como os dados são tratados, além da flexibilidade de criar novos modelos conforme cada necessidade.

Com isto, este trabalho atesta a viabilidade de intergrar o banco de dados relacional com o banco de dados em grafos com a finalidade de ser utilizado para a parte analítica, desde que a necessidade de atualização dos dados não seja crucial.

\subsection{Contribuições}

Foram realizadas comparações entre os modelos orientados a grafos e o relacional visando identificar quais fatores são relevantes ao se executar consultas no modelo relacional ou o modelo orientado a grafos.

Constatou-se que existem vantagens em se utilizar o banco de dados orientado a grafos para pesquisa com várias indireções, comprovando as vantagens da adjacência livre de índice.

A caracterização das consultas com a explicitação de parâmetros que norteiam suas execuções nos bancos de dados relacionais ou orientado a grafos foi uma identificação bem relevante. Conforme verificado, consultas com alto grau de indireção executadas em bancos de dados com grande volume de dados são melhores atendidas pelo modelo orientado a grafo.

A influência no tempo de execução das consultas, ao se introduzir cláusulas de pesquisa, como o GROUP BY e o operador IN, pôde ser observada. A inclusão do GROUP BY é importante, pois ratifica que o modelo de dados orientado a grafos possui uma estrutura de dados diferente. Este comando é interpretado de outra forma, sendo assim com melhor desempenho.

Já no caso do operador IN, apesar da redução de desempenho em ambos os modelos, é mais conveniente utilizá-lo que se executá-lo em várias consultas para atender a uma pesquisa.

Uma contribuição relacionada a este trabalho e que motivou a necessidade de consultas eficientes para avaliar redes de colaboração dos autores foi a publicação do capítulo "DataUSP-PosGrad: Um conjunto de Serviços Analíticos para Apoio à Tomada de Decisão da PRPG USP" no livro "USP 80 anos”, [Ferreira 2015]

Uma outra contribuição no qual este trabalho se insere e será implementado é o artigo 
publicado: "DataUSP: Conjunto de Serviços Analíticos para Apoio à Tomada de Decisões em uma Instituição de Ensino Superior” [Catarino 2016]

\subsection{Trabalhos futuros}

Quanto aos trabalhos futuros, as possibilidades apresentadas a seguir complementam o estudo deste trabalho tendo como base a conclusão de que o banco de dados orientado a grafos pode ser integrado ao banco de dados relacional quando este necessita atender as consultas com grande número de indireções e com um volume de dados considerável.

Sendo o Neo4J um banco de dados de código livre, seria útil estudar uma integração automatizada entre os dois modelos, na qual fosse possível realizar configurações nas tabelas a serem utilizadas.

Por fim, após o resultado deste trabalho, seria oportuno realizar análises nas informações extraídas da Plataforma Sucupira, Web of Science e da Universidade de São Paulo a fim de compreender melhor as relações existentes entre a internacionalização e o desempenho de um programa de pós-graduação. 


\section{Apêndice A}

\section{Scripts para criação das tabelas para o Mysql}

Este apêndice contém os scripts que foram utilizados para a criação das tabelas utilizadas no modelo relacional.

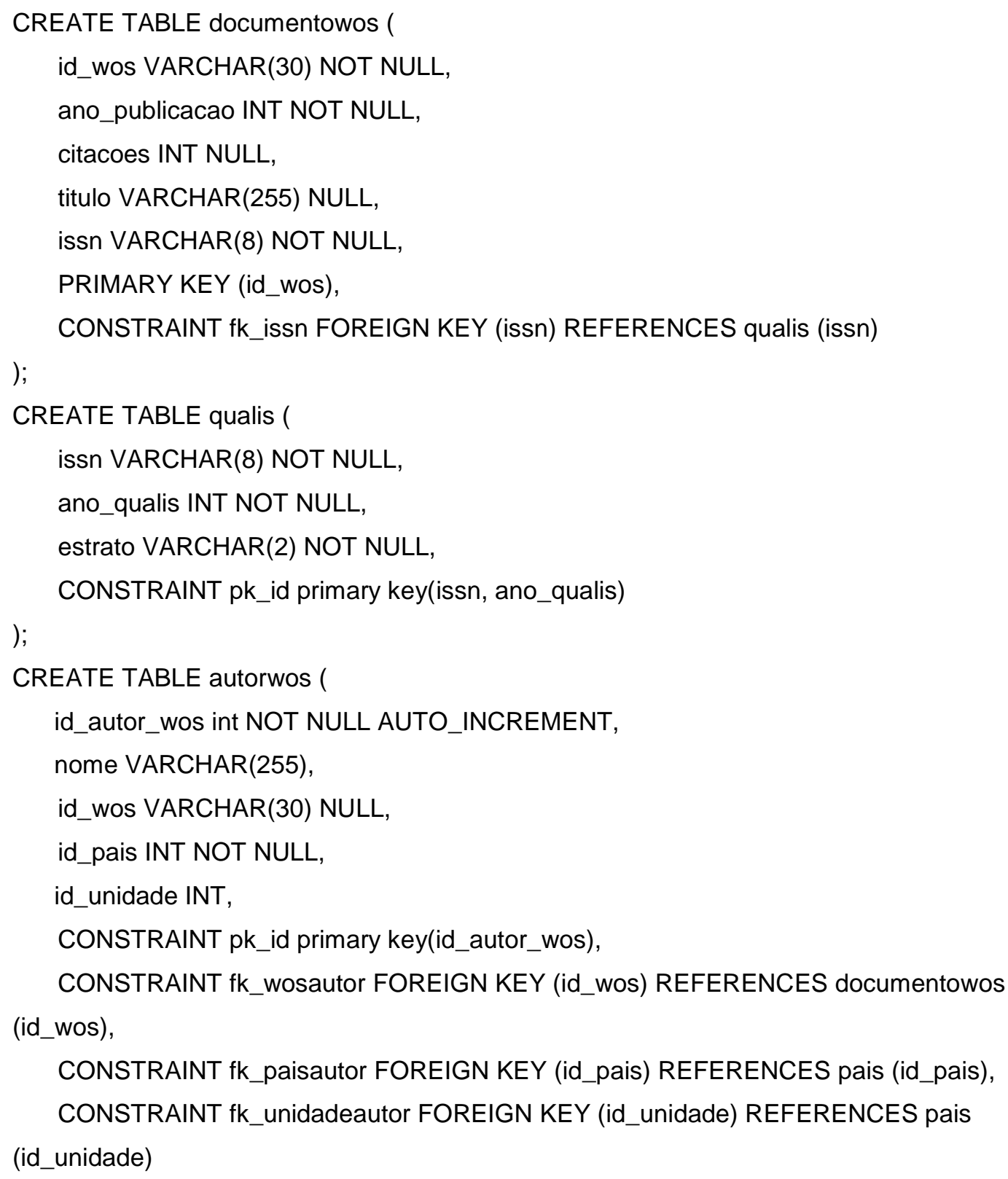

CONSTRAINT fk_paisautor FOREIGN KEY (id_pais) REFERENCES pais (id_pais), CONSTRAINT fk_unidadeautor FOREIGN KEY (id_unidade) REFERENCES pais (id_unidade) 


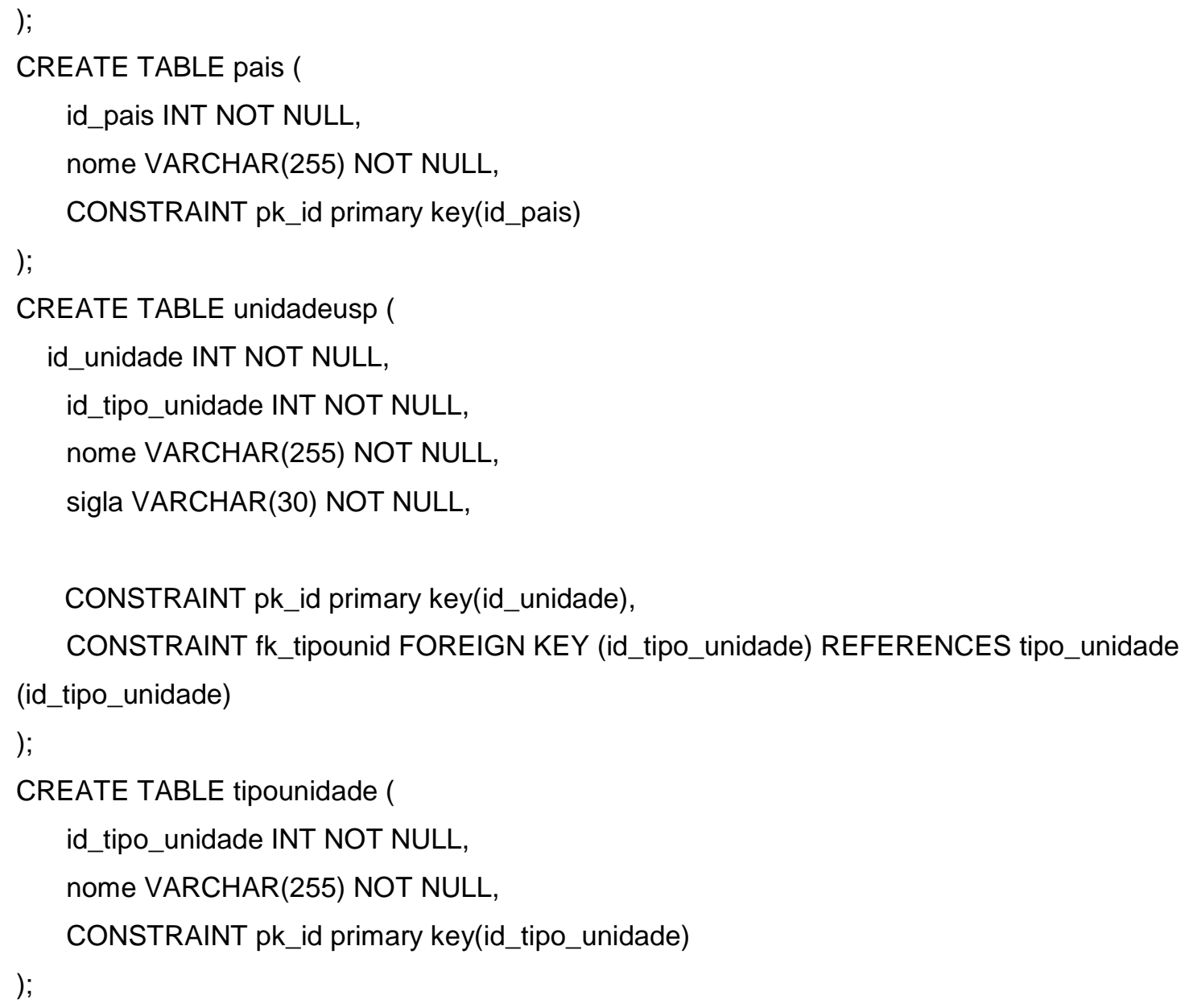




\section{Apêndice B}

\section{Consultas em SQL para o Mysql}

Este apêndice contém as consultas que foram utilizadas em cada um dos experimentos, escritas na linguagem SQL, conforme o padrão do banco de dados MySQL.

\section{Consulta 1:}

SELECT count(a.id_wos) as publicacoes FROM autorwos as a USE INDEX (idxa_wos) INNER JOIN pais as $\mathrm{p}$ ON (a.id_pais = p.id_pais AND p.nome <> 'Brazil');

\section{Consulta 2:}

SELECT a.id_wos, count(a.id_wos) as publicacoes FROM autorwos as a

INNER JOIN pais as $\mathrm{p}$ ON (a.id_pais = p.id_pais AND p.nome <> 'Brazil')

GROUP BY id_wOS

ORDER BY publicacoes;

\section{Consulta 3:}

SELECT distinct d.id_wos, d.titulo, d.citacoes FROM autorwos as u

INNER JOIN documentowOS as d ON (d.id_wOS = u.id_wOS) INNER JOIN pais as p ON (p.id_pais = u.id_pais AND p.nome = 'USA') ORDER BY d.citacoe;

\section{Consulta 4:}

SELECT q.estrato, count(distinct d.id_wos) as quantidade FROM autorwos as a

INNER JOIN documentowOS as d ON (a.id_wOS $=$ d.id_wOS)

INNER JOIN qualis as $q$ ON (d.issn = q.issn AND d.ano_publicacao = 
q.ano_qualis)

INNER JOIN pais as $p$ ON (a.id_pais = p.id_pais AND p.nome <> 'Brazil')

GROUP BY q.estrato;

\section{Consulta 5:}

SELECT un.nome, count(distinct a.id_autor_wos) as autores FROM autorwos as a

INNER JOIN documentowos as d ON (d.id_wos $=$ a.id_wos)

INNER JOIN qualis as $q$ ON (d.issn = q.issn and d.ano_publicacao = q.ano_qualis and q.estrato in ('A1', 'A2'))

INNER JOIN unidadeusp as un ON (un.id_unidade = a.id_unidade)

INNER JOIN tipo_unidade as $t$ ON (t.id_tipo_unidade = un.id_tipo_unidade AND t.id_tipo_unidade $=2$ )

GROUP BY un.id_unidade

ORDER BY autores;

\section{Consulta 6:}

SELECT count(distinct a.id_autor_wos) FROM autorwos as a

INNER JOIN documentowos as d ON (d.id_wos $=$ a.id_wos)

INNER JOIN pais as $\mathrm{p}$ ON (p.id_pais = a.id_pais AND p.nome = 'Brazil')

INNER JOIN qualis as $q$ ON (d.issn $=$ q.issn and d.ano_publicacao = q.ano_qualis and $q$.estrato = 'Al')

INNER JOIN unidadeusp as un ON (un.id_unidade = a.id_unidade)

INNER JOIN tipo_unidade as $t$ ON (t.id_tipo_unidade = un.id_tipo_unidade AND t.id_tipo_unidade $=2$ );

\section{Consulta 7:}

SELECT un.nome, count(distinct a.id_autor_wos) as autores

FROM autorwos as a

INNER JOIN documentowos as d ON (d.id_wos = a.id_wOS)

INNER JOIN pais as $\mathrm{p}$ ON (p.id_pais = a.id_pais AND p.nome = 'Brazil')

INNER JOIN qualis as $q$ ON (d.issn $=$ q.issn and d.ano_publicacao $=$ q.ano_qualis and $q$.estrato = 'Al')

INNER JOIN unidadeusp as un ON (un.id_unidade = a.id_unidade)

INNER JOIN tipo_unidade as $t$ ON (t.id_tipo_unidade = 
un.id_tipo_unidade AND t.id_tipo_unidade $=2$ )

GROUP BY un.id_unidade

ORDER BY autores DESC LIMIT 10;

\section{Consulta 8:}

SELECT un.nome, count(distinct a.id_autor_wos) as autores

FROM autorwos as a

INNER JOIN documentowos as d ON (d.id_wOS = a.id_wOS)

INNER JOIN pais as $\mathrm{p}$ ON (p.id_pais = a.id_pais AND p.nome = 'Brazil')

INNER JOIN qualis as $q$ ON (d.issn $=$ q.issn and d.ano_publicacao $=$ q.ano_qualis and q.estrato = 'A2')

INNER JOIN unidadeusp as un ON (un.id_unidade = a.id_unidade)

INNER JOIN tipo_unidade as $t$ ON (t.id_tipo_unidade= un.id_tipo_unidade AND t.id_tipo_unidade = 2)

GROUP BY un.id_unidade

ORDER BY autores DESC LIMIT 10;

\section{Consulta 9:}

SELECT un.nome, count(distinct a.id_autor_wos) as autores FROM autorwos as a

INNER JOIN documentowos as d ON (d.id_wOS $=$ a.id_wOS)

INNER JOIN pais as $\mathrm{p}$ ON (p.id_pais = a.id_pais AND p.nome = 'Brazil')

INNER JOIN qualis as $q$ ON (d.issn $=$ q.issn and d.ano_publicacao $=$ q.ano_qualis and q.estrato in ('A1', 'A2'))

INNER JOIN unidadeusp as un ON (un.id_unidade $=$ a.id_unidade)

INNER JOIN tipo_unidade as $t$ ON (t.id_tipo_unidade= un.id_tipo_unidade AND t.id_tipo_unidade $=2$ )

GROUP BY un.id_unidade

ORDER BY autores DESC LIMIT 10;

\section{Consulta 10:}

SELECT un.nome, count(distinct a.id_autor_wos) as autores FROM autorwos as a

INNER JOIN documentowos as d ON (d.id_wOS $=$ a.id_wOS)

INNER JOIN pais as $\mathrm{p}$ ON (p.id_pais = a.id_pais AND p.nome = 
'Brazil')

INNER JOIN qualis as $q$ ON (d.issn $=$ q.issn and d.ano_publicacao = q.ano_qualis and q.estrato in ('A1', 'A2'))

INNER JOIN unidadeusp as un ON (un.id_unidade = a.id_unidade)

INNER JOIN tipo_unidade as $t$ ON (t.id_tipo_unidade = un.id_tipo_unidade AND t.id_tipo_unidade $=2$ )

INNER JOIN autorwos as e ON (d.id_wos $=$ e.id_wos)

INNER JOIN pais as ep ON (ep.id_pais = e.id_pais AND ep.nome = 'Brazil')

INNER JOIN unidadeusp as eun ON (eun.id_unidade $=$ e.id_unidade and eun.id_unidade $<>$ a.id_unidade)

INNER JOIN tipo_unidade as et ON (et.id_tipo_unidade= eun.id_tipo_unidade AND et.id_tipo_unidade $=2$ )

GROUP BY un.id_unidade

ORDER BY autores DESC LIMIT 10; 


\section{Apêndice $\mathbf{C}$}

\section{Consultas na linguagem Cypher do Neo4J}

Este apêndice contém as consultas que foram utilizadas em cada um dos experimentos, escritas na linguagem Cypher, conforme o padrão do banco de dados orientado a grafos Neo4J.

\section{Consulta 1:}

MATCH (d:WOs) - $[r:$ ESTRANGEIRO $]->(a$ :Autorwos $)$

RETURN count (d.wOSID) ;

\section{Consulta 2:}

MATCH (d:Wos) - $r$ :ESTRANGEIRO $]->(a$ :Autorwos $)$

RETURN d.wOsID, count $(*)$

ORDER BY count (*) DESC LIMIT 10;

\section{Consulta 3:}

MATCH (d:Wos) - $[r:$ ESTRANGEIRO $]->(a:$ Autorwos $)$

WHERE a.pais = 'USA'

RETURN d.wosID, d.titulo, d.citacoes

ORDER BY d.citacoes DESC LIMIT 10;

\section{Consulta 4:}

MATCH (d:Wos) - $[r:$ ESTRANGEIRO $]->(a$ :Autorwos $)$

RETURN d.estrato, count (distinct d.wosID) as quantidade

ORDER BY d.estrato;

\section{Consulta 5:}

MATCH (d:Wos) - []-> (a:Autorwos $)$

WHERE d.estrato IN ['A1', 'A2']

RETURN a.unidade, count (distinct a.autorID) as total

ORDER BY total DESC limit 10; 


\section{Consulta 6:}

MATCH (d:Wos) $-[r:$ NACIONAL $]->(a:$ Autorwos $)$

WHERE d.estrato = 'Al' and a.sigla $<>$ '' and a.tipo = 'Ensino e Pesquisa'

RETURN count(distinct a.autorID);

\section{Consulta 7:}

MATCH (d:WOs) $-[r:$ NACIONAL $]->(a$ :Autorwos $)$

WHERE d.estrato $=$ 'A1'

RETURN a.unidade, count(distinct a.autorID) as total

ORDER BY total DESC limit 10;

\section{Consulta 8:}

MATCH (d:Wos $)-[r:$ NACIONAL $]->(a:$ Autorwos $)$

WHERE d.estrato $=$ 'A2'

RETURN a.unidade, count(distinct a.autorID) as total

ORDER BY total DESC limit 10;

\section{Consulta 9:}

MATCH (d:Wos) - $r:$ NACIONAL $]->(a:$ Autorwos $)$

WHERE d.estrato IN ['A1', 'A2']

RETURN a.unidade, count(distinct a.autorID) as total

ORDER BY total DESC limit 10;

\section{Consulta 10:}

MATCH (d:Wos) $-[r:$ NACIONAL $]->(a:$ Autorwos $)$

WHERE d.estrato IN ['A1', 'A2']

AND toInt (d.unidades) $>=2$

RETURN a.unidade, count(distinct a.autorID) as total

ORDER BY total DESC limit 10; 


\section{Apêndice D}

\section{Script de importação dos arquivos}

Os scripts que foram executados para importar as informações para as tabelas do banco de dados MySQL juntamente com a quantidade de linhas inseridas:

LOAD DATA INFILE 'documentowos.txt' INTO TABLE documentowos FIELDS TERMINATED BY

';' ENCLOSED BY '"' LINES TERMINATED BY 'In';

Foram considerados somente os documentos que tinham ISSN cadastrado, assim dos 67.349 documentos obtidos, 1.718 foram descartados, totalizando 65.631 documentos únicos do Web of Science carregados no banco de dados.

LOAD DATA INFILE 'qualis.txt' INTO TABLE qualis FIELDS TERMINATED BY ';' ENCLOSED BY

'"' LINES TERMINATED BY ' In';

Foram carregados 244.109 publicações com seus referidos estratos por ano de avaliação Qualis e área de avaliação Capes. O tratamento dos dados para manter somente o estrato com o maior valor no ano de avaliação foi feito posteriormente a carga.

LOAD DATA INFILE 'tipo_unidade.txt' INTO TABLE tipo_unidade FIELDS TERMINATED BY ';' ENCLOSED BY "'" LINES TERMINATED BY ' $n$ ';

Sendo inserido 6 tipos de unidade.

LOAD DATA INFILE 'unidadeusp.txt' INTO TABLE unidadeusp FIELDS TERMINATED BY ';' ENCLOSED BY '"' LINES TERMINATED BY 'In';

Foram carregadas 101 unidades da Universidade de São Paulo.

LOAD DATA INFILE 'pais.txt' INTO TABLE pais FIELDS TERMINATED BY ';' ENCLOSED BY '"' LINES TERMINATED BY 'In';

Onde foram inseridos 152 países. 
LOAD DATA INFILE 'autorwos.txt' INTO TABLE autorwos FIELDS TERMINATED BY ';'

ENCLOSED BY '"' LINES TERMINATED BY 'In';

Foram inseridos 352.642 autores, incluindo os autores que são docentes da Universidade de São Paulo. 


\section{Referências Bibliográficas}

Abadi, D. J., Marcus, A., Madden, S. R., and Hollenbach, K. (2009). Sw-store: A vertically partitioned dbms for semantic web data management. The VLDB Journal, 18(2):385-406.

Abramova (2014a), V. and Jorge Bernardino and Furtado, P., Experimental Evaluation of NoSQL Database, International Journal of Database Management Systems (IJDMS), vol. 6, pp. 1-16, 2014.

Abramova V, Bernardino J, Furtado P (2014b). Which nosql database? a performance overview. Open J Databases (OJDB) 1(2): 17-24.

Aho, A. and Ullman, J. (1995). Foundations of Computer Science: C Edition. Principles of Computer Science Series. W. H. Freeman.

Ahuja, S. P. and Moore, B. (2013). State of Big Data Analysis in the Cloud. Network and Communication Technologies, 2(1), p62. doi:10.5539/nct.v2n1p62.

Alves, B. R., Pavanelli, M. A. and Oliveira, E. F. T. (2014). Rede de coautoria institucional em Ciência da Informação: uma comparação entre indicadores de rede e os conceitos CAPES, Revista da Faculdade de Biblioteconomia e Comunicação da UFRGS, v. 20, n.3 - Edição Especial 2014.

Angles, R., Gutierrez, C. (2008). Survey of Graph Database Models, ACM Computing Surveys (CSUR) 2008.

Angles, R. (2012). A Comparison of Current Graph Database Models, ICDEW '12 Proceedings of the 2012 IEEE 28th International Conference on Data Engineering Workshops, Pages 171-177, 2012.

Aniche, M. F., Oliva, G. A. and Gerosa, M. A. (2014). Are the Methods in Your Data Access Objects (DAOs) in the Right Place? A Preliminary Study. In: Proceeding: MTD '14 Proceedings of the 2014 Sixth International Workshop on Managing Technical Debt. Pages 47-50, 2014.

Autran, M. M. M., Borges, M. M., Mena-Chalco, J. P., Pinheiro, V. G. (2015). Perfil de produção acadêmica dos programas brasileiros de pós-graduação em Ciência da Informação 2008-2012. Perspectivas em Ciência da Informação (Impresso), v. 20, p. 57-78, 2015.

Balancieri, R. et al. (2005). A Análise de redes de colaboração científica sob as novas tecnologias da informação e comunicação: um estudo na Plataforma Lattes. Ciência da Informação, Brasília, v. 34, n. 1, p. 64-77, jan./abr. 2005. 
Barmpis, K and Kolovos, D. ( 2014), 'Evaluation of Contemporary Graph Databases for Efficient Persistence of Large-Scale Models' Journal of Object Technology, vol 13, no. 3, pp. 3:1-26, 2014.

Batra, S. and Tyagi, C. (2012). Comparative Analysis of Relational And Graph Databases, Thapar University, Patiala, India, 2012, International Journal of Soft Computing and Engineering (IJSCE) ISSN: 2231-2307, Volume-2, Issue-2, May 2012.

Beaver, Donald B. and Rosen, R. (1979). Studies in scientific collaboration: part III: professionalization and the natural history of modern scientific co-authorship. Scientometrics, v. 1, p. 231-245, 1979.

Boicea, A., Radulescu, F., and Agapin, L. I. (2012). MongoDB vs Oracle - Database Comparison. MongoDB vs Oracle - database comparison, pages 330-335.

Bondy, A. and Murty, U. (2008). Graph theory. New York: Springer, 2008. (Graduate Texts in Mathematics).

Brito, R. W. (2010). Bancos de Dados NoSQL x SGBDs Relacionais: Análise Comparativa.

Capes (2016). Capes web site. http://www.capes.gov.br/.

Catarino, M. H.; Padilha, B.; Ferreira, J. E.. DataUSP: Conjunto de Serviços Analíticos para Apoio à Tomada de Decisões em uma Instituição de Ensino Superior. In: XII Escola Regional de Banco de Dados, 2016, Londrina. Anais da XII Escola Regional de Banco de Dados, 2016. p. 143-146.

Cattell, R., (2010). Scalable SQL and NoSQL Data Stores, ACM SIGMOD Record archive, Volume 39 Issue 4, December 2010, Pages 12-27

Chadegani, A. A. (2013). Comparison between Two Main Academic Literature Collections: Web of Science and Scopus Databases, Asian Social Science; Vol. 9, No. 5; 2013.

Chang, F. et al. (2006). Bigtable: A Distributed Storage System for Structured Data, in OSDI'06: Seventh Symposium on Operating System Design and Implementation, Seattle, WA, November, 2006.

Chaudhuri, S and Dayal, U. (1997). An Overview of Data Warehousing and OLAP Technology. ACM Sigmod Record, 26(1):65-74, 1997

Cheng, J., Ke, Y., Ng, W.: (2009). Efficient query processing on graph databases. ACM Trans. Database Syst. (TODS) 34(1), 2, 2009.

Chodorow, K., (2013) MongoDB: the definitive guide. " O’Reilly Media, Inc.”, 2013.

Ciglan, M., Averbuch, A. and Hluchy, L. (2012). Benchmarking Traversal Operations over Graph Databases, ICDEW, 2012, 2013 IEEE 29th International Conference on Data Engineering Workshops (ICDEW), 2013 IEEE 29th International Conference on Data Engineering Workshops (ICDEW) 2012, pp. 186-189, doi:10.1109/ICDEW.2012.47 
Codd, E. F. (1970). A relational model of data for large shared data banks. Commun. ACM, New York, NY, USA, v. 13, n. 6, p. 377-387, Jun. 1970.

Cormen, T. H.; Leiserson, C. E.; Rivert, R. L.; Stein, C. (2001). Introduction to algorithms. Massachusetts - USA: The MIT Press, 2001

CouchDB (2016). CouchDB web site. http://couchdb.apache.org/.

Cronin, B. (2005). The hand of science: academic writing and rewards. Oxford: Scarecrow Press, 2005. 214 p.

Curé, O., Kerdjoudj, F., Faye, D., C., Duc, C. L. and Lamolle, M., (2012). On the Potential Integration of an Ontology-Based Data Access Approach in NoSQL Stores. IEEE Computer Society. Emerging Intelligent Data and Web Technologies, Sep 2012, Bucarest, Romania. pp.166-173, 2012.

Curé, O., Hecth, R., Faye, D., C., Duc, C. L. and Lamolle, M., (2011). Data Integration over NoSQL Stores Using Access Path Based Mappings. DEXA 2012, Aug 2011, Toulouse, France. 6860, pp.481-495, 2011, Lecture Notes in Computer Science.

DB-Engines (2016). Db-engines web site. http://db-engines.com/en/ranking.

DeCandia, G. et al. (2007). Dynamo: amazon's highly available key-value Store, ACM SIGOPS Operating Systems Review - SOSP '07 Homepage, Volume 41 Issue 6, December 2007, Pages 205-220, 2007.

de Souza, V., C., O. and dos Santos, M., V., C. (2015). Maturing, Consolidation and Performance of NoSQL Databases - Comparative Study, SBIS 2015 Proceedings. Paper 69, 2015

Eclipse (2016). Eclipse web site. https://eclipse.org/

Elmasri, R.; Navathe, S. B. (2011). Sistemas de banco de dados. 6. ed. Pearson Education, Set. 2011.

Escobar, G.A.P. ; Pabon, O.S. (2014). A comparison of NoSQL graph databases, Publication Year: 2014, Page(s):128 - 131, 2014.

Ferreira, J. E. ; Franco, B. D. G. M. ; Catarino, M. H. ; Takecian, P. L. ; Agopyan, V. . DataUSP-PosGrad: Um conjunto de Serviços Analíticos para Apoio à Tomada de Decisão da PRPG USP. In: José Goldemberg. (Org.). USP 80 anos. 1ed.São Paulo: Editora Universidade de São Paulo (EDUSP), 2015, v. 1, p. 433-451.

Gajendran, S. K. (2012). A survey on NoSQL databases, University of Illinois Technical report, 2012.

Gilbert, S. and Lynch, N. (2012). Perspectives on the CAP Theorem, Journal Computer, Volume 45, Issue 2, February 2012, Pages 30-36.

Glanzel, W. and Schubert, A. (2001). Double effort = Double impact? A critical view at international co-authorship in chemistry Scientometrics, Amsterdam, v.50, n.2, p.199-214. 2001.

Gómez, C. O., Perianez-Rodriguez, A., Ovalle-Perandones, M. A. (2008). Estructura 
de las redes de colaboración científica entre las universidades españolas. Ibersid. (2008) 129-140.

Gubichev, A., Bedathur, S.J., Seufert, S., Weikum, G. (2010). Fast and accurate estimation of shortest paths in large graphs. In: CIKM '10 Proceedings of the 19th ACM on Information and knowledge management, pp.499-508.

Harary, F. (1969). Graph theory. USA: Addison-Wesley, 1969. (Addison-Wesley Series in Mathematics).

Hayashi, C. R. M.; et. al. (2012). Análise de redes de colaboração científica entre educação especial e fonoaudiologia. Rev. Interamericana de Bibliotecológia, v. 35, n. 3, p. 285-297, 2012.

Hayashi, M. C. P. I.; Hayashi, C. R. M..and Lima, M.Y. (2008). Análise de redes de co-autoria na produção científica em educação especial. Liinc em Revista, v. 4, n.1, p. 84-103, mar. 2008.

Hecht, R. and Jablonski, S. (2011). Nosql evaluation: A use case oriented survey. In International Conference on Cloud and Service Computing (CSC), pages 336-341.

Indrawan-Santiago, M. (2012). Database research: Are we at a crossroad? In NetworkBased Information Systems (NBiS), NBIS '12, pages 45-51, Washington, DC, USA. IEEE Computer Society.

Iordanov, B. (2010). Hypergraphdb: A generalized graph database. In Shen, H., Pei, J., Ozsu, M., Zou, L., Lu, J., Ling, T.-W., Yu, G., Zhuang, Y., and Shao, J., editors, '. WebAge Information Management, volume 6185 of Lecture Notes in Computer Science, pages 25-36. Springer Berlin Heidelberg.

ISSN (2016). ISSN web site. http://www.issn.org/.

Jouili, S. and Vansteenberghe, V. (2013). An Empirical Comparison of Graph Databases, in Social Computing (SocialCom), 2013 International Conference on, Sept. 2013, Pages $708-715$.

Kim, K.,W. (2006). Measuring international research collaboration of peripheral countries: taking the context into consideration. Scientometrics, Amsterdam, v.66, n.2, p.231-40, 2006.

King, E. (2015), The real world of the database administrator, Produced by Unisphere Research, a Division of Information Today, Inc., March 2015.

Kolomicenko, V., Svoboda, M. and Mlýnková, I. H. (2013). Experimental Comparison of Graph Databases, IIWAS '13 Proceedings of International Conference on Information Integration and Web-based Applications \& Services, p. 115 , ACM, NY.

Kretschmer, H. (2004). Author productivity and geodesic distance in bibliographic coauthorship networks, and visibility on the Web. Scientometrics, Amsterdam, v.60, n.3, p.409-20, 2004.

Lakshman, A. and Malik, P. (2010) Cassandra: A decentralized structured storage system. SIGOPS Oper. Syst. Rev., 44(2):35-40, April 2010 
Leavitt, Neal. Will NoSQL Databases Live Up to Their Promise?. Computer. IEEE, New York,, vol. 43, n. 2, p.12-14, Fev. 2010.

Li, Y. and Manoharan, S. (2013). A performance comparison of SQL and NoSQL databases. pages 15-19.

Loney, K. (2008) Oracle Database 11g The Complete Reference. McGraw-Hill, Inc., 2008.

Lourenço, J. and Cabral, B. and Carreiro, P. and Vieira, M. and Bernardino, J., (2015). "Choosing the right NoSQL database for the job: a quality attribute evaluation", Journal of Big Data 2015, vol. 2, 2015.

Maia, M. F. S., Caregnato, S. E. (2008). Co-autoria como indicador de redes de colaboração científica, Perspectivas em Ciência da Informação, v. 13, n. 2, p. 18-31, maio/agosto 2008.

Marek, C., Alex, A., and Ladialav, H. (2012). Benchmarking traversal perations over graph databases. IEEE, 12:1-5

Martínez-Bazan, N., Gomez-Villamor, S. and Escale-Claveras, F. (2011). DEX: A high-performance graph database management system. In GDM 2011, ICDE Workshops, 2011.

Matheus, R. F. and Silva, A. B. O. Fundamentação básica para a análise de redes sociais: conceitos, metodologia e modelagem matemática. In: POBLACIÓN, Dinah Aguiar (Org.). Redes sociais e colaborativas em informação científica. São Paulo: Angellarra, 2009, p. 239-287.

Maven (2016). Apache Maven web site. https://maven.apache.org.

McColl, R., Ediger, D., Poovey, J., Campbell, D. and Bader, D.A. (2014). A Performance Evaluation of Open Source Graph Databases, The 1st Workshop on Parallel Programming for Analytics Applications (PPAA 2014) held in conjunction with the 19th ACM SIGPLAN Symposium on Principles and Practice of Parallel Programming (PPoPP 2014), Orlando, Florida, February 16, 2014.

Meijer, E. and Bierman, G. M. (2011). A co-relational model of data for large shared data banks. Commun. ACM, 54(4):49-58, 2011.

Microsoft (2016). Microsoft sql server web site. www.microsoft.com/en-us/servercloud/products/sql-server.

Miler, M., Medak, D. and Odobašić, D. (2014). The shortest path algorithm performance comparison in graph and relational database on a transportation network, Promet - Traffic\&Transportation, Vol. 26, 2014, No. 1, 75-82.

Momjian, B. (2001). PostgreSQL: introduction and concepts, volume 192. AddisonWesley New York, 2001.

MongoDB (2016). Mongodb web site. http://mongodb.org.

Montenegro, M. R. and Alves, V. A. F. (1987). Critérios de autoria e co-autoria em trabalhos científicos. Revista do Instituto de Medicina Tropical de São Paulo. 
Instituto de Medicina Tropical, v. 29, n. 4, p. 191-193, 1987.

Mpinda, S. A. T.;Ferreira, L. C.; Ribeiro, M. X. e Santos, M. T. P. (2015). Evaluation of Graph Databases Performance Through Indexing Techniques. International Journal of Artificial Intelligence \& Applications (IJAIA) Vol. 6, No. 5, September 2015.

Nance, C., Losser, T., Iype, R., \& Harmon, G. (2013). NoSQL vs RDBMS - why there is room for both. In Proceedings of the Southern Association for Information Systems Conference (pp. 111-116), 2013.

Näsholm, P. (2012). Extracting Data from NoSQL Databases-A Step towards Interactive Visual Analysis of NoSQL Data. Chalmers University of Technology, 2012.

Nayak, A., Poriya, A. and Poojary, D., (2013). Article: Type of NOSQL Databases and its Comparison with Relational Databases. International Journal of Applied Information Systems 5(4):16-19, March 2013.

Neo4J (2016). Neo4J web site. http://neo4j.com.

NetBeans (2016). NetBeans web site. https://netbeans.org/.

Netto, P. O. B. (2003). Grafos - Teoria, Modelos, Algoritmos. $2^{\mathrm{a}}$ ed. São Paulo: Ed. Edgard Blucher Ltda, 2001.

Neumann, T. and Weikum, G. (2010). The rdf-3x engine for scalable management of rdf data. The VLDB Journal, 19(1):91-113.

Newman, M. E. J. (2001). Scientific collaboration networks. II. Shortest paths, weighted networks, and centrality, Physical Review E, volume 64, 2001.

NoSQL (2016). NoSQL Databases. http://nosql-database.org/.

Oliveira, E. F. T., Gracio, M. C. C., Segundo, J. E. S. (2009). Redes brasileiras de colaboração científica em Organização e Representação do Conhecimento: análise de coautorias dos Encontros Nacionais de Pesquisa em Ciência da Informação (ENANCIBs). Ibersid: revista de sistemas de información y documentación 3, 163 $168,2009$.

Oliveira, W. A., Silva, F. F., Hayashi, C. R. M. (2014). Redes de coautoria em educação: uma análise a partir de artigos científicos produzidos nos Programas de Pós-Graduação. In: XVIII Seminário Nacional de Bibliotecas Universitárias, 2014, Belo Horizonte-MG. Anais do XVIII Seminário Nacional de Bibliotecas Universitárias. Belo Horizonte-MG: UFMG, 2014.

Oracle. (2007). Oracle's 30th Anniversary. http://www.oracle.com/us/corporate/profit/p27anniv-timeline-151918.pdf (acessado em 02 de maio de 2016).

Oracle (2016). Oracle web site. http://www.oracle.com/.

OrientDB (2016). OrientDB web site. http://orientdb.com. 
Parker, Z., Poe, S., and Vrbsky, S. V. (2013). Comparing NoSQL MongoDB to an SQL DB. Proceedings of the 51st ACM Southeast Conference on - ACMSE'13, page 1 .

Patil, S.; Vaswani, G.; Bhatia, A. (2014), Graph Databases - An Overview, International Journal of Computer Science \& Information Technolo;2014, Vol. 5 Issue 1, p657, Academic Journal, January 2014.

Patterson, A. C., (1971). A Data Base Management System, Proceeding ACM '71 Proceedings of the 1971 26th annual conference, Pages 197-209.

Pokorny, J. Nosql databases: A step to database scalability in web environment. In: Proceedings of the 13th International Conference on Information Integration and Web- based Applications and Services, 2011. iiWAS '11. New York, NY, USA: ACM. p. 278-283.

POM (2016). Apache web site. https://maven.apache.org/pom.html

PostgreSQL (2016). Postgresql web site. http://postgresql.org.

Pritchett, D. (2008). BASE: An Acid Alternative, ACM Queue vol. 6, no. 3, Julho 2008.

Qualis (2016). Qualis Capes web site. http://www.capes.gov.br/avaliacao/instrumentosde-apoio/classificacao-da-producao-intelectual

Robinson, I., Webber, J., Eifrem, E. (2013). Graph Databases. [S.1.]: O'Reilly Media, Inc. 2013. Disponível em : Acesso em: 01 maio 2013

Rodriguez, M. A. and Neubauer, P. (2010). The graph traversal pattern. CoRR, abs/1004.1001.

Rodriguez, M. A. and Shinavier, J. (2008). Exposing multi-relational networks to singlerelational network analysis algorithms. CoRR, abs/0806.2274, 2008.

Sattar, A.; Lorenzen, T.; Nallamaddi, K. Incorporating nosql into a database course. ACM Inroads, New York, NY, USA, v. 4, n. 2, p. 50-53, Jun. 2013.

Schmid, S.; Galicz, E.; Reinhardt, W. (2015). "WMS performance of selected SQL and NoSQL databases", Military Technologies (ICMT), 2015 International Conference on, On page(s): $1-6$.

SCImago (2012). SCImago web site. http://www.scimagoir.com/.

Shalini, M. and Dhamodharan, S. (2014). Performance and Scaling Comparison Study of RDBMS andNoSQL (MongoDB) COMPUSOFT, An international journal of advanced computer technology, 3 (11), November-2014 (Volume-III, Issue-XI).

Sharma, S. (2015). An Extended Classification and Comparison of NoSQL Big Data Models, http://arxiv.org/abs/1509.08035, 2015.

Shi, Y., Meng, X., Zhao, J., Hu, X., Liu, B., Wang, H. (2010). Benchmarking cloudbased data management systems, Proceedings of the second international workshop on Cloud data management, October 30-30, 2010, Toronto, ON, Canada.

Sidone, O. J. G., Haddad, E. A., \& Mena-Chalco, J. (2014). Padrões de Colaboração 
Científica no Brasil: O Espaço Importa? In Anais do XLI Encontro Nacional de Economia. ANPEC-Associação Nacional dos Centros de Pós-graduação em Economia, 2014.

Silberschatz, A., Korth, H. F. and Sudarshan, S. (1999). Sistema de Banco de Dados. São Paulo. Makron Books, 1999.

Silva, E. L. (2002). Rede científica e a construção do conhecimento. Informação e Sociedade: Estudos, João Pessoa, v.12, n.1, p.120-48, 2002.

Singh, M. (2015) An Efficient Schema Extraction Technique for Graph Databases, Thapar University, India, 2015.

Stonebraker, M. Sql databases v. nosql databases. Commun. ACM, ACM, New York, NY, USA, v. 53, n. 4, p. 10-11, 2010. ISSN 0001-0782.

Sumathi, S., Esakkirajan, S. (2007). Fundamentals of Relational Database Management Systems. Springer. ISBN 3540483977, 13 Feb 2007.

Tiwari, S. (2011). Professional NoSQL, John Wiley \& Sons. 2011.

Vicknair, C. et al. (2010). A Comparison of a Graph Database and a Relational Database. ACMSE' '10, Oxford, MS, USA, 2010.

Vogels, W. (2008). Eventually Consistent, Scalable Web Services, Volume 6, No. 6, Outubro de 2008.

Yoshikane, F., \& Kageura, K. (2004). Comparative analysis of coauthorship networks of different domains: the growth and change of networks. Scientometrics, 60(3), $433-444$.

Wei, Z., Pierre, G. and Chi, C. (2009). Scalable Transactions for Web Applications in the Cloud. In proc. of the Euro-Par Conference, Janeiro 2009.

Weisz, J. and Roco, M. C. (1996). Redes de pesquisa e educação em engenharia nas américas. Rio de Janeiro: FINEP, 1996.

Welling, L. and Thomson, L. (2003). PHP and MySQL Web development. Sams Publishing, 2003.

Zawodny, J. (2009). Redis: Lightweight key/value store that goes the extra mile. Linux Magazine, August 2009. 